\title{
A Dynamic Model of Embeddedness in Digital Infrastructures
}

\author{
Fürstenau, Daniel; Baiyere, Abayomi; Kliewer, Natalia
}

Document Version

Accepted author manuscript

Published in:

Information Systems Research

DOI:

$10.1287 /$ isre.2019.0864

Publication date:

2019

License

Unspecified

Citation for published version (APA):

Fürstenau, D., Baiyere, A., \& Kliewer, N. (2019). A Dynamic Model of Embeddedness in Digital Infrastructures. Information Systems Research, 30(4), 1319-1342. https://doi.org/10.1287/isre.2019.0864

Link to publication in CBS Research Portal

\section{General rights}

Copyright and moral rights for the publications made accessible in the public portal are retained by the authors and/or other copyright owners and it is a condition of accessing publications that users recognise and abide by the legal requirements associated with these rights.

Take down policy

If you believe that this document breaches copyright please contact us (research.lib@cbs.dk) providing details, and we will remove access to the work immediately and investigate your claim. 


\section{A Dynamic Model of Embeddedness in Digital Infrastructures}

\section{Daniel Fürstenau, Abayomi Baiyere, and Natalia Kliewer}

Journal article (Accepted manuscript*)

Please cite this article as:

Fürstenau, D., Baiyere, A., \& Kliewer, N. (2019). A Dynamic Model of Embeddedness in Digital Infrastructures. Information Systems Research, 30(4), 1319-1342.

https://doi.org/10.1287/isre.2019.0864

\section{DOl: 10.1287/isre.2019.0864}

Uploaded to CBS Research Portal in agreement with informs' Open Access policy

* This version of the article has been accepted for publication and undergone full peer review but has not been through the copyediting, typesetting, pagination and proofreading process, which may lead to differences between this version and the publisher's final version AKA Version of Record.

Uploaded to CBS Research Portal: May २०२० 


\title{
A Dynamic Model of Embeddedness in Digital Infrastructures
}

\author{
Daniel Fürstenau ${ }^{1,2}$ \\ ${ }^{1}$ Freie Universität Berlin \\ School of Business \& Economics \\ Department of Information Systems \\ Garystr. 21, 14195 Berlin, Germany \\ daniel.fuerstenau@fu-berlin.de \\ ${ }^{2}$ Einstein Center Digital Future \\ Wilhelmstr. 67, 10117 Berlin, Germany \\ Abayomi Baiyere ${ }^{3}$ \\ ${ }^{3}$ Copenhagen Business School \\ Department of Digitalization \\ Howitzvej 60, 2000 Frederiksberg, Denmark \\ aba.digi@cbs.dk \\ Natalia Kliewer ${ }^{4}$ \\ ${ }^{4}$ Freie Universität Berlin \\ School of Business \& Economics \\ Department of Information Systems \\ Garystr. 21, 14195 Berlin, Germany \\ natalia.kliewer@fu-berlin.de
}




\title{
A Dynamic Model of Embeddedness in Digital Infrastructures
}

\begin{abstract}
Digital infrastructures are a result of individual yet interdependent systems evolving in relation to each other. In this paper, we identify three processes by which individual systems become embedded into digital infrastructures. First, there are parallel processes, in which systems become embedded independently of each other. Second, there are competitive processes, in which the embeddedness of one system increases at the expense of another. Finally, there are spanning processes, in which bridges are built between different embedded systems. The three processes, synthesized into a dynamic model of digital infrastructure embeddedness, offer much needed conceptual clarity to the area of digital infrastructure evolution. They also provide insight into the emergence of three forms of digital infrastructures: silofied, regenerated, and unified. Reflecting an interconnection view, our research further facilitates an understanding of infrastructure inertia and its associated consequence.
\end{abstract}

\section{Keywords}

Digital Infrastructures, Embeddedness, Inertia, Mixed Methods, Process Models 


\section{A Dynamic Model of Embeddedness in Digital Infrastructures}

\section{Introduction}

The literature on digital infrastructures has long noted a tension between dynamic flexibility and stability underlying the mechanisms that facilitate infrastructure evolution (Hanseth et al. 1996; Hanseth and Lyytinen 2010; Tilson et al. 2010). Companies often struggle to find a balance between allowing new and tailored applications, as well as IT capabilities, to connect to the established infrastructure, and ensuring that those innovative efforts are sufficiently aligned with corporate goals and principles. While the uncontrolled introduction of new systems and connections makes infrastructures overly complex, too strict rules may focus efforts firmly on one rigid, standard approach (Ciborra and Failla 2000; Hanseth and Lyytinen 2010). Therefore, companies need to be mindful of how individual systems are embedded within a digital infrastructure.

Many new systems are initially intended to solve a specific business problem. As they become increasingly popular and entrenched in people's working lives, these systems grow and more systems are connected to them (Henfridsson and Bygstad 2013). In turn, many such systems far exceed their intended life span (Agarwal and Tiwana 2015). In practice, decision-makers often feel powerless when the growth process of a system has progressed for too long (Furneaux and Wade 2011). Such systems, also known as legacy systems, are often highly advanced but also extremely rigid (Bisbal et al. 1999), as illustrated by the $€ 1 \mathrm{bn}$ multi-year project to move away from complex, organically grown mainframe solutions embarked on by Deutsche Bank (Flinders 2015). Before such costly IT transformation, huge resources are needed for operations and maintenance, while some companies fail to take full advantage of the innovative capability offered by new digital services and processes.

In contexts where a system's extensibility is limited, users may seek to satisfy their requirements by introducing new systems or extensions independently of the original system (Gregory et al. 2018). Examples are "workarounds" (Pollock 2010), "end user-developments" (Fischer et al. 2004), "bottomup" (Chua and Storey 2017), or "shadow systems" (Behrens 2009). As a consequence, and as Henfridsson and Bygstad (2013) note, the scope of a single system is no longer sufficient to describe the challenges managers and CIOs face today, whereby systems are interconnected in various and 
complex ways. In light of this, we refer to a set of interconnected information systems as a digital infrastructure. As Tilson et al. (2010) also note, a digital infrastructure may support or enable a global, national, regional, industry, or corporate entity but it has no strict boundaries or distinct set of functions. Boundaries are constructed and constantly renegotiated by users and may be limited by the technologies they draw upon to achieve their goals. According to Henfridsson and Bygstad (2013), the "inner workings" of digital infrastructure evolution deserve special attention. Problems arise when many different systems work together in complex ways but full transparency is lacking. In line with these opening issues, we seek to answer the question: How do information systems become embedded into a digital infrastructure over time?

Drawing on an interconnection view of embeddedness and rich empirical evidence from a longitudinal mixed-methods study in a recycling firm, our paper concludes that there are three embeddedness processes in a digital infrastructure: parallel, competitive, and spanning. The enactment of these processes contributes to the emergence of a digital infrastructure. This integrates into what we call the Dynamic Model of Embeddedness in Digital Infrastructures. The model outlines how the three processes when taken together, provide a theoretical explanation of how different forms of digital infrastructures emerge. With this understanding we propose that the embeddedness process underlying a digital infrastructure can determine if the infrastructure will become silofied, regenerated, or unified.

\section{Views on Embeddedness in Digital Infrastructures}

The information systems literature has developed a broad contextual understanding of what is meant by "embeddedness" and what concepts and processes it describes. It typically draws on sociological and organizational research without making embeddedness the object of a distinct processual theory development. One example is the work of Furneaux and Wade (2011), who understand system embeddedness with reference to organizational routine research as "the extent to which the use of an information system is an integral part of organizational activity" (p. 579). This can be determined as a variable, either by checking the number of other systems a certain system is interlinked with, or how much it is embedded into organizational routines. 
In prior works on digital infrastructures, in which a more dynamic understanding of embeddedness is developed, at least three research streams can be differentiated (see Table 1). A first stream goes under the broad label of institutionalization. Grounded in the literature on the social construction of reality and habitualization (Berger and Luckmann 1966; Schutz and Luckmann 1973), such works typically highlight how systems become, through perpetual use, part of people's routines. They become unquestioned and taken-for-granted. In this view, infrastructures emerge from individual systems and become virtually invisible to users, reducing complexity (Bowker and Star 1999; Karasti and Blomberg 2017; Star and Ruhleder 1996). Infrastructures are therefore embedded in a network of relationships, which only appear when actualized by certain users or user communities (Pipek and Wulf 2009; Vaast and Walsham 2009). Inertia may occur where dysfunctional worldviews or patterns of action become entrenched; often without the users' awareness. Alternatively, normative, cultural, or other habits as well as material and physical constraints may inhibit change. For example, Star and Ruhleder (1996) study a large-scale scientific infrastructure and show how the lack of embeddedness in the users' practices, due to technical problems, contributed to its failure as people preferred the internet to fulfil their information needs.

Second, the embeddedness view of path dependence is premised on the insight that embedding generates increasing returns. After initial uncertainty, a positive spiral in the use of a system, triggered by the path-creating actions of one or more actors (Henfridsson and Yoo 2014), leads to its further improvement. This happens when complementary products are introduced, which in turn creates incentives for the community to adopt it more. Infrastructures, in this view, emerge from a heterogeneous installed base of systems, actors, and their relations (Hanseth and Lyytinen 2004). This view was made popular by the work of Hanseth (2000), based on fundamental insights into the economics of standards and path dependence (Arthur 1989, 1994, 2018; David 1985). It was modified and extended, for example, by highlighting and identifying how systems in early development phases can generate the necessary momentum (Aanestad and Jensen 2011; Hanseth and Aanestad 2003; Hanseth and Lyytinen 2010; Hughes 1987). Moreover, at least implicitly, this thinking is subject to the generative mechanisms of adoption and scaling outlined by Henfridsson and Bygstad (2013), who describe an interplay between individual micro-level decisions and emergent infrastructural outcomes. 
Many of the studies based on this notion of self-reinforcing mechanisms and path dependence recognize the double-edged nature of such processes (Dobusch and Schüßler 2013; Sydow et al. 2009). While selfpropelled growth appears to be desirable at first glance, increasing inertia accumulates over time. The result is irreversibility and lock-in. In classical studies inspired by path dependence, these lock-ins are found in demand-side market situations, e.g., where buyers are tied to the wrong technologies/standards (Arthur 1989) or companies to the wrong vendors (Greenstein 1997; Monteiro 2003). This idea has also been interpreted more broadly and projected onto many organizational coordination problems, which lead over time to a narrowed scope of action due to learning, adaptive expectation, or complementarity (Sydow et al. 2009).

The last research stream views embeddedness from an assemblage perspective. Drawing on actor-network theory (Callon 1991; Latour 1987, 2005), the basic idea is that large-scale systems need to be understood as "heterogeneous assemblages of human and material elements" (Koch 2007, p. 427). According to this view, embeddedness describes "the entanglement of one technology with other apparently unrelated ones" (Monteiro et al. 2013, p. 575). It has been noted in the literature on digital infrastructures that many systems are not equipped per se to meet the user needs within their initial design focus (Monteiro et al. 2014). New systems are constantly being connected to, and stacked under and on top of existing systems, where they are needed to connect people and processes (Hanseth and Braa 2001). Such processes can be triggered by human or material needs and constraints. This is illustrated by the Hydro Bridge project in Norway, where the "Bridge," conceived as a corporate infrastructure for digital cooperation, was constantly expanded by building new systems on top of existing ones, extending them, or connecting them by means of data exchange interfaces. For example, an SAP infrastructure extended the Hydro Bridge infrastructure and was gradually absorbed by it (Hanseth and Braa 2001). It also involved the embedding of the Hydro Bridge infrastructure on top of underlying infrastructure such as operating systems or server hardware, of which only some were standardized. Infrastructures and systems mostly intended to connect split divisions at Hydro. Evolutionary processes contribute to their stabilization and destabilization (Henningsson and Hanseth 2011). The result of these processes of embeddedness is an increasingly complex and entangled digital infrastructure. 
Table 1 Views on embeddedness in digital infrastructures

\begin{tabular}{|c|c|c|c|c|}
\hline $\begin{array}{l}\text { Research } \\
\text { stream }\end{array}$ & Foundational literature & $\begin{array}{l}\text { Definition (of } \\
\text { embeddedness) }\end{array}$ & $\begin{array}{l}\text { Inertial } \\
\text { consequences }\end{array}$ & Example references \\
\hline $\begin{array}{l}\text { Institutio- } \\
\text { nalization }\end{array}$ & $\begin{array}{l}\text { Social construction and } \\
\text { habitualization: } \\
\text { - Berger and Luckmann } \\
\text { (1966) } \\
\text { - Schutz and Luckmann } \\
(1973)\end{array}$ & $\begin{array}{l}\text { The processes by which users } \\
\text { increasingly take a system } \\
\text { for granted as they make it } \\
\text { part of their routines }\end{array}$ & $\begin{array}{l}\text { Normative or } \\
\text { cultural } \\
\text { persistence }\end{array}$ & $\begin{array}{l}\text { Eriksson and Âgerfalk } \\
\text { (2010); Pipek and } \\
\text { Wulf (2009); Ribes } \\
\text { and Finholt (2009); } \\
\text { Star and Ruhleder } \\
\text { (1996) }\end{array}$ \\
\hline $\begin{array}{l}\text { Path } \\
\text { depen- } \\
\text { dence }\end{array}$ & $\begin{array}{l}\text { Economics of standards } \\
\text { and path dependence } \\
\text { theory: } \\
\text { - Arthur }(1989,1994) \\
\text { - Hughes }(1987)\end{array}$ & $\begin{array}{l}\text { The process of increasing } \\
\text { returns, by which users are } \\
\text { increasingly drawn to an } \\
\text { installed base of social and } \\
\text { technical components while } \\
\text { the system becomes } \\
\text { increasingly refined }\end{array}$ & $\begin{array}{l}\text { Lock-in, } \\
\text { irreversibility }\end{array}$ & $\begin{array}{l}\text { Hanseth and Aanestad } \\
\text { (2003); Hanseth and } \\
\text { Braa (2000); Hanseth } \\
\text { and Lyytinen (2010); } \\
\text { Henfridsson and } \\
\text { Bygstad (2013) }\end{array}$ \\
\hline $\begin{array}{l}\text { Assem- } \\
\text { blage }\end{array}$ & $\begin{array}{l}\text { Actor-network and } \\
\text { assemblage theories: } \\
\text { - } \quad \text { Callon }(1991) \\
\text { - } \quad \text { Latour }(1987,2005)\end{array}$ & $\begin{array}{l}\text { The processes by which } \\
\text { technologies and their human } \\
\text { and material elements get } \\
\text { entangled with each other }\end{array}$ & $\begin{array}{l}\text { Complexity of } \\
\text { the assem- } \\
\text { blage }\end{array}$ & $\begin{array}{l}\text { Hanseth and Braa } \\
(2001) \text {; Henningsson } \\
\text { and Hanseth (2011); } \\
\text { Monteiro et al. (2013) }\end{array}$ \\
\hline
\end{tabular}

Together, these three research streams provide rich contextual insights into the processes of embeddededness in digital infrastructures, but they currently lack the granularity and detail necessary to fully unpack the evolution of embeddedness in digital infrastructures. This detail is important to understand the link between embeddedness and continuance inertia and ultimately, to make timely decisions on system replacements, reengineering, and new system investments. Thus, our study aims to develop a process model of embeddedness in digital infrastructures based on a network foundation.

\section{An Interconnection View on Embeddedness in Digital Infrastructures}

The new perspective developed here is premised on the importance of a fine-grained, evolutionary process view (van de Ven and Poole 1995) in embedding systems into digital infrastructures. While earlier research on digital infrastructures challenged the rational actor view of digital infrastructure evolution, the research discussed here calls into question the beliefs that aggregated evolution paths work in the same way on a smaller scale, that generative mechanisms will be universally present (or absent) in all parts of a digital infrastructure, and that the scaling speed of a digital infrastructure is uniform across its constituent parts (Lyytinen et al. 2017). While recognizing that the generative mecahnisms of adoption, innovation, and scaling drive the growth of a digital infrastructure as a whole, we want to explore another set of processes here; ones that change the digital infrastructure from within, 
more endogenously, more subtly, and more granularly, but no less considerably. Such processes are "sequences of "events"” (Langley 1999, p. 692) fueled by the local demands that actors face, the interdependencies between actors and systems, the boundaries set up, and global necessities. Ciborra and Hanseth (2000, p. 2) note:

Infrastructures are puzzles, or better [yet] collages, and so are the design and implementation processes that lead to their construction and operation ... Interdependence, intricacy, and interweaving of people, systems, and processes are the cultural bed of infrastructures.

Dreyfus and Iyer (2008, p. 115), similarly, but more technically, write:

The pattern of interconnections among the deployed software components [-] is frequently the result of multiple, imperfectly coordinated decision makers operating over time. Individual decision-makers frequently make local design decisions regarding infrastructure and application design, deployment, updating, upgrading, and decommissioning that have enterprise-wide ramifications.

From this perspective, embeddedness is not universally present or absent across all the parts that constitute a digital infrastructure. Rather, embedding is seen here as a set of fine-grained processes that happen with different forces and speeds to different elements of a digital infrastructure.

Our view acknowledges and builds on prior network research as proposed by Granovetter (1985) and many others. He and subsequent peers put relation first and stress the importance of "concrete personal relations and structures (or 'networks') of such relations in generating trust and discouraging malfeasance" (1985, p. 490). Relations are not merely transmitters ("pipes") through which resources flow (e.g., data and functions). Instead, they are both "pipes and prisms" (Podolny 2001, p. 33). They create signals and dependencies that the actors involved in a relation act upon (Sundararaja et al. 2014). This thinking is important for understanding why interconnectedness - the way in which elements in a digital infrastructure are related to each other-not only reveals obvious information flows but, more importantly, creates cues for where decision-makers will direct their attention for the future development of a digital infrastructure.

This notion of embeddedness is also key in work that has been done on the evolution of networks (e.g., Barabási 2016, Palla et al. 2007). Structural patterns such as what communities belong together may emerge early on and be reinforced over time through an ongoing sequence of steps creating new 
interconnections and thus dependencies (Singh et al. 2011). These processes are not deterministic individually, but are driven by mindful actions of particular actors, communities, and projects, although with partly unintended outcomes. Eventually, however, this shows that the individual system in a digital infrastructure is not independent; its evolution is interdependent with a host of other systems, which are in turn pushed by the intentions and actions of particular actors. It also suggests that some systems may become important control points that develop a prominent position for the growth and long-term evolution of the digital infrastructure as a whole.

Our view on the emergence of digital infrastructures as a result of fine-grained system-level processes may be best illustrated by a metaphor. Continued proliferation is one of the most important characteristics of digital technologies. Single systems emerge here and there as islands, and nobody can say initially when and where these will grow together or become integrated on a higher level. This understanding owes much to Ortmann's (1984) image of mold on jam, which emerges in spots on the surface and finally grows together into a cotton-wool and felt-like coating that eventually leads to putrefaction. No plan controls the whole thing, and yet there is an underlying process. Each system develops individually but in relation to other systems in a digital infrastructure, and no finite boundaries define the digital infrastructure. Still, we recognize when embedding has happened, and we can determine whether a system has remained in its small isolated silo or has grown together with other systems into an emergent digital infrastructure.

We consider our advanced interconnection view to be pertinent in understanding how the processes of embedding systems shape a digital infrastructure for at least two reasons. Firstly, it is logical to expect that different organizational demands will lead to different embeddedness outcomes, yet we do not understand the primary process through which these unfold. For example, how do local organizational demands versus centralized organizational demands (e.g., mergers and acquisitions) determine the underlying process of embeddedness, and how do such processes influence the trajectory of the digital infrastructure? Secondly, prior research has noted the tension between the flexibility and stability agenda of an organization's digital infrastructure (Hanseth et al. 1996; Hanseth and Lyytinen 2010; Tilson et al. 2010). However, we lack understanding of the processes that underlie the interplay of these tensions at a granular level. Perhaps more importantly, prior research tends to overlook how 
these minute interactions define the fine-grained embeddedness process that forms the building blocks of a digital infrastructure.

Informed by ideas of network embeddedness, network evolution, and Ortman's idea of “mold on jam," this paper outlines a perspective of digital infrastructure embeddedness as a result of individual yet interdependent systems evolving in relation to each other. This perspective is central to our analysis of a large distributed company evolving its digital infrastructure. In the study described in this paper, we examine the processes of embeddedness in a digital infrastructure that unfold-over a period of twenty years - and what implications arise from them. These processes differ in the way that the individual systems involved in embedding interrelate, either independently or relationally, and in the nature of the relationship, which can be either synergistic or predatory. Our analysis provides the groundwork for a Dynamic Model of Embeddedness in Digital Infrastructures that offers a conceptual lens through which to focus on types of processes that the views of institutionalization, path dependence, and assemblage cannot discern. In most organizations, embedding will occur through a variety of logics. Indeed, the study reveals elements of institutionalization triggered by routine work in which particular systems are gradually taken for granted. More significantly, however, the study shows the critical role of interconnection processes of embeddedness enacted by system owners locally embedding their systems over time. This interconnection logic has been largely overlooked in digital infrastructures studies and appears to be relevant in the digital age of modular and layered innovation; hence, it is the focus of our attention.

\section{Methodological Framework}

\subsection{The Recycle Inc. Case Context}

We conducted a longitudinal study to explore how and why systems become embedded in a digital infrastructure (Pettigrew 1990; Yin 2013). The case company, which we disguise as Recycle Inc., is a German waste services enterprise. Founded in 1968, it employed nearly 9,000 people when we entered the field. Its business lines are waste management, recyclables trading, corporate services, steel, and metals recycling. 
Recycle Inc. was selected for three reasons, guided by theoretical considerations (Eisenhardt 1989; Flyvbjerg 2006; Siggelkow 2007). First, we assumed that a medium to large company with a multi-corporate structure would be subject to inertia. While smaller companies can focus on one or a few products and services, larger companies require many different capabilities, systems, and integrative devices to fulfill their tasks (Lawrence and Lorsch 1967). Second, we aimed for a critical example of a digital infrastructure that was described by key informants as rigid. We chose Recycle Inc.'s business area of waste management because it was facing major transformation difficulties at the time of our entry into the field. Third, the case selection was justified because the area chosen was characterized by a high degree of dispersion with respect to the business units' volume and variety. The business area under study (waste management) consisted of approximately 40 legally-independent subsidiaries ranging from tiny recycling sites to large companies with several hundred employees. Selecting a highlydispersed company, we expected to see high levels of consolidation reinforcing tendencies toward the centralization of solutions, in contrast to settings which have less need to integrate specific local demands. Thus, Recycle Inc. represents a company balancing tension between dynamic flexibility and stability in the evolution of its digital infrastructures.

\subsection{Data Sources}

Following the guidelines for conducting case study research (Yin 2013), we relied on multiple sources of data. One data set was the IT architecture data from Recycle Inc. that provided information about the systems used in 26 of the 40 subsidiaries, and their integration. Hereafter, we call this document $\left(a_{1}\right)$ the IT support matrix. The data was collected in a real requirements engineering project conducted over three months in 2011. Access to the data was granted by the headquarter IT architecture group. To create comparability between the units, the project team predefined a standard waste management process and a reporting template, which was completed together with the company delegates in semi-structured interviews. In this template, each subsidiary specified what systems were used along the predefined process. This was made possible because the business models of most subsidiaries hardly differed, while the execution of individual activities differed widely. 
A document on integration relationships supplemented the data. It listed source and target systems as well as some qualifying attributes (e.g., online versus offline integration and transferred data). The data stemmed from modeling efforts by technical experts in the subsidiaries, supported by central IT architects, and were from 2011.

As a second important source of information and an attempt to understand the processes of embedding and its links to inertial dynamics, we conducted 20 semi-structured interviews with 14 key informants (see Table 2). The first round of 15 interviews took place over a period of four months in 2012. Five additional interviews with key informants were conducted in 2015-2016. These interviews generally lasted 60-90 minutes and were tape-recorded and transcribed. To triangulate the data, we also collected a large amount of additional material (see Table 2). This material comprised the 2011 IT project portfolio planning $\left(a_{2}\right)$, which also included financial information along with three important success stories $\left(a_{3}, a_{4}\right.$, and $\left.a_{5}\right)$ capturing periods from 1995 onward. These gave insights into the company's waste management infrastructure and IT strategy at that time and served as valuable sources for limiting retrospective biases in the study (Street and Ward 2011). Our study covered the period from 1995 to 2015.

Table 2 Data sources

\begin{tabular}{llll}
\hline Semi-structured interviews $(\boldsymbol{N}=\mathbf{2 0})$ & \# Interviews \\
\hline$\#$ & Key informant & Position and engagement with Recycle Inc. & 4 \\
\hline 1 & IT Demand Manager & IT demand manager for waste management (2010-2013) & 1 \\
2 & Corporate CIO & Head of group IT (since 2009) & 2 \\
3 & Developer 1 & Senior system developer ORDER (since 1974) & 1 \\
4 & Developer 2 & System developer ORDER (since 1995) & 1 \\
5 & IT Project Mgr. 1 & Responsible for IT projects in Southern Germany (since 2010) & 1 \\
6 & IT Project Mgr. 2 & Responsible for IT projects in headquarters (2011-2013) & 1 \\
7 & Business IT Analyst & Business and IT analyst (2011-2013) & 1 \\
8 & Business Manager 1 & Commercial director in headquarters (since 2005) & 1 \\
9 & Business Manager 2 & Commercial assistant in headquarters (since 2009) & 1 \\
10 & Business Manager 3 & Operation manager in headquarters (since 2007) & 1 \\
11 & Business Manager 4 & Head of one Eastern German subsidiary (since 2007) & 1 \\
\hline
\end{tabular}




\begin{tabular}{|c|c|c|c|}
\hline 12 & Controller & Corporate controller in headquarters (2011-2014) & 3 \\
\hline 13 & In-house Consultant & In-house consultant involved in ERP selection (2011-2016) & 1 \\
\hline 14 & Vendor Manager & Key account manager ORDER (since 1995) & 1 \\
\hline \multicolumn{4}{|c|}{ Observations $(N=2)$} \\
\hline \# & Observation & Detail & $\begin{array}{l}\# \\
\text { Observations }\end{array}$ \\
\hline $\mathrm{o}_{1}$ & User training & $\begin{array}{l}\text { 1-day training for marketing employees on using ORDER and its } \\
\text { reporting component ( } 8 \text { hours) }\end{array}$ & 1 \\
\hline $\mathrm{O}_{2}$ & IT workshop & $\begin{array}{l}\text { Internal workshop in waste management by IT department to } \\
\text { facilitate transformation ( } 2 \text { hours) }\end{array}$ & 1 \\
\hline \multicolumn{4}{|c|}{ Archival documents $(N=27)$} \\
\hline \# & Type & Detail & \# Documents \\
\hline$a_{1}$ & IT support matrix & $\begin{array}{l}\text { Overview of system/applications, integration relations, and usage } \\
\text { relations (timestamp: 2011, cross-sectional) }\end{array}$ & 1 \\
\hline$a_{2}$ & IT project portfolio & $\begin{array}{l}\text { IT project planning with financial information } \\
\text { (timestamp: 2011, cross-sectional) }\end{array}$ & 1 \\
\hline$a_{3}$ & Journal publication & $\begin{array}{l}\text { Article on selecting/implementing ORDER as a central system } \\
\text { (timestamp: 1999, period captured: 1995-1999) }\end{array}$ & 1 \\
\hline$a_{4}$ & Public report & $\begin{array}{l}\text { Report on process of outsourcing the IT department } \\
\text { (timestamp: 2003; period captured: 1998-2003) }\end{array}$ & 1 \\
\hline$a_{5}$ & Success story & $\begin{array}{l}\text { Report on changing the system/network outsourcing vendor } \\
\text { (timestamp: 2006; period captured: } 1997-2005 \text { ) }\end{array}$ & 1 \\
\hline $\mathrm{a}_{6}$ & Other documents & $\begin{array}{l}\text { Company brochures (5), annual reports (10), newspaper articles (6), } \\
\text { industry news (1) }\end{array}$ & 22 \\
\hline
\end{tabular}

\subsection{Data Analysis}

Several procedures were carried out to reconstruct the "inner workings" of the digital infrastructure at specific points in time. Our starting point was a quantitative study from an interconnection viewpoint. Firstly, based on the IT support matrix, all potential systems were listed as of 2011 . We adopted a definition of systems consistent with Hanseth and Lyytinen's (2010) notion of "applications" as our analytical focus. The raw data set consisted of 231 systems (excluding duplicates), which described relatively self-contained functional modules.

Secondly, following from this analytical focus, we considered two broad directions for identifying linkages between systems: firstly, there is a more technical interaction through concrete information flows. Secondly, there is a more social perspective to be considered (Pipek and Wulf 2009; Vaast and Walsham 2009). Linkages can be constructed if human actors create, use or manage different 
systems simultaneously. In this paper, we chose to examine the technical interaction between systems. We used the bidirectional information on interfaces between systems to construct a directed network that serves as one important representation of the digital infrastructure. The arrows of the links were modelled along the direction of the data flow as specified in the integration relation (from source to target). For example, an incoming link to an ERP from a price calculation spreadsheet could represent prices being uploaded to the ERP. The link does not show how often this happens or the strength of the connection, only that there is a connection. When integration relations existed in both directions (from system $A$ to system $B$ and from system $B$ to system $A$ ), two links were constructed. In this way, we considered data and functional (inter-)dependencies between systems.

Subsequently, this enabled us to create a network visualization of systems and integration relations. A network visualization lends itself well to the network analysis approach then used in the embeddedness evaluation. It is valuable in providing a clearer picture of the structure and connections within a company (Dreyfus and Iyer 2008; Lagerström et al. 2014; Lipnack and Stamps 1997). We iteratively cleansed the data and constructed an adjacency matrix that formed the backdrop to our approach. As only integrated systems were of interest to us, we removed several unconnected systems $(N=19)$. We proceeded with a subset of 212 systems (nodes) that had 264 documented integration relations (directed links).

To evaluate the embeddedness level, we performed a network analysis on the resulting network. This analysis had two parts. The first referred to the level of the whole network and was intended to examine structural features from which conclusions could be drawn about the network's growth. This included a test for preferential attachment (Barabási 2016; Barabási and Albert 1999). The second part was based on the micro-level of individual systems. One premise of this study is that a system's network position can indicate its degree of embeddedness. To this end, we focused on finding metrics for the influence of systems on others. In network analysis, various centrality measures are used to assess a node's influence (Jackson 2008; Wasserman and Faust 1994). We focused on two-degree and betweenness centrality $\left(C_{D}\right.$ and $\left.C_{B}\right)$. We chose these metrics because they are well-used in network research on micro-level centrality and they allow for distinct interpretations. Regarding degree centrality, Dreyfus and Iyer (2008) note that degree allows the positional value of a system to be 
described. They note that systems "with high positional value may be important because they influence many other [systems]" (p. 124) and give the example of a search engine, which can, due to its positional value, become a gateway or a bottleneck. However, degree centrality shows only part of the picture, since only the immediate vicinity of a node is considered, not the paths and connections within the overall network, which is particularly characteristic of the betweenness centrality (Freeman 1977). By means of the betweenness centrality, brokerage and intermediation processes can be determined, which we also assumed to be central, based, e.g., on Hanseth and Braa's (2001) analysis of the Hydro Bridge infrastructure.

Next, we classified the systems for degree and betweenness values by performing an exploratory cluster analysis (Hair et al. 2014). Following Ketchen and Shook's (1996) suggestion, we combined multiple clustering methods to reduce early misclassification. In a first step, we used an agglomerative hierarchical cluster analysis with Ward's Method on the squared Euclidean distance between each system. Based upon the resulting dendrogram and applying the elbow-criterion, we were able to identify the preferable number of three clusters for the dataset. In a second step, we used a non-hierarchical $k$ means clustering method with the fixed number of three clusters, which we called lightly embedded systems, heavily embedded systems, and bridges.

Based on this analysis, we adopted a qualitative approach (involving observation and interview instruments) that also spanned different levels of analysis. At the level of the digital infrastructure as a whole, we reconstructed a case history for the entire study period (1995-2015) (see also Appendix 1). In this step, the qualitative process data helped verify our assumptions, working backward and forward from the 2011 quantitative network data (Newman and Robey 1992). The qualitative process data enabled us to view the architectural excerpts from an event-based perspective, framed by "temporal bracketing" (Langley 1999), and allowed us to accentuate important infrastructural changes and inflection points.

On the micro-level of individual systems, we used qualitative data to investigate how and why embeddedness occurs, along with the implications of inertia associated with heavily embedded systems. We adopted a thematic analysis approach to make sense of the qualitative data in light of the emergent findings from the quantitative data. To do so, our analysis followed the method of Gioia et al. (2012), 
whereby it is customary in qualitative research to iteratively analyze the data concurrently with data collection. This led to an initial list of first-order concepts from the data. As we proceeded to iterate between the coding and data collection, our theorizing began to form around two emerging ideas: a) the process through which the systems attained their respective level of embeddedness and b) the associated consequence. The qualitative approach was structured to help extract a deeper understanding of how a system's degree of embeddedness is associated with the inertia enveloping it, as well as the underlying explanation for the possible digital infrastructure evolution outcomes.

Combining qualitative and quantitative research approaches is valuable in our study as it allows us to highlight the importance of the social and technical elements in the ongoing process of system embedding and its implications. The insights we derived from this study were possible due to the joint interplay of both approaches (Venkatesh et al. 2013). While the quantitative analysis enabled us to see and classify the structure of the digital infrastructure and to discern individual systems' embeddedness levels through network analysis, the qualitative analysis enabled us to draw insights about the underlying processes of embedding. Lastly, the interaction between both research approaches allowed us to triangulate our findings and provided us with a stronger explanatory foundation for our subsequent theoretical and practical implications.

\section{Results}

\subsection{Growth of the Waste Management Infrastructure}

Episode 1 - Implementing standard systems. In the first episode, between 1995 and 1999, the company moved from isolated silo systems to standardized systems. Following an IT strategy discussion, the company concluded that it needed to "reduce the heterogeneity of different software systems in-use for core processes" (as noted in $a_{4}$ ). Triggered by the availability of standard software for cross-industry administrative processes and the need to consolidate different technology platforms, the company implemented SAP R/3. In particular, the finance module (FIN) became a central system. A complementary industry solution for waste management supporting the company's demands was not available at that time; therefore Recycle Inc.'s leadership team triggered the custom development of an order management system, ORDER, which emerged in collaboration with an external vendor. In most 
subsidiaries, ORDER replaced LEGA, a legacy software with similar capabilities limited in its technology platform, as well as several standalone solutions. By 1999, ORDER had been rolled out in all but two of the company's then 15 subsidaries in Germany and Eastern Europe.

Figure 1 illustrates the core process of waste management in three essential steps: (1) distribution, (2) operations that include collecting and disposing of waste, and (3) financial accounting. It also displays the main systems in use at that time to support each of those steps. In network terminology, these are the nodes. In this process, FIN mainly supported invoicing and financial steps, while ORDER mainly covered the distribution and operations steps. Systems that were located in the value chain before the financial system (FIN) were referred to as "upstream systems," indicating the leadership team's high prioritization of financial matters. As shown in the figure, LEGA and several standalone solutions still existed. The standalone solutions were supposed to be abandoned soon after this.

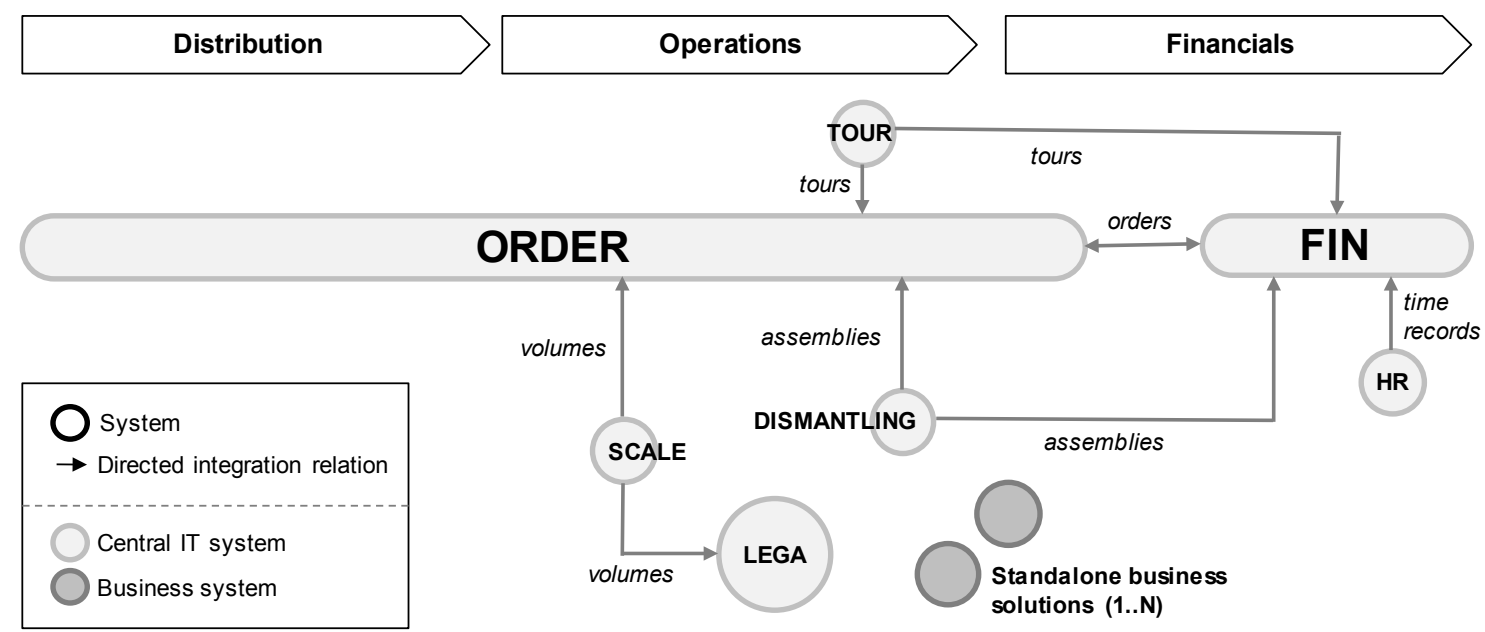

Figure 1 Digital infrastructure for waste management as of 1999 
Episode 2: Organic growth. The second period, characterized by poorly controlled growth, took place between 1999 and 2011. At that time, the company outsourced its IT operations and implemented an IT chargeback model, whereby the subsidiaries had to contract the IT unit for their services. Furthermore, central resources and investments were kept to a minimum and IT acted as an autonomous entity that was not subsidized by the group or the subsidiaries. Thus, the IT unit was forced to focus on profitable deals while largely neglecting overarching or innovative projects.

On the system level, the rigid IT investment policy had a profound impact, as it promoted local initiatives and shadow ITs within the subsidiaries. The company's CIO, for instance, mentioned that the subsidiaries compensated and substituted for the centralized systems' lack of innovativeness by investing in their own solutions. One key informant explained: "Often the companies had ideas. Then IT said: the price is this-and-that. Then the companies said: that's too much. We will do it on our own" (IT Demand Manager $\left._{1}\right)$.

The data confirms that the trend toward shadow IT was reinforced by three distinct factors. First, as the central systems such as FIN and ORDER aged, their architectural quality suffered and it became harder and more costly to implement new business demands within these systems. Investments for their update or maintenance were only allocated when absolutely necessary. As a consequence, and as suggested by the quote, subsidiaries often turned to local solutions to solve their immediate problems in more cost-effective ways. Second, the company started pursuing a strong external growth path by acquiring several other large waste management companies, creating a need to integrate the system landscape of these companies. For instance, the company bought a competitor in Southern Germany that had installed another standard waste management solution, LOX. The CIO, explaining what he thinks are the reasons for the heterogeneity observed, said:

To summarize - acquisitions, little standardization on the market/IT vendor side, so we turned to proprietary solutions ... we also withheld a lot on another critical issue, the positioning of the IT... which led to a conservative investment policy. But as demands from business units still existed, this produced a situation where a lot of uncontrolled growth occurred. This explains those many small systems, starting with Excel to Access to other special systems, ... which were also necessary to satisfy the[ir] customers. (Corporate $\mathrm{CIO}_{2}$ )

Episode 3: Attempts to consolidate and stagnation. In 2011, a CIO change triggered a strategic transformation of the IT function. The designated CIO announced measures to renew the fragmented IT 
infrastructure. To improve the identification and bundling of demands, IT was reorganized from a system-based silo structure to a functional domain structure. Development teams were now grouped according to functional areas (e.g., waste management) instead of systems (e.g., ORDER). The CIO installed new business-IT-linkage roles such as demand managers and business analysts to increase the IT unit's responsiveness to local demands. Furthermore, all IT employees underwent extensive training in business-IT-alignment skills, such as IT project management, and town hall meetings were conducted to increase the subsidiaries' awareness of the new IT capabilities. The IT maxim that emerged was "one unified business solution." To prepare the consolidation mission, a project was begun to identify the requirements in the subsidiaries and to gain transparency about the number and types of systems used in the domain. The architectural data we received originated from this effort.

Based on this, Figure 2 illustrates the variety of different systems and their integration on the level of the whole network constituting the digital infrastructure (see also Appendix 2). FIN, ORDER, LOX, $L E G A, B O A R D$, a board computer solution, and SIGN, a solution for hazardous waste reporting, which are most important for our theorizing, are highlighted in the figure. 


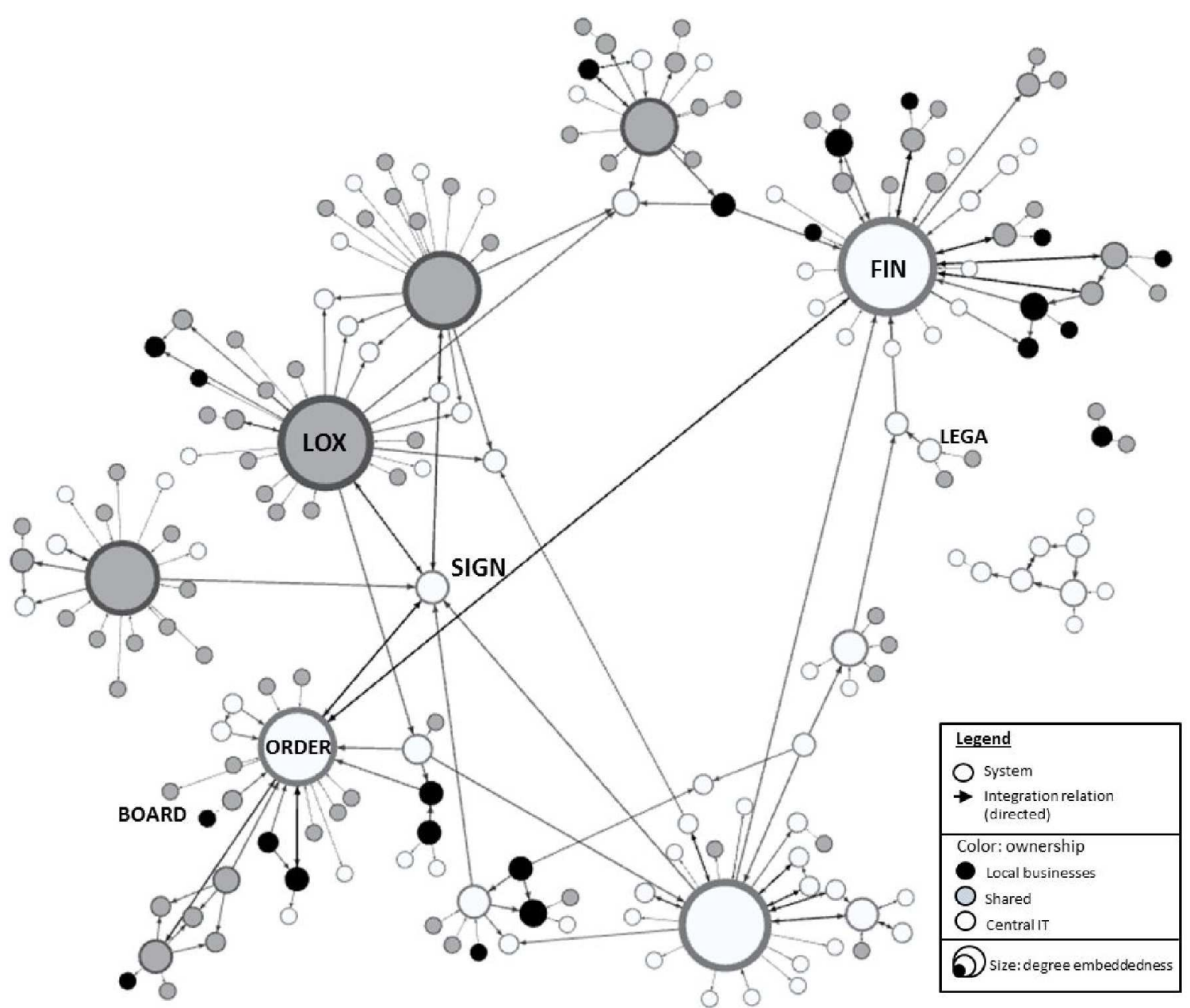

Figure 2

Digital infrastructure for waste management in 2011 after a decade of uncontrolled growth

Consolidation efforts came to a halt in 2013. Once again, the IT was reorganized. Two important decisions were made. First, the consolidation project was halted and resources were withdrawn from the project (at that time, a vendor selection was taking place). Second, the waste management IT was closed down. IT management and operations staff were relocated either to subsidiaries or to headquarters, or they left the company. At the end of our investigation, growth for systems such as ORDER stagnated and the consequences of IT reorganization had not yet become apparent in the digital infrastructure.

\subsection{Discerning Embeddedness in the Digital Infrastructure}

This section establishes to what extent certain systems are embedded into the digital infrastructure. Table 3 identifies three groups of systems based on exploratory cluster analysis. The first group shows low degree and low betweenness values. We call these lightly embedded systems. The second group 
comprises systems with high degree and medium or high betweenness values. These are the heavily embedded systems, either hubs or mega-hubs. A third group shows average degree and high betweenness values. We call this last group, consisting of one system, the bridge category. ${ }^{1}$ Table 3 shows examples, which are also highlighted in Figure 2.

Table 3 Quantitative assessment of embeddedness in the digital infrastructure

\begin{tabular}{lllllll}
\hline Category & $\boldsymbol{N}$ & \multicolumn{2}{c}{ Degree $\left(\boldsymbol{C}_{\boldsymbol{D}}\right)$} & \multicolumn{2}{c}{ Betweenness $\left(\boldsymbol{C}_{\boldsymbol{B}}\right)$} & Example(s) \\
& & Avg. & Std. dev. & Avg. & Std. dev. & \\
\hline 1: Lightly embedded & 205 & 1.81 & 1.61 & 0.0004 & 0.0022 & LEGA, BOARD \\
2: Heavily embedded & 6 & 24.17 & 4.14 & 0.0337 & 0.0122 & FIN, ORDER, LOX \\
3: Bridge & 1 & 9.00 & 0.00 & 0.0642 & 0.0000 & SIGN \\
\hline Total & 212 & & & & & \\
\hline
\end{tabular}

Lightly embedded systems. Lightly embedded systems are the largest group $(N=205)$. Both BOARD $\left(C_{D}=1, C_{B}=0.0000\right)$ and LEGA $\left(C_{D}=3, C_{B}=0.0008\right)$ belong to this category and do not figure prominently in degree and betweenness analysis. LEGA was the predecessor to ORDER and can be understood as a peripheral system that has lost importance over time. BOARD receives data for route planning and, like many other lightly embedded systems, it can be understood as a functional complement to a heavily embedded system, in this case ORDER.

Heavily embedded systems. The second group $(N=6)$ consists of heavily embedded systems. FIN $\left(C_{D}=30, C_{B}=0.0326\right)$, a first example, is a long-established SAP system for financials. It is the most heavily embedded system and integrated with LOX and ORDER, as well as many lightly embedded systems. Many of the small nodes in Figure 2 represent extensions to it such as local archives, controlling cockpits, and tour planning solutions, as well as a centralized data warehouse. Numerous transactional systems deliver data to FIN, including ERP/logistics systems such as LOX and ORDER.

$$
\text { LOX }\left(C_{D}=26, C_{B}=0.0470\right) \text {, a second heavily embedded example, was part of Recycle Inc.'s }
$$
acquisition strategy in the 2000s. It connects to many small nodes, mostly lightweight programs in support of activities such as tour planning, weighing, and company and management reporting in the company's southern region. The grey color in Figure 2 indicates responsibility shared between an IT team from the subsidiary and a delegate from the central IT department. As already mentioned, a final example of a heavily embedded system is ORDER, where the "core component of the ORDER" is

\footnotetext{
${ }^{1}$ The solution found was robust against a further increase in the number of clusters.
} 
represented $\left(C_{D}=22, C_{B}=0.0449\right)$. While it has built a significant installed base in many subsidiaries, it has still failed to mobilize new users recently. An IT project manager reflected on LOX compared to ORDER:

LOX has a very high standing in the business units, they value it and are very committed to it so there are lot of "shoots" around it, I would say. Mainly in the area of controlling different sorting and sales processes that are not well covered by the system. For instance, it does not have a customer relationship management module, so a lot of things emerged with Access and Excel. LOX diffused very strongly in the business units and it is rooted in the business units, more than ORDER (IT Project Manager ). .

Bridges: The bridge category is represented by SIGN $\left(C_{D}=9, C_{B}=0.0642\right)$. SIGN scores highest in betweenness, but its degree embeddedness is not very high. The system originally acted as a read-only data aggregator and was procured primarily as a reporting tool without writing or updating functions. Our results, however, suggest that it later began to bridge different systems in different regions. Its central position allows SIGN to become more and more of a gateway. Since it was introduced in 2008, it has grown toward a middleware that exchanges messages between ERPs in different regions. We can derive its significance from its central positioning and speculate about the expected impact of its failure on the entire infrastructure: its position makes it an important boundary spanner, connecting different parts of the network.

\subsection{Growth Patterns of Embeddedness in Digital Infrastructures}

This section presents quantitative evidence for the existence of certain growth patterns within digital infrastructures, which can be described as preferential growth. Our starting point is the work of Barabási and Albert (1999), who conclude that many real-world processes follow a certain logic: new nodes in a growing network are preferentially attached to nodes that are already very important, i.e., they have accumulated many resources and connections in the past. This corresponds to a generative mechanism because it initiates a self-reinforcing dynamic, which further favors people, resources, or components that are already preferred. On the other hand, already disadvantaged components receive even less attention, which corresponds to a degenerative mechanism.

This has been expressed formally in the Barabási-Albert model. Consider a network in which new nodes attach themselves to existing ones with a probability proportional to their degree. A new node appears in each period and creates a connection to existing nodes. Over time, the distribution of 
degrees - a plot of the number of links and their frequency of occurrence-will come to be fat-tailed (Barabási 2016). This means that there are more nodes with a very high degree than is usually expected from a random growth process. The distribution of degrees also shows more nodes with low degree (the spokes), because many nodes will receive little attention (cf. Jackson 2008, p. 131). Substantiating this claim is typically achieved by (a) eyeballing the degree distribution of a network and (b) by performing a regression analysis of the log-logged degree distribution (cf. Jackson 2008).

As Figure 3a shows, in our conceptualization of a digital infrastructure, the horizontal axis of the degree distribution indicates a system's number of connections, while the vertical axis shows the number of systems with this number of connections. Eyeballing the plot is a valuable initial vantage point to argue for the fat-tailed structure typical in preferential attachment (Jackson 2008). Figure 3a indicates an imbalance between the relatively large number of systems with a low and high number of connections and the comparatively small number of systems with medium number of connections.

A further transformation step in the network's degree distribution from a plot of absolute occurrences into a log-logged plot is necessary in order to substantiate the preferential growth proposition. This plot enables the computation of the relative frequencies from the absolute values, which are then brought into a logarithmic form. This is important because previous work indicates that log-logged degree distributions help infer patterns of growth from a network's actual distribution of degree (Jackson 2008). Barabási and Albert's (1999) main observation was that preferential growth would be reflected numerically in a good fit of a straight line in the log-logged degree distribution (Jackson 2008). Thus, we performed an additional regression analysis to establish whether the loglogged degree distribution fits with a linear model. In Figure 3b, the straight line in the log-log plot provides evidence of a preferential attachment process. The regression points to a robust linear relationship $\left(R^{2}=0.89, p \leq 0.001\right)$ between the logged degree and the logged relative frequency of occurrences.

Viewed together, figures $3 \mathrm{a}$ and $\mathrm{b}$ suggest that the digital infrastructure can be described as a scale-free network, the growth of which is subject to preferential attachment. This means that a few important (heavily embedded) systems — such as FIN and ORDER—have been surrounded increasingly 
by (light) spokes such as BOARD, while less important systems such as LEGA have faded into insignificance.
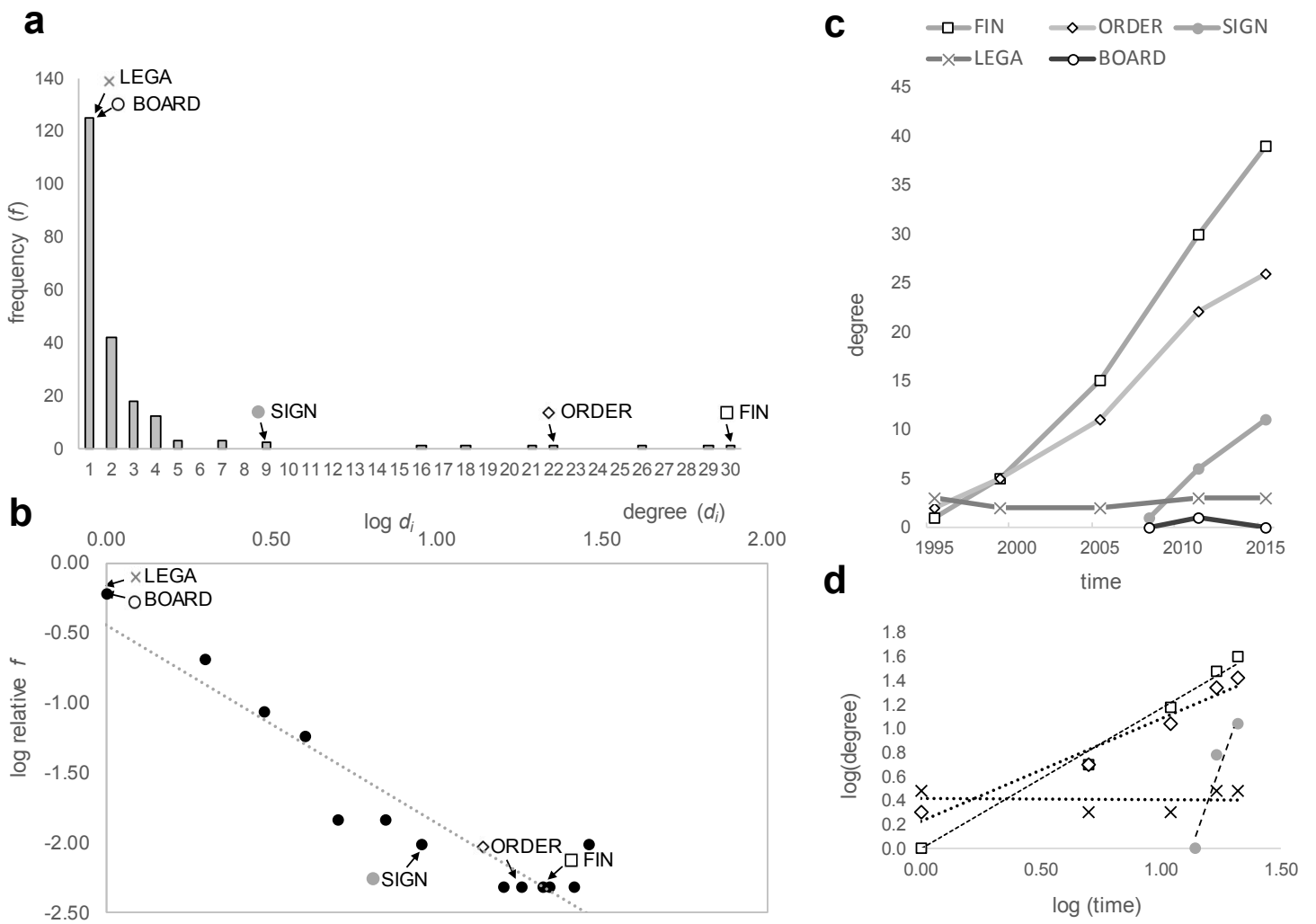

\section{Figure 3 Degree distribution of embeddedness levels: (a) absolute (b) log-logged, (c) sample} trajectories, and (d) their log-logged degrees

If the real dynamics of growth are examined (figures $3 \mathrm{c}$ and $\mathrm{d}$ ), it becomes clear that although the Barabási-Albert Model explains the fundamental underlying mechanism, there are noticeable differences between systems. The log-log representation of growth shows that FIN, for example, has grown more strongly than ORDER. In addition, SIGN has grown rapidly in a very short period of time. On the other hand, growth of LEGA stagnated and BOARD disappeared completely after a short time. Thus, our understanding of the process of embedding over time would benefit from richer (qualitative) data. By drawing on our qualitative data as well, we were able to go beyond the quantitative observations to uncover some underlying processes of embeddedness in digital infrastructures. Our findings suggest that the growth process requires the differentiation of at least three micro-level processes-parallel, competitive, and spanning (see Table 4). We will now illustrate these with examples from our empirical data. 


\subsection{The Processes of Embeddedness in Digital Infrastructures}

\subsubsection{The Parallel Process}

Our data confirm that some systems have increased in size and embeddedness gradually and relatively independently. We refer to this process as a parallel process, which denotes a sequence of events whereby a heavily embedded system emerges and grows independently of others. As Figure 4 shows, systems $\mathrm{S}_{1}$ and $\mathrm{S}_{2}$ grow independently over time. In this situation, each system's loss of connections or gain of extra connections occurs regardless of the presence of the other system.

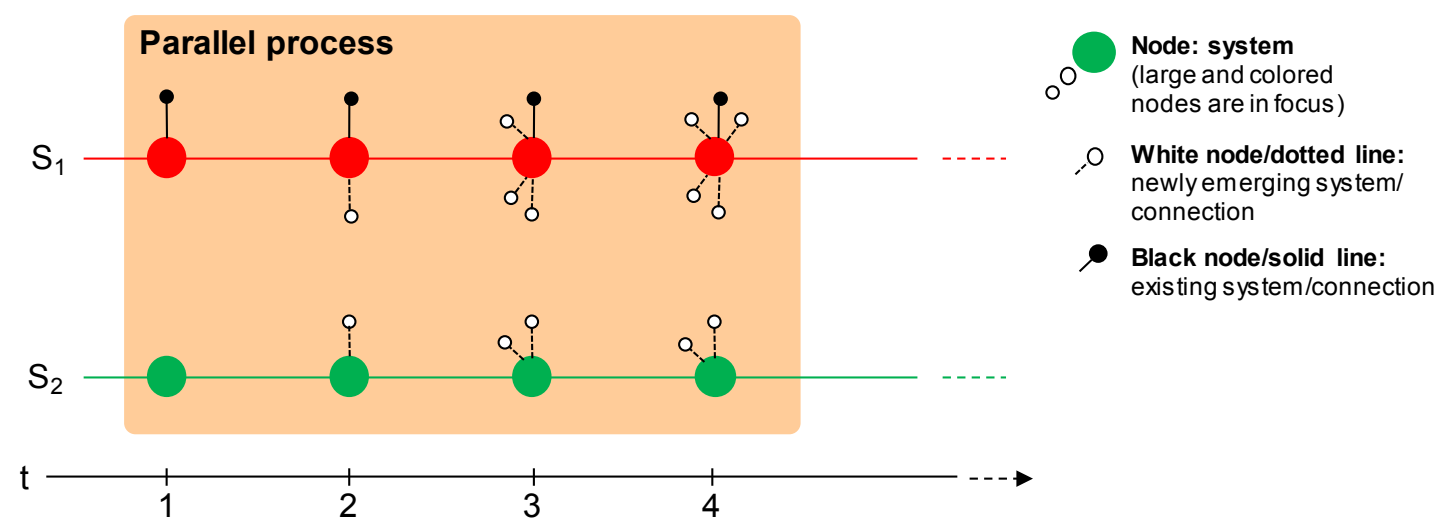

Figure 4 Parallel process of embeddedness

At the field site, parallelity evolved in the context of a growing corporation. New subsidiaries/companies had been added to the group continuously, in southern and eastern Europe, for instance. External acquisitions played a key role in this context, although integration into and with existing systems was not a priority. As the CIO stated, "it is not the case that every waste operations company has different business models and the situation is therefore highly heterogeneous, but...it is based on many acquisitions."

ORDER and related examples demonstrate this well. Firstly, since scale systems are essential for the workflow and complement the order management, and since individual preferences existed at the individual waste yards, various scale systems were connected to ORDER, some as online (real-time) and others as offline solutions. While most of the companies were working with proprietary scales with their own interfaces, ORDER was connected to an external partner solution, which had to be integrated 
in turn with the companies' existing infrastructure. This posed major challenges for harmonization and led to many different weighing systems being connected to ORDER.

Another example is tour planning and on-board computer solutions. Because they played an important role in handling the process and because the standard functionality was insufficient, new solutions were repeatedly introduced and linked to ORDER. A particularly illustrative example occurred in a company in which an external partner was assigned to implement a board computer system (BOARD). This system was introduced independently of the central IT, and interfaces to ORDER were created later on. However, the system was not powerful enough, and additional problems with the supplier occurred. Similarly, there were a number of other initiatives, their goal being to complement the much-needed functionality and thus increase the value of ORDER. The corresponding processes can be described as "parallel," since similar solutions have been identified and implemented for other heavy systems, independent of ORDER. For example, companies in the South had decided much earlier to introduce on-board computers on a wide-scale basis.

One boundary condition of the process concerned the orientation of IT. While the management was interested in increasing sales and profits, IT standardization was not in the foreground. As the IT Demand Manager ${ }_{1}$ remarked:

"So, a consistent topic for the whole of Recycle Inc. and a crux for Recycle Inc. and its IT is letting a lot of things go. Well, Recycle Inc. IT didn't take care of some things at all. Whether it was from not wanting to or not being able to, I don't know."

This is why new projects often introduced new systems and there was a lack of interest in merging disparate (lightly embedded) systems into the heavy systems. While yearly investments of about one million euros contributed to adapting ORDER to changing business circumstances, embedding the system mostly meant tinkering with and expanding it via add-ons and extensions. Overall, both ORDER and the systems connected to it illustrate a parallel dynamic well, when we consider the largely independent growth of embeddedness compared to LOX or other systems.

\subsubsection{The Competitive Process}

Our data analysis reveals a second process that is characterized by alternating dynamics between different systems. In extreme cases, this becomes a "zero-sum" dynamic in the sense that the gain of one system represents the loss of another. We refer to this process as a competitive process, which 
denotes a process in which one system loses connections to another system. Figure 5 shows how two systems, $\mathrm{S}_{3}$ and $\mathrm{S}_{4}$, are in a competitive flux for connections.

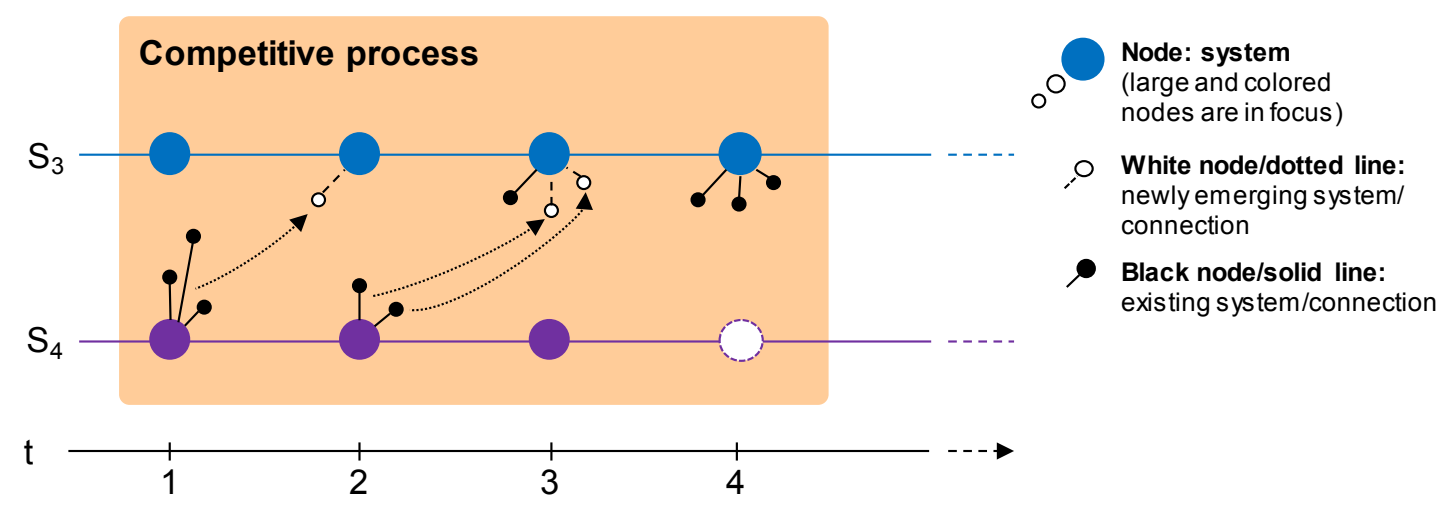

Figure 5 Competitive process of embeddedness

This process is relational and can be observed in contexts in which systems compete for resources. This occurred especially when heavy systems had strong functional overlaps and the user base suggested a decision for a certain system. LEGA and ORDER are examples of this. LEGA was developed by a software supplier working with Recycle Inc., from 1980 onward. In the early 1990s, Recycle Inc., used LEGA in headquarters and in 10 Eastern German subsidiaries. However, the technology platform was limited, and all subsidiaries operated their own servers and client terminals. In 1994, an IT strategy discussion took place and the result was LEGA's discontinuation, so migrating all subsidiaries to ORDER. The resulting ORDER system held the promise of a centralized database system, as it contained standardized master data management and multi-client capability. Moreover, it was aligned to Recycle Inc.'s strategy of migrating to the Windows platform.

The rollout process of ORDER began in 1996 and was completed in 1999. The benefits of focusing on only one of the two systems were easier administration and operations processes. The growth of ORDER and its increasing embeddedness coincided with the decline in the embeddedness of LEGA. A plausible explanation is given by the evolution of ORDER: it subsumed the functions of LEGA and gradually pulled existing and potential connecting systems away from LEGA. In the initial phase especially, the individual value of a system played an important role, so that even initially lightly embedded systems (ORDER) were able in principle to overtake more heavily embedded systems 
(LEGA). This illustrates both systems' opposing directions of growth from the inception of ORDER. However, LEGA did not disappear completely but was further maintained and used in a lightweight fashion by one subsidiary. Such step-wise replacement, with leftovers, can often be observed. Another example of this in Table 4 is a system for municipal waste disposal later replaced by ORDER.

The competitive dynamic observed was primarily a result of the pressure to eliminate existing inefficiencies. However, it is clear from the examples that this was only the case when it was absolutely necessary (e.g., because the technology was no longer available or developers had left the company). On the other hand, IT only made a limited contribution to getting this process going.

\subsubsection{The Spanning Process}

Besides these two processes, we observed a third one. We call this a spanning process, which denotes a process by which connections are established between different heavy systems. As Figure 6 shows, systems $S_{1}$ and $S_{2}$ are connected via the addition of a new system $-S_{5}$, bridging the two parallel branches

in the infrastructure. Similarly, two existing systems, $S_{2}$ and $S_{3}$, are connected to each other, thereby increasing both systems' level of embeddedness. This spanning process can be considered a bridging process between systems across the digital infrastructures.

Our empirical material for this process shows that bridge systems such as SIGN in this case played an important role. The process occurred in the context of the IT leadership team's shifting focus on overarching issues and integration, when a greater awareness of the different data and systems led to measures to integrate and standardize information. The best example of this is SIGN, which started as a read-only data aggregator in the context of hazardous waste. Over time, SIGN developed into a form of middleware to organize the exchange of data between the company's various order processing systems, thus creating bridges between previously separate system worlds. In one sense, the SAP system (FIN) and the standardization imposed by it also emerged as a bridge technology. In the course of the process, upstream systems were connected to it, which gradually contributed to the consolidation of the digital infrastructure. As one IT project manager stated: "Data need to be transferred to financial accounting according to certain criteria, indeed everything had to fit reciprocally. Really, nothing exists outside of these ranges because you won't get the data into the [FIN] system otherwise" (IT Project Manager 6 ). 


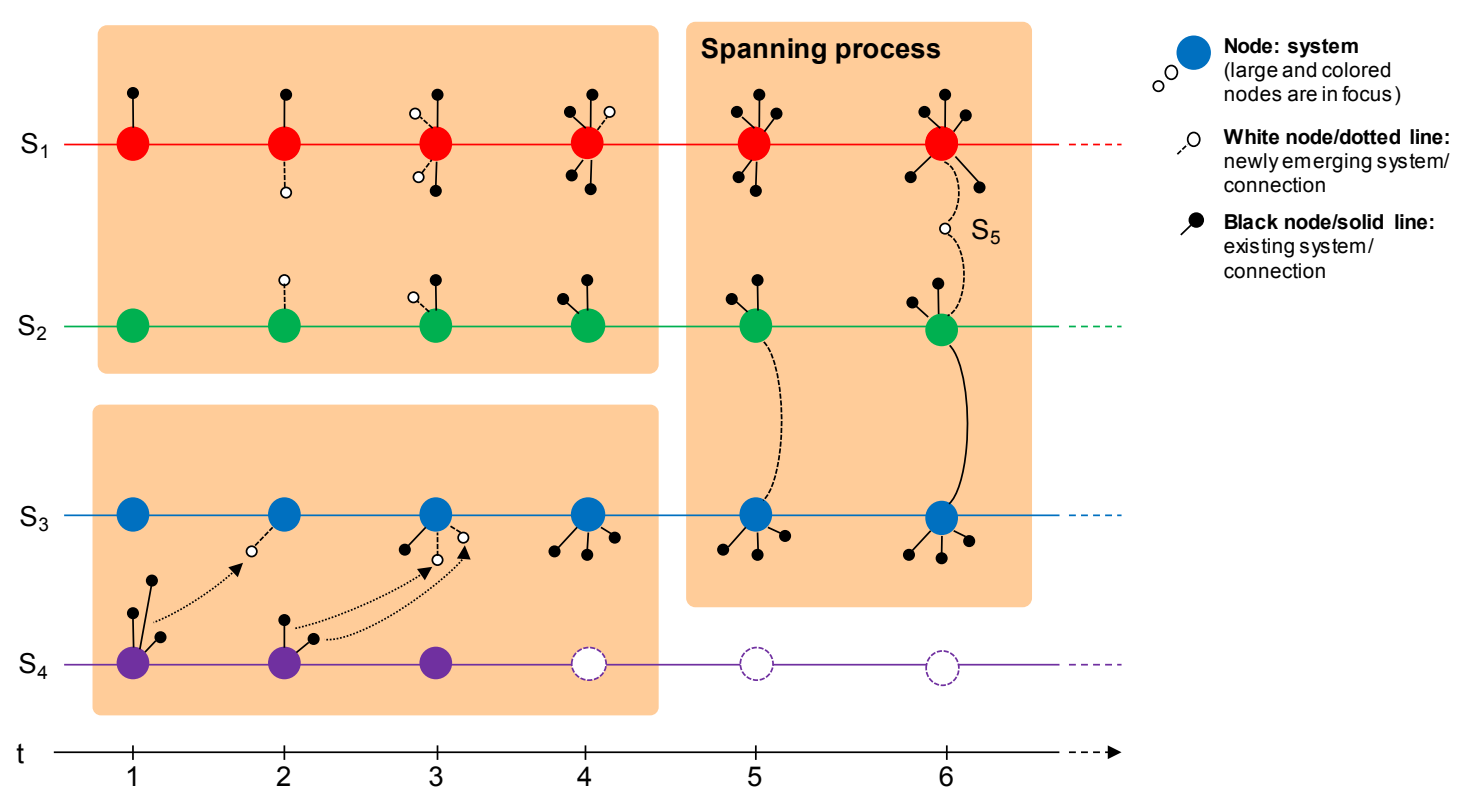

Figure 6 Spanning process of embeddedness

However, the overall extent of integration remained limited. Various data formats and standards, e.g., for the classification and description of materials, customers, and orders in different systems, prevented further integration beyond financial and legal-regulatory purposes. Parallel and competitive processes dominated, while spanning processes developed only to a limited extent.

Table 4 Processes of embeddedness in digital infrastructures

\begin{tabular}{|c|c|c|}
\hline \multicolumn{3}{|c|}{ Theme 1: Creating connections to heavy systems independently (parallel processes) } \\
\hline Code & Explanation & Exemplary quote \\
\hline $\begin{array}{l}\text { Independent } \\
\text { weighing } \\
\text { systems- } \\
\text { online and } \\
\text { offline }\end{array}$ & $\begin{array}{l}\text { In the case of the weighing system, the starting point is } \\
\text { the complementary relationship between the physical } \\
\text { scale, the weighing software and the commercial } \\
\text { systems. Weighing is very complex, and it needs to be } \\
\text { standardized to avoid disruptions. There were grown } \\
\text { structures on the respective sites, and it was hard for } \\
\text { central IT to create aligned structures on the IT side } \\
\text { (concerning ORDER). With the help of the weighing } \\
\text { system, an automation gap could be closed, and the value } \\
\text { of ORDER could be increased. ORDER, however, } \\
\text { developed its weighing integration independently from } \\
\text { LOX or other systems. }\end{array}$ & $\begin{array}{l}\text { "The essential interfaces were } \\
\text { actually the scales. Because } \\
\text { ORDER did not really work } \\
\text { without scales. Because } \\
\text { ultimately the whole process } \\
\text { starts at the scales. How much of } \\
\text { what quantity at what price do we } \\
\text { actually have? And that price is } \\
\text { also fluctuating.... The existing } \\
\text { vendor] had the advantage that } \\
\text { we already had interfaces. And } \\
\text { we understood that." (In-house } \\
\text { Consultant }{ }_{13} \text { ). }\end{array}$ \\
\hline $\begin{array}{l}\text { Integrating } \\
\text { tour planning } \\
\text { and board } \\
\text { computers- } \\
\text { mostly } \\
\text { external }\end{array}$ & $\begin{array}{l}\text { There had been a long-term need for board computer } \\
\text { integration, and a system was initially designed and } \\
\text { introduced by one subsidiary, which was independent of } \\
\text { the infrastructure. In the course of time, however, there } \\
\text { was a need to access existing data from ORDER. }\end{array}$ & $\begin{array}{l}\text { "So the need for such a solution } \\
\text { [on-board computers] existed in } \\
\text { the company for a long time ... } \\
\text { and there have been different } \\
\text { ideas and approaches" (IT } \\
\text { Demand Manager }{ }_{1} \text { ). }\end{array}$ \\
\hline \multicolumn{3}{|c|}{ Theme 2: Swapping connections in a zero-sum fashion (competitive processes) } \\
\hline $\begin{array}{l}\text { LEGA loses its } \\
\text { connections to } \\
\text { ORDER }\end{array}$ & $\begin{array}{l}\text { LEGA, which lost importance over time compared to } \\
\text { ORDER, exemplifies a competitive dynamic whereby the } \\
\text { gain of one system represents the loss of another. Early }\end{array}$ & $\begin{array}{l}\text { "For us, of course, it made it } \\
\text { easier to administer the new } \\
\text { system [ORDER]. It also became }\end{array}$ \\
\hline
\end{tabular}




\begin{tabular}{|c|c|c|}
\hline & $\begin{array}{l}\text { on, an IT strategy discussion took place, deciding to } \\
\text { discontinue LEGA and to migrate all (but two) } \\
\text { subsidiaries to ORDER. }\end{array}$ & $\begin{array}{l}\text { easier for the developers to roll } \\
\left.\text { out changes" (Developer }{ }_{4}\right) \text {. }\end{array}$ \\
\hline $\begin{array}{l}\text { Municipality } \\
\text { system loses } \\
\text { its connections } \\
\text { to ORDER }\end{array}$ & $\begin{array}{l}\text { Despite Recycle Inc.'s focus on private waste disposal, in } \\
\text { one case the company cooperated with a municipality. } \\
\text { This created special requirements that could not be met } \\
\text { by standard systems, which is why the subsidiary } \\
\text { developed its own Access-based system. However, the } \\
\text { parallel development of several systems created more and } \\
\text { more problems over time. One of the core developers was } \\
\text { to retire, and a replacement could not be found. } \\
\text { Therefore, the system was replaced, and the functionality } \\
\text { was integrated into ORDER, including connections to the } \\
\text { municipality. }\end{array}$ & $\begin{array}{l}\text { "Two years ago, the entire } \\
\text { ACCESS solution, everything to } \\
\text { do with logistics, was integrated } \\
\text { into ORDER, which was } \\
\text { reprogrammed accordingly. And } \\
\text { adapted. And new functions were } \\
\text { created" (Business Manager }{ }_{4} \text { ). }\end{array}$ \\
\hline \multicolumn{3}{|c|}{ Theme 3: Connecting heavily embedded systems (spanning processes) } \\
\hline $\begin{array}{l}\text { SIGN connects } \\
\text { ORDER to } \\
\text { other heavy } \\
\text { systems and } \\
\text { beyond }\end{array}$ & $\begin{array}{l}\text { In } 2008 \text {, a portal at the federal authority was introduced, } \\
\text { in which all processes involving hazardous substances } \\
\text { had to be stored. This meant that waste producers had to } \\
\text { send data via providers to this portal. This implied great } \\
\text { technical and processual change in the whole waste } \\
\text { industry and required the introduction of electronic } \\
\text { verification procedures. While SIGN was primarily } \\
\text { procured as a reporting tool for hazardous waste without } \\
\text { writing or updating functions, it became a bridge between } \\
\text { different parts of the digital infrastructure and beyond. }\end{array}$ & $\begin{array}{l}\text { "And build interfaces, even in the } \\
\text { direction of this centralized } \\
\text { portal [via SIGN].... This means } \\
\text { that we offer, also for our } \\
\text { subsidiaries, a signature pad and } \\
\text { a portal [SIGN] and stuff like } \\
\text { that" (Business IT Analyst } 7 \text { ). }\end{array}$ \\
\hline $\begin{array}{l}\text { A bridge } \\
\text { between } \\
\text { ORDER and } \\
\text { FIN }\end{array}$ & $\begin{array}{l}\text { Since the SAP [FIN] system was a central tool for group } \\
\text { management, the interfaces were defined by it. This } \\
\text { resulted in an asymmetrical distribution of roles in which } \\
\text { the source systems had to supply data to SAP and comply } \\
\text { with its logic. Subsidiaries had to somehow create the } \\
\text { interfaces, e.g., from ORDER, to get the information in } \\
\text { the SAP system. }\end{array}$ & $\begin{array}{l}\text { "The subsidiaries had to maintain } \\
\text { and supervise our templates } \\
\text { according to the specifications of } \\
\text { the holding... we have uploaded } \\
\text { this information via interfaces to } \\
\text { SAP" (Controller }{ }_{12} \text { ). }\end{array}$ \\
\hline
\end{tabular}

Table 4 illustrates the three processes and gives examples. Firstly, we observed a boost to the heavy systems from having light systems connected to them, independent of other heavy systems (theme 1: parallel processes). Secondly, we found a relational process of different heavy systems competing for resources and related alternating dynamics (theme 2: competitive processes). Thirdly, the table further demonstrates how heavy systems connect to other heavily embedded systems, e.g., via SIGN, to exchange data and ensure an integrated work process across system boundaries (theme 3: spanning processes).

\section{Discussion}

Considerable progress has been made in understanding the nature and evolution of digital infrastructures (Constantinides et al. 2018; Henfridsson and Bygstad 2013; Tilson et al. 2010). Because a digital infrastructure emerges from multiple, heterogeneous systems working and evolving in concert, it is pivotal to understand how systems are embedded in digital infrastructures and by what processes this 
happens. Our interconnection view on embeddedness in digital infrastructures is sensitive to the "generative mechanisms" (Henfridsson and Bygstad 2013) governing digital infrastructures' evolution. At the same time, it is more specific with respect to the system-level processes driving embeddedness. In particular, our quantitative network analysis offers evidence that a system's position in a system-ofsystems network indicates its future dynamics.

On the other hand, our qualitative study reveals that there are other factors at play, such as the individual value of a system, which explain why some systems grow stronger than others. The combination of the qualitative and quantitative approaches then identifies the three processes that explain how different local and global demands lead to increases, stabilization, or even losses in embeddedness. In this way, evolutionary pathways of systems emerge, which can help us understand how systems grow "in parallel” or "in relation" and so form what becomes a digital infrastructure. In essence, our discussion of the evolution of a digital infrastructure rests on three key findings.

a) There are three underlying sets of processes of system embeddedness in a digital infrastructure-parallel, competitive, and spanning.

b) The processes are triggered by specific local and global demands and are situated in, and bound by the setting in which they arise.

c) The consolidation or fragmentation of these processes shapes the emergence of a digital infrastructure.

\subsection{Influence of System Embeddedness Processes on a Digital Infrastructure}

Our study has laid out three processes by which systems become embedded in a digital infrastructure. The first is a parallel process, whereby systems become embedded independently of each other. The second is a competitive process, whereby systems compete for resources and attention and one system usually thrives while the other system loses importance. This process is "relational" in the sense that it creates a mutual dependence between systems, which can lead to the eventual replacement or reduced presence of one system by another. The third is a spanning process characterizing a situation of boundary-spanning between distinct parts of a digital infrastructure. This process is also "relational," in 
that it creates interdependencies among systems. It causes larger structural patterns to emerge, which may be considered a consolidation of mini-digital infrastructures into an holistic view of an organization's digital infrastructure. Figure 7 shows these processes as well as their triggers and the ensuing digital infrastructure outcome, in what we call the Dynamic Model of Embeddedness in Digital Infrastructures.

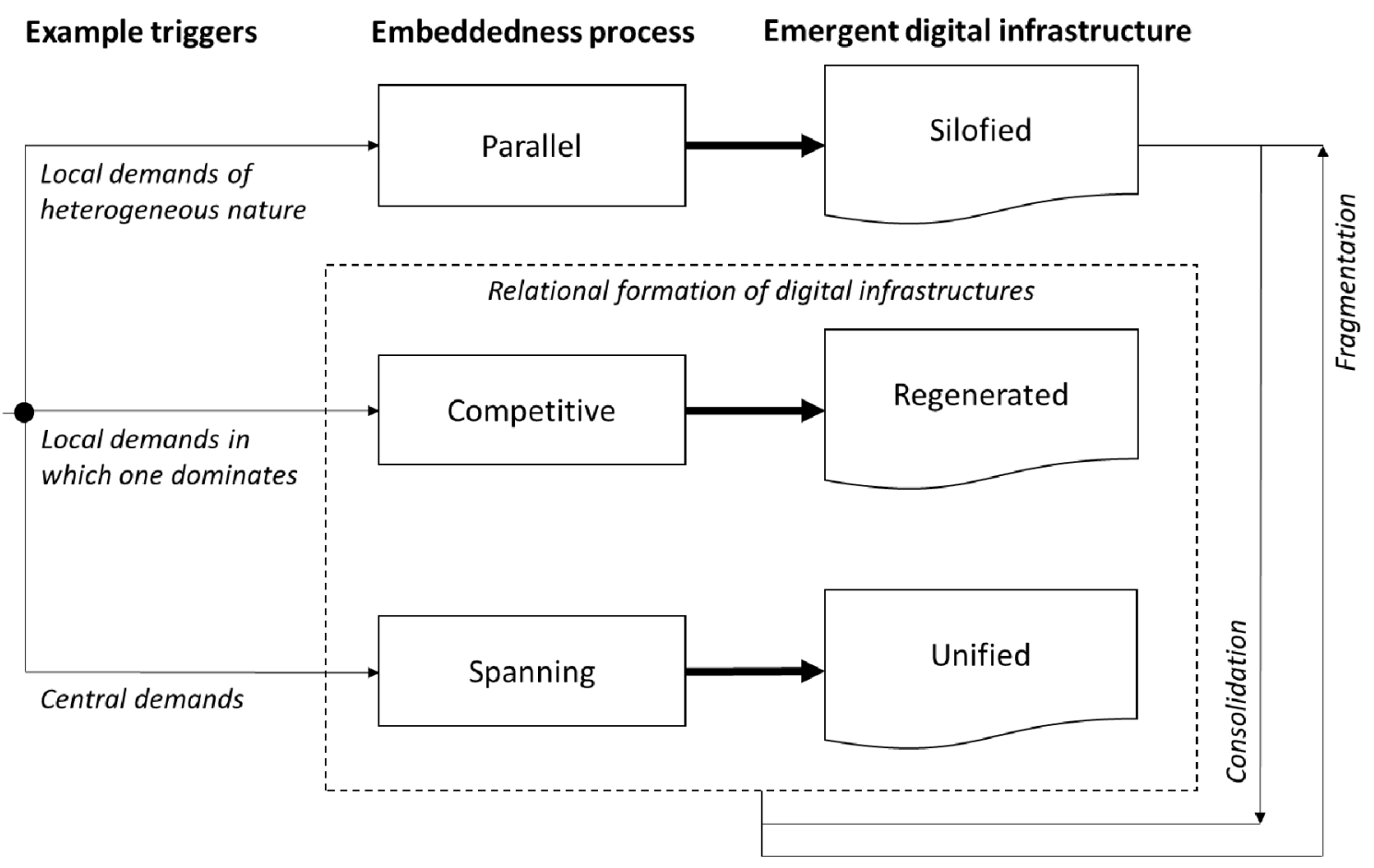

Figure 7 Dynamic Model of Embeddedness in Digital Infrastructures

The model holds that depending on the type of demands and the context in which they arise, distinct processes will occur, which lead to distinct digital infrastructure outcomes. Under a situation of heterogeneous local demands and in which there is a need for a specific local solution (Gregory et al. 2018), a parallel process will likely take place. This leads to a local increase in embeddedness for the system subject to such processes. When local demands are competing for attention and resources and one dominates the other, a competitive process will occur and eventually favor one system over another. Lastly, when global or centralized demands occur (Tanriverdi 2006) they can trigger a spanning process that will lead to a dynamic in which multiple areas or clusters of the digital infrastructure become connected. It is worth noting that these processes sometimes also trigger each other and are interdependent. Most importantly, parallel processes will lead over time to a "silofied" or fragmented 
view (Gal et al. 2008) of the digital infrastructure. That is, a constellation of systems grows out of a particular area or domain. In some cases, these growths may mean strong constellations or stagnated islands of systems. From an organizational perspective, this may be desired if the aim is to develop independent units. However, in a digital era in which value can be amplified by leveraging the combination of data from a variety of sources (Henfridsson and Bygstad 2013; Tilson et al. 2010), this fragmented view may not be desirable. Then, spanning processes will be needed to consolidate the system within the overarching digital infrastructure. This is what we observed in the case of ORDER, when the growth chart indicated stagnation toward the end of our investigation. Only when a larger structure or infrastructure is formed, which is what happened when SIGN was introduced, could there be further opportunities for growth.

Furthermore, the model represents a dynamic rather than a static view of digital infrastructure evolution, incorporating a perspective in which movement between the three infrastructural states is possible. We capture these dynamics as the consolidation and fragmentation of a digital infrastructure. Consolidation implies that different parts of the infrastructure are being brought together. For example, in the case of competitive processes, this may be triggered by the introduction of a new system into the infrastructure, which then gradually replaces a prior system. Or it could also be that two communities of practice have seemingly related processes but different systems for fulfilling those demands (Levina and Vaast 2006). In this case, the process of consolidation implies that one of the two systems used in the separate communities would gradually subsume part or all of the other system's responsibilities. Furthermore, when the spanning process is in place, a new system may integrate disparate systems and communities (see Figure 6). Fragmentation, on the other hand, captures the dynamic when a digital infrastructure is split apart, resulting in multiple islands of digital infrastructures. In a fragmented digital infrastructure, the view of the emergent infrastructure depends on the level of abstraction. For example, from the corporate headquarters' view, each digital infrastructure fragment/island forms part of the whole corporate digital infrastructure; at the level of the corporate branch, however, the fragment that defines their community of practice captures their local view of a digital infrastructure. We elaborate further on the dynamic model of embeddedness in digital infrastructures and the underlying processes and premises in subsequent sections. 


\subsubsection{Silofied Digital Infrastructure}

This is a digital infrastructure that emerges via the parallel process of embedding, in which the overall digital infrastructure comprises two or more independent "islands." Each island in this view represents a digital infrastructure within the context of a particular community of practice or user base (Levina and Vaast 2006). This silo view of digital infrastructure (Gal et al. 2008) is deepened when a parallel embedding process is in action. Parallel processes leading to a silofied digital infrastructure can be triggered by heterogeneous local demands from users (e.g., van Donselaar et al. 2010; Gregory et al. 2015, 2018). For example, at the recycling company's subsidiaries, some users perceived the need for board computers. Others needed a specific computer-based scale to support their workflows. Given resource shortcomings and the unwillingness of the IT department, they turned to local solutions to satisfy their needs. While these needs may arise equally in different subsidiaries of a large company, the parallel process occurs when demands are not "universalized" (Rolland and Monteiro 2002). They remain specific to the local context. Practices such as IT demand management, project management, and portfolio management represent a management perspective aimed at promoting the use of crossfunctional synergies and avoiding excessively localized requirements that generate high costs for unstandardized and redundant solutions (e.g., Blichfeldt and Eskerod 2008; Tanriverdi 2006).

The logic of the parallel process is that a system develops independently. Those who make changes locally may consider other systems "discontinuous" (Star and Ruhleder 1996), or they may simply not know about them, reinforcing the parallel boundaries within a digital infrastructure. Political and economic factors may also play a role (King 1983). This includes the time and effort for negotiations with the IT department over making adjustments. Sometimes the IT department may be dominated by a particular department or manager, leading to the devaluation of other departments' requirements. This happened at the recycling company, where subsidiaries remote from the head office had great difficulties getting their demands realized and were therefore forced to implement their own solutions.

In the recycling company, some systems - such as ORDER and LOX-occupied parallel universes within the digital infrastructure. These systems grew out of their own contexts and communities, remaining largely discontinuous. Support structures differed. In consequence, while these systems overlapped functionally, they grew as independent "islands." As the literature notes, having 
multiple systems running in parallel opens up challenges of silos within the infrastructure (Gal et al. 2008). This could lead to a lack of integration that would hinder the effective flow of business processes, particularly when the same data have to be entered multiple times into different systems (MacArthur et al. 1994). We argue that an understanding of this embeddedness process can help companies mindfully watch a system's trajectory of embeddedness and a tendency to "silofy" the infrastructure. It can also help prevent shadow IT from growing unintentionally beyond the control of central IT departments (Behrens 2009; Furstenau et al. 2017; Winkler et al. 2014).

\subsubsection{Regenerated Digital Infrastructure}

This is a digital infrastructure that emerges due to the competitive dynamic of systems replacing each other, either fully or partly. The emergent digital infrastructure in this view is analogous to leaves on a plant changing color because of the changing seasons or the shedding of leaves to create room for a budding leaf. In this sense, systems are replaced either partially or totally by either new systems or prior existing systems within the infrastructure. This process sheds redundancies within a digital infrastructure. For example, when ORDER replaced a municipal waste solution in one subsidiary, it also took over the information flows to the municipality. The process does not always have to run simultaneously, but it can also support a portfolio view, with time overlaps in the replacement of individual systems by others (Swanson and Dans 2005). In addition, different approaches may describe the replacement, for example, "big bang" (e.g., Bisbal et al. 1999, Hanseth 2010). It does not always lead to a full replacement of one solution by another; an overtaken system may remain partially operational, as when data are needed from or stored in the system.

The logic of the competitive process is relational, in that connections held by one system are transferred to another. We observed that the competitive process can be triggered by competing local demands, whereby one dominates the other. As Pollock et al. (2007) note in the context of enterprise software, pressures for consistency will often harmonize local demands and make the organization carve out the commonalities in the local. The condition leading to the competitive process may vary. It may be the liminality of a technical platform, an organizational restructuration, a compliance program, or a large-scale infrastructural transformation (e.g., Gregory et al. 2015). In each case, these situations may 
condition a need to rethink local solutions, trying to replace one, typically local, with another possibly more global one.

The competitive process implies a choice between two competing options (cf. Farjoun 2010; Wareham et al. 2014) and plays out as redistribution. In this process, a more highly embedded (legacy) system has an advantage, but can be overtaken if the benefits of the other system clearly outweighs it. It also indicates "degenerative mechanisms" (Henfridsson and Bygstad 2013) — not so commonly discussed in the literature on digital infrastructures - in which a system loses importance or value over time due to a lack of relevance for users or connection possibilities. In a way, competitive processes are key to the renewal of digital infrastructure. Old systems are replaced by new ones, resulting in the emergence of a regenerated digital infrastructure. Thus, embeddedness due to the competitive process is not necessarily negative but rather a key mechanism of change in digital infrastructures.

\subsubsection{Unified Digital Infrastructure}

This is a digital infrastructure that emerges from the bridging of different parts of the infrastructure to form a connected and holistic view. In contrast to the silofied digital infrastructure, the unified digital infrastructure brings together independent silos to form a consolidated view. This consolidated view reflects a synergistic status, whereby the connected parts gain more capabilities than they could as separate constellations. Taking our earlier mold analogy, the resulting mold when two spots merge indicates an expansion of their prior status. This view of a digital infrastructure results from an underlying spanning process of system embeddedness.

The logic of the spanning process may include the implementation of middleware, portals, or other integrative technologies (Bidan et al. 2012; Ellingsen and Monteiro 2003; Ellingsen and Røed 2010). These technologies help to connect formerly "discontinuous" terminologies, processes, and contexts (Star and Ruhleder 1996). The spanning process can be triggered by global or central organizational demands. For example, management wants to get an overview or local stakeholders recognize the need to exchange data. Such situations subsequently lead to the need for these islands to be connected and a willingness for the governing community of the silos to (partially) retract their autonomy. 
The outcome of the spanning process is a unified digital infrastructure, whose span is expanded from the perspective of the prior silo infrastructures. The bridge between the infrastructures may be a new system that automatically becomes highly embedded in the digital infrastructure or a connection between existing systems, which increase in value due to their newly acquired boundary-spanning attribute. Drawing from the literature on boundary spanners (Andersson et al. 2008) and the concept of bridging structural holes described by Brass et al. (2004) and Lingo and O’Mahony (2010), this process shifts the focal measure of a system's embeddedness from a solely quantitative assessment exercise to one considering the qualitative value of connections. This is typified by the realization that the value of the connection between systems can be disproportionally high or disproportionally low. For example, the bridge between FIN and LOX is considered highly valuable due to both systems' high embeddedness, while SIGN is valuable because it bridges disparate parts of the network. Value is understood here in terms of socioeconomic implications, for example the efforts/costs caused by removing a connection, or the broader social and organizational consequences brought about by a change in such a connection. The embeddedness of a system cannot simply be evaluated as the sum of its connections. Hence, considering that not all connections are equal reveals the unified digital infrastructure and the underlying spanning process. Therefore, we cannot conclude on embeddedness within a digital infrastructure by assuming that a system with more connections is necessarily more embedded than one with fewer connections. On the contrary, it can be deduced that the value of individual nodes varies with the qualitative importance attached to the system or node they are being connected to.

\subsection{Inertia Entrapment Implications}

As part of alternative views on embeddedness, individual users' habitual behavior and resistance have been discussed as sources of inertia in the event of replacing information systems (Ciborra and Failla 2000; Eriksson and Âgerfalk 2010; Polites and Karahanna 2012). Path dependence, lock-in, and sociotechnical complexity also appear as potential limitations for system replacements (Hanseth 2000; Hughes 1987). Interconnectedness has also been discussed as an obstacle (Monteiro et al. 2013), but its 
development has not yet been sufficiently studied. Our study contributes here by linking the processes of embedding systems in a digital infrastructure to the inertial consequences.

There comes a time when a company faces the risk of being entrapped by a heavily embedded system, as the system becomes more critical and valuable. This can be traced to the simple fact that as the system's importance and criticality increase, so does the continuance inertia-hence the dilemma. Newton's law of inertia puts this into perspective: In its basic form, inertia indicates that a system will continue in a state of rest or uniform motion unless an external force acts on it (Hanson 1963). Change will not occur unless there is a substantial push or motivation for it.

Investigating how processes of embedding relate to inertia entrapment reveals that each of the processes reflects the inertia tendency on the system differently. Firstly, the parallel process leads to a system that becomes a "honeypot", attracting new systems and potentially shadow IT systems. It is the attractiveness that acts as an allure, leading to increasing embeddedness and inertia entrapment in this process. Secondly, the competitive process unfolds in a duality of criticality and redundancy due to its predatory nature. Hence, this process reflects inertia in a kind of "see-saw" arrangement, whereby the gradual decrease in the embeddedness of one system translates to the increasing embeddedness and subsequent inertia capacity of another. Thirdly, spanning processes may create inertia beyond the pure number of connections when they connect multiple heavy systems. In this sense, the observed development of embeddedness and inertia does not take a linear path whereby the addition of one connection is $=+1$; instead, inertia in this process can grow exponentially with the connection of a single system. The source of inertia in this scenario is not based on direct connections to the system alone, but on sub-systems' or constellations of systems' dependency on this linkage.

These embeddedness processes may mean a system remains critical for the company regardless of capability shortcomings. As discussed in the empirical section, ORDER, one of the case company's major ERP systems, stayed important as a system despite several operational shortcomings and innovation bottlenecks. This is because it was already so deeply embedded in the digital infrastructure that replacing it would have been costly and resource intensive (see also Appendix 3, which reflects on the financial costs associated with replacing the sample systems; it illustrates how high levels of integration manifest in high switching costs). The resulting entrapment could lead to an inability to take 
advantage of recent technological advances and innovations, which could disrupt the company (Baiyere and Salmela 2013) or introduce uncertainty into a rather stable setup.

The ORDER system also illustrates how inertia entrapment may sometimes even stretch a system's continuance beyond its technological and informational capacities. Succumbing to inertia for too long may lead to financial costs, business loss, process breakdown, a new learning curve, and system incompatibility, among others. For instance, internal estimates revealed that it would cost Recycle Inc. up to 20 million euros to transform the infrastructure. Although there may be many rational justifications for not changing a highly embedded system, until change is the only option left. The transition from a state of inertial entrapment to a state of liberation (system replacement) is one that managers dreadbut which offers opportunity for interesting theoretical insights for researchers (Agarwal and Tiwana 2015).

\subsection{Limitations and Future Directions}

Of course, there are some limitations to this research project. We have looked at how systems are embedded in a digital infrastructure based on existing integration relationships between systems and related qualitative assessments. However, our qualitative study also showed similarities to other legacy system studies focusing on cultural and normative, lock-in-related, and complexity challenges in adapting and replacing legacy information systems (Bennett 1995; Bisbal et al. 1999; Kelly et al. 1999; Polites and Karahanna 2012). A more complex characterization of the dependencies between elements in a digital infrastructure is therefore needed in the future. This should include users as well as their perceptions, business units, and infrastructure-external elements in a socio-technical network of human beings and technologies. Cyclical, indirect, and transitive dependencies can also arise in such a network, opening up remarkable opportunities for further research. Finally, considering the contextual nature of this study, we believe further studies could provide more insights into the nonlinear growth of embeddedness by incorporating more related contexts. We have, however, benefited from our study's limited context by relying on an extensive longitudinal study that allowed an evolutionary view and helped to strengthen the value of our observations across several data points. 
For possible future research, we have advanced the processes of system embeddedness in digital infrastructures and hereby present a call for them to be substantiated, tested, and extended empirically. The need to understand a system's level of embeddedness and its inertial implications is intensified because deciding to discontinue a highly embedded system requires careful—and often costly— consideration of the dependencies and associated systems that could be affected as well. This remains an open area of inquiry worthy of further scholarship. Another possible future research direction could be exploring how a critical system's value can be accrued without being entrapped by its inertia, particularly in this era of fast-changing business requirements. Future work may also connect our findings to the governance and collective action stream of the digital infrastructure literature (e.g., Constantinides and Barrett 2014; Gregory et al. 2018), as this stream is concerned with mechanisms and processes to codify and institutionalize some of the triggers of the embeddedness processes we have presented.

One other plausible and pertinent research area opened up by this paper is the development of actionable methods or models for assessing the degree of embeddedness and inertia of systems within a digital infrastructure. Information systems paradigms such as design science research and action design research (Hevner et al. 2004; Sein et al. 2011) could find value in such studies. Additionally, from a managerial point of view, a prescriptive study that presents managers with possible solutions after they have identified the level of embeddedness of systems in their infrastructure would provide avenues for engaged scholarship with actionable recommendations. In this context, the initial step of assessing and identifying the areas in which a digital infrastructure might be plagued by inertia becomes highly relevant. Notably for practitioners, it is vital to clarify how to overcome the challenges of embeddedness and the associated consequence of inertia entrapment.

\subsection{Conclusion}

This study holds two implications for the literature on digital infrastructures. Firstly, the paper addresses the implications of yielding to embeddedness in lieu of the propensity of inertial entrapment (Hanseth et al. 1996; Hanseth and Lyytinen 2010; Tilson et al. 2010). It is necessary for both researchers and practitioners to further understand the relationship between "avoiding" inertia and aiming for a balance between stability and flexibility. This is akin to understanding the balance between taking advantage of 
innovations in IT and having a "good enough" system. Secondly, the digital infrastructure literature has long noted that infrastructures are "patchworks" (Ellingsen and Monteiro 2003), ensembles of multiple heterogeneous systems. Our perspective helps to better understand the emergent interconnection dynamics that glue together such ensembles and shape a digital infrastructure's gestalt. Besides parallel embeddedness processes, we conclude that the emergence of overarching digital infrastructures requires competitive and spanning processes for a powerful digital infrastructure to emerge.

\section{References}

Aanestad, M., and Jensen, T. B. 2011. Building Nation-wide Information Infrastructures in Healthcare through Modular Implementation Strategies. Journal of Strategic Information Systems 20(2) 161176.

Agarwal, R., and Tiwana, A. 2015. Editorial-Evolvable Systems: Through the Looking Glass of IS. Information Systems Research 26(3) 473-479.

Andersson, M., Lindgren, R., and Henfridsson, O. 2008. Architectural knowledge in inter-organizational IT innovation. The Journal of Strategic Information Systems 17(1) 19-38.

Arthur, W. B. 1989. Competing Technologies, Increasing Returns, and Lock-In by Historical Events. The Economic Journal 99(394) 116-131.

Arthur, W. B. 1994. Increasing Returns and Path Dependence in the Economy, Economics, cognition, and societyUniv. of Michigan Press, Ann Arbor.

Arthur, W. B. 2018. Self-Reinforcing Mechanisms in Economics. The Economy as an Evolving Complex System, P. W. Anderson, K. J. Arrow, and D. Pineseds. 9-32.

Baiyere, A., and Salmela, H. 2013. Review: Disruptive Innovation \& Information Technology - Charting a Path. Proceedings of the 24th Australasian Conference on Information Systems 1-11.

Barabási, A.-L. 2016. Network Science, Cambridge University Press, Cambridge, UK.

Barabási, A.-L., and Albert, R. 1999. Emergence of Scaling in Random Networks. Science 286(5439) 509-512.

Behrens, S. 2009. Shadow Systems: The Good, the Bad and the Ugly. Communications of the ACM 52(2) 124-129.

Bennett, K. 1995. Legacy Systems: Coping with Success. IEEE Software 12(1) 19-23.

Berger, P. L., and Luckmann, T. 1966. The Social Construction of Reality, Penguin Group (1st ed) Penguin, London, U.K.

Bidan, M., Rowe, F., and Truex, D. 2012. An Empirical Study of IS Architectures in French SMEs: Integration Approaches. European Journal of Information Systems 21(3) 287-302.

Bisbal, J., Lawless, D., and Grimson, J. 1999. Legacy Information Systems: Issues and Directions. IEEE Software 16(5) 2-10.

Blichfeldt, B. S., and Eskerod, P. 2008. Project Portfolio Management - There's More To It Than What Management Enacts. International Journal of Project Management 26(4) 357-365.

Bowker, G. C., and Star, S. L. 1999. Sorting Things Out: Classification and Its Consequences, MIT Press, Cambridge, Mass.

Brass, D. J., Galaskiewicz, J., Greve, H. R., and Tsai, W. 2004. Taking Stock of Networks and Organizations: A Multilevel Perspective. Academy of Management Journal 47(6) 795-817.

Callon, M. 1991. Techno-Economic Networks and Irreversibility. A Sociology of Monsters: Essays on Power, Technology and Domination, J. Lawed. 132-165.

Chua, C. E. H., and Storey, V. C. 2017. Bottom-up Enterprise Information Systems: Rethinking the Roles of Central IT Departments. Communications of the ACM 60(1) 66-72.

Ciborra, C. U. 2000. A Critical Review of the Literature on the Management of Corporate Information Infrastructure. From Control to Drift: The Dynamics of Corporate Information Infrastructures, C. Ciborra, K. Braa, A. Cordella, B. Dahlbom, A. Failla, O. Hanseth, V. Hepso, J. Ljungberg, E. 
Moneiro, and K. A. Simoneds. (1st ed) 15-40.

Ciborra, C. U., and Failla, A. 2000. Infrastructure as a Process: The Case of CRM at IBM. From Control to Drift: The Dynamics of Corporate Information Infrastructures, C. Ciborra, K. Braa, A. Cordella, B. Dahlbom, A. Failla, O. Hanseth, V. Hepso, J. Ljungberg, E. Moneiro, and K. A. Simoneds. (1st ed) $105-124$.

Ciborra, C. U., and Hanseth, O. 2000. Introduction. From Control to Drift: The Dynamics of Corporate Information Infrastructures, C. Ciborra, K. Braa, A. Cordella, B. Dahlbom, A. Failla, O. Hanseth, V. Hepso, J. Ljungberg, E. Moneiro, and K. A. Simoneds. (1st ed, ) 1-14.

Constantinides, P., and Barrett, M. 2014. Information Infrastructure Development and Governance as Collective Action. Information Systems Research 26(1) 40-56.

Constantinides, P., Henfridsson, O., and Parker, G. 2018. Platforms and Infrastructures in the Digital Age. Information Systems Research 29(2) iii-vi.

David, P. A. 1985. Clio and the Economics of QWERTY. American Economic Review 75(2) 332-337.

Dobusch, L., and Schüßler, E. 2013. Theorizing Path Dependence: A Review of Positive Feedback Mechanisms in Technology Markets, Regional Clusters, and Organizations. Industrial and Corporate Change 22(3) 617-647.

van Donselaar, K. H., Gaur, V., van Woensel, T., Broekmeulen, R. A. C. M., and Fransoo, J. C. 2010. Ordering Behavior in Retail Stores and Implications for Automated Replenishment. Management Science 56(5) 766-784.

Dreyfus, D., and Iyer, B. 2008. Managing Architectural Emergence: A Conceptual Model and Simulation. Decision Support Systems 46(1) 115-127.

Eisenhardt, K. M. 1989. Building Theories from Case Study Research. Academy of Management Review 14(4) $532-550$.

Ellingsen, G., and Monteiro, E. 2003. A Patchwork Planet: Integration and Cooperation in Hospitals. Computer Supported Cooperative Work 12(1) 71-95.

Ellingsen, G., and Røed, K. 2010. The Role of Integration in Health-based Information Infrastructures. Computer Supported Cooperative Work 19(6) 557-584.

Eriksson, O., and Âgerfalk, P. J. 2010. Rethinking the Meaning of Identifiers in Information Infrastructures. Journal of the Association for Information Systems 11(8) 433-454.

Fischer, G., Giaccardi, E., Ye, Y., Sutcliffe, A. G., and Mehandjiev, N. 2004. Meta-Design: A Manifesto for End-User Development. Communications of the ACM 47(9) 33-37.

Flinders, K. 2015. SAP Core Banking Platform Will Ease Deutsche Bank Split Following Strategic Retail Review. Computer Weekly. Retrieved (September 20, 2017), http://www.computerweekly.com/news/4500244734/SAP-core-banking-platform-will-easeDeutsche-Bank-split-following-strategic-retail-review.

Flyvbjerg, B. 2006. Five Misunderstandings About Case-Study Research. Qualitative Inquiry 12(2) 219-245.

Freeman, L. C. 1977. A Set of Measures of Centrality Based on Betweenness. Sociometry 40(1) 35-41.

Furneaux, B., and Wade, M. 2011. An Exploration of Organizational Level Information Systems Discontinuance Intentions. MIS Quarterly 35(3) 573-598.

Furstenau, D., Rothe, H., and Sandner, M. 2017. Shadow Systems, Risk, and Shifting Power Relations in Organizations. Communications of the Association for Information Systems 41(1) Article 3.

Gal, U., Lyytinen, K., and Yoo, Y. 2008. The Dynamics of IT Boundary Objects, Information Infrastructures, and Organisational Identities: The Introduction of 3D Modelling Technologies into the Architecture, Engineering, and Construction Industry. European Journal of Information Systems 17(3) 290-304.

Gioia, D. A., Corley, K. G., and Hamilton, A. L. 2012. Seeking Qualitative Rigor in Inductive Research: Notes on the Gioia Methodology. Organizational Research Methods 16(1) 15-31.

Granovetter, M. 1985. Economic Action and Social Structure: The Problem of Embeddedness. American Journal of Sociology 91(3) 481-510.

Greenstein, S. M. 1997. Lock-In and the Costs of Switching Mainframe Computer Vendors: What Do Buyers See?. Industrial and Corporate Change 6(2) 247-274.

Gregory, R. W., Kaganer, E., Henfridsson, O., and Ruch, T. J. 2018. IT Consumerization and the Transformation of IT Governance. MIS Quarterly 42(4) 1225-1253.

Gregory, R. W., Keil, M., Muntermann, J., and Mähring, M. 2015. Paradoxes and the Nature of 
Ambidexterity in IT Transformation Programs. Information Systems Research 26(1) 57-80.

Hair, J. F., Black, W. C., Babin, B. J., and Anderson, R. E. 2014. Multivariate Data Analysis, (7th ed) Pearson Education Limited, Harlow.

Hanseth, O. 2000. The Economics of Standards. From Control to Drift: The Dynamics of Corporate Information Infrastructures, C. Ciborra, K. Braa, A. Cordella, B. Dahlbom, A. Failla, O. Hanseth, V. Hepso, J. Ljungberg, E. Moneiro, and K. A. Simoneds. (1st ed) 56-70.

Hanseth, O. 2010. From Systems and Tools to Networks and Infrastructures-from Design to Cultivation: Towards a Design Theory of Information Infrastructures. Industrial Informatics Design, Use and Innovation: Perspectives and Services 122-156.

Hanseth, O., and Aanestad, M. 2003. Design as Bootstrapping. On the Evolution of ICT Networks in Health Care. Methods of Information in Medicine 42(4) 385-391.

Hanseth, O., and Braa, K. 2000. Globalization and "Risk Society." From Control to Drift: The Dynamics of Corporate Information Infrastructures, C. Ciborra, K. Braa, A. Cordella, B. Dahlbom, A. Failla, O. Hanseth, V. Hepso, J. Ljungberg, E. Moneiro, and K. A. Simoneds. (1st ed) 41-55.

Hanseth, O., and Braa, K. 2001. Hunting for the Treasure at the End of the Rainbow: Standardizing Corporate IT Infrastructure. Computer Supported Cooperative Work 10 261-292.

Hanseth, O., and Lyytinen, K. 2010. Design Theory for Dynamic Complexity in Information Infrastructures: The Case of Building Internet. Journal of Information Technology 25(1) 1-19.

Hanseth, O., Monteiro, E., and Hatling, M. 1996. Developing Information Infrastructure: The Tension Between Standardisation and Flexibility. Science, Technology and Human Values 21(4) 407-426.

Hanson, N. R. 1963. The Law of Inertia: A Philosopher's Touchstone. Philosophy of Science 30(2) 107121.

Henfridsson, O., and Bygstad, B. 2013. The Generative Mechanisms of Digital Infrastructure Evolution. MIS Quarterly 37(3) 907-931.

Henfridsson, O., and Yoo, Y. 2014. The Liminality of Trajectory Shifts in Institutional Entrepreneurship. Organization Science 25(3) 932-950.

Henningsson, S., and Hanseth, O. 2011. The Essential Dynamics of Information Infrastructures. ICIS 2011 Proceedings

Hevner, A. R., March, S. T., Park, J., and Ram, S. 2004. Design Science in Information Systems Research. MIS Quarterly 28(1) 75-105.

Hughes, T. P. 1987. The Evolution of Large Technological Systems. The Social Construction of Technological Systems 51-82.

Jackson, M. O. 2008. Social and Economic Networks, Princeton Univ. Press, Princeton and NJ.

Karasti, H., and Blomberg, J. 2017. Studying Infrastructuring Ethnographically. Computer Supported Cooperative Work (CSCW)

Kelly, S., Gibson, N., Holland, C., and Light, B. 1999. Focus Issue on Legacy Information Systems and Business Process Change: A Business Perspective of Legacy Information Systems. Communications of the Association for Information Systems 2(7) 1-27.

Ketchen, D. J. J., and Shook, C. L. 1996. The Application of Cluster Analysis in Strategic Management Research: An Analysis and Critique. Strategic Management Journal 17(6) 441-458.

King, J. L. 1983. Centralized versus Decentralized Computing: Organizational Considerations and Management Options. ACM Computing Surveys 15(4) 319-349.

Koch, C. 2007. ERP - A Moving Target. International Journal of Business Information Systems 2(4) $426-443$.

Lagerström, R., Baldwin, C. Y., MacCormack, A., and Aier, S. 2014. Visualizing and Measuring Enterprise Application Architecture: An Exploratory Telecom Case. HICSS 2014 Proceedings 3847-3856.

Langley, A. 1999. Strategies for Theorizing from Process Data. Academy of Management Review 24(4) 691-710.

Latour, B. 1987. Science in Action: How to Follow Scientists and Engineers Through Society, Harvard University Press, Cambridge, Mass.

Latour, B. 2005. Reassembling the Social - An Introduction to Actor-Network-Theory, Oxford University Press, Oxford, U.K.

Lawrence, P. R., and Lorsch, J. W. 1967. Differentiation and Integration in Complex Organizations. Administrative Science Quarterly 12(1) 1-47. 
Levina, N., and Vaast, E. 2006. Turning a Community into a Market: A Practice Perspective on Information Technology Use in Boundary Spanning. Journal of Management Information Systems 22(4) 13-37.

Lingo, E. L., and O’Mahony, S. 2010. Nexus Work: Brokerage on Creative Projects. Administrative Science Quarterly 55(1) 47-81.

Lipnack, J., and Stamps, J. 1997. Virtual Teams: Reaching Across Space, Time, and Organizations with Technology, (1st ed) John Wiley \& Sons, New York.

Lyytinen, K., Sørensen, C., and Tilson, D. 2017. Generativity in Digital Infrastructures. The Routledge Companion to Management Information Systems, R. D. Galliers and M.-K. Steineds.

MacArthur, P. J., Crosslin, R. L., and Warren, J. R. 1994. A Strategy for Evaluating Alternative Information System Designs for Business Process Reengineering. International Journal of Information Management 14(4) 237-251.

Monteiro, E. 2003. Integrating Health Information Systems: A Critical Appraisal. Methods of Information in Medicine 42(4) 428-432.

Monteiro, E., Pollock, N., Hanseth, O., and Williams, R. 2013. From Artefacts to Infrastructures. Computer Supported Cooperative Work (CSCW) 22(4-6) 575-607.

Monteiro, E., Pollock, N., and Williams, R. 2014. Innovation in Information Infrastructures: Introduction to the Special Issue. Journal of the Association for Information Systems 15(AprilMay 2014) i-x.

Newman, M., and Robey, D. 1992. A Social Process Model of User- Analyst Relationships. MIS Quarterly 16(2) 249-266.

Ortmann, G. 1984. Der zwingende Blick: Personalinformationssysteme - Architektur der Disziplin [in German], Campus, Frankfurt, New York.

Palla, G., Barabási, A.-L., and Vicsek, T. 2007. Quantifying Social Group Evolution. Nature 446(7136) 664-7.

Pettigrew, A. M. 1990. Longitudinal Field Research on Change: Theory and Practice. Organization Science 267-292(1) 3.

Pipek, V., and Wulf, V. 2009. Infrastructuring: Toward an Integrated Perspective on the Design and Use of Information Technology. Journal of the Association for Information Systems 10(5) 447-473.

Podolny, J. M. 2001. Networks as the Pipes and Prisms of the Market. American Journal of Sociology 107(1) 33-60.

Polites, G. L., and Karahanna, E. 2012. Shackled to the Status Quo: The Inhibiting Effects of Incumbent System Habit, Switching Costs, and Inertia on New System Acceptance. MIS Quarterly 36(1) 2142 .

Pollock, N. 2010. When is a Workaround? Conflict \& Negotiation in Computer Systems Development. Science Technology And Human Values 30(4) 496-514.

Ribes, D., and Finholt, T. A. 2009. The Long Now of Technology Infrastructure: Articulating Tensions in Development. Journal of the Association for Information Systems 10(May 2009) 375-398.

Rolland, K. H., and Monteiro, E. 2002. Balancing the Local and the Global in Infrastructural Information Systems. Information Society 18(2) 87-100.

Schutz, A., and Luckmann, T. 1973. The Structures of the Life-world, Northwestern University Press, Evanston.

Sein, M. K., Henfridsson, O., Purao, S., Rossi, M., and Lindgren, R. 2011. Action Design Research. Management Information Systems Quarterly 35(1) 37-56.

Siggelkow, N. 2007. Persuasion with Case Studies. Academy of Management Journal 50(1) 20-24.

Singh, P. V., Tan, Y., and Mookerjee, V. 2011. Network Effects: the Influence of Structural Capital on Open Source Project Success. Mis Quarterly 35(4) 813-829.

Star, S. L., and Ruhleder, K. 1996. Steps Toward an Ecology of Infrastructure: Design and Access for Large Information Spaces. Information Systems Research 7(1) 111-134.

Street, C. T., and Ward, K. W. 2011. Improving Validity and Reliability in Longitudinal Case Study Timelines. European Journal of Information Systems 21(2) 160-175.

Sundararaja, A., Provost, F., Oestreicher-Singer, G., and Aral, S. 2014. Research Commentary Information in Digital, Economic, and Social Networks. Information Systems Research 24(4) 883905.

Swanson, E. B., and Dans, E. 2005. System Life Expectancy and the Maintenance Effort: Exploring 
Their Equilibration. MIS Quarterly 24(2) 277-297.

Sydow, J., Schreyögg, G., and Koch, J. 2009. Organizational Path Dependence: Opening the Black Box. Academy of Management Review 34(4) 689-709.

Tanriverdi, H. 2006. Performance Effects of Information Technology Synergies in Multibusiness Firms. MIS Quarterly 30(1) 57-77.

Tilson, D., Lyytinen, K., and Sørensen, C. 2010. Digital Infrastructures: The Missing IS Research Agenda. Information Systems Research 21(4) 748-759.

Vaast, E., and Walsham, G. 2009. Trans-Situated Learning: Supporting a Network of Practice with an Information Infrastructure. Information Systems Research 20(4) 547-564.

van de Ven, A. H., and Poole, M. S. 1995. Explaining Development and Change in Organizations. Academy of Management Review 20(3) 510-540.

Venkatesh, V., Brown, S. A., and Bala, H. 2013. Bridging the Qualitative-Quantitative Divide: Guidelines for Conducting Mixed Methods Research in Information Systems. Management Information Systems Quarterly 37(1) 21-54.

Wasserman, S., and Faust, K. 1994. Social network analysis: Methods and applications, Structural analysis in the social sciences (19th ed, Vol. 8) Cambridge Univ. Press, Cambridge.

Winkler, T. J., Brown, C. V., and Ozturk, P. 2014. The Interplay of Top-Down and Bottom-Up: Approaches for Achieving Sustainable Health Information Exchange. ECIS 2014 Proceedings 17.

Yin, R. K. 2013. Case Study Research: Design and Methods, Essential guide to qualitative methods in organizational researchApplied Social Research Methods Series (5th ed, Vol. 5) Sage Publications, Thousand Oaks, California. 


\section{Appendices}

Appendix 1: System embeddedness on the level of the whole network

\begin{tabular}{llllll}
\hline System & $\mathbf{1 9 9 5}$ & $\mathbf{2 0 0 0}$ & $\mathbf{2 0 0 5}$ & $\mathbf{2 0 1 0}$ & $\mathbf{2 0 1 5}$ \\
\hline No. nodes/systems & 10 & 22 & 64 & 212 & 215 \\
No. links/integration & 7 & 15 & 66 & 263 & 268 \\
\hline
\end{tabular}

Appendix 2: Number of subsidaries connected to the systems ${ }^{\dagger}$

\begin{tabular}{llllll}
\hline System & $\mathbf{1 9 9 5}$ & $\mathbf{2 0 0 0}$ & $\mathbf{2 0 0 5}$ & $\mathbf{2 0 1 0}$ & $\mathbf{2 0 1 5}$ \\
\hline FIN & 5 & 5 & 8 & 9 & 9 \\
ORDER & 1 & 13 & 13 & 14 & 14 \\
LOX & - & - & - & 7 & 7 \\
SIGN & - & - & - & 16 & 16 \\
LEGA & 11 & 1 & 1 & 1 & 1 \\
BOARD & - & - & - & 1 & - \\
\hline
\end{tabular}

Based on a non-exhaustive sample of 29 subsidiaries. This table represents our own reconstruction of usage in subsidiaries based on sources $\mathrm{a}_{1}-\mathrm{a}_{4}$, as well as interview data. The data was verified by two key informants from the company. For FIN, we report only on the subsidaries that were actively using the system; all others were still oblidged to deliver accounting data in the prescribed format.

\section{Appendix 3: Financial view on interconnectedness}

\begin{tabular}{|c|c|c|c|}
\hline $\begin{array}{l}\text { System } \\
\text { (\#links) }\end{array}$ & Main purposes & Standalone costs & Embeddedness/interconnection costs \\
\hline $\begin{array}{l}\text { FIN } \\
(30)\end{array}$ & $\begin{array}{l}\text { Invoicing, } \\
\text { financial } \\
\text { accounting and - } \\
\text { consolidation }\end{array}$ & $\begin{array}{l}\text { Yearly licenses of } \sim 2 \mathrm{M} \text { EUR from } \\
\text { all subsidiaries, covering costs for } \\
\text { maintenance and further } \\
\text { developments. No information } \\
\text { about replacement costs available }\end{array}$ & $\begin{array}{l}\text { Core interfaces: Upstream systems } \\
\text { (ORDER, LOX, etc.), Controlling / CO, } \\
\text { Business warehouse, human resources (and } \\
\text { other corporate systems), archiving systems }\end{array}$ \\
\hline $\begin{array}{l}\text { ORDER } \\
(22)\end{array}$ & $\begin{array}{l}\text { Distribution and } \\
\text { order mgmt. }\end{array}$ & $\begin{array}{l}\text { Yearly licenses of } \sim 1 \mathrm{M} \text { EUR from } \\
\text { all subsidiaries, covering costs for } \\
\text { maintenance and further } \\
\text { developments. Overall estimate } \\
\text { for replacement: } 15-20 \mathrm{M} \text { EUR } \\
\text { (incl. requirements engineering, } \\
\text { and interface harmonization) }\end{array}$ & $\begin{array}{l}\text { Core interfaces: Scales (online, offline), } \\
\text { corporate systems (FIN), legal reporting } \\
\text { (SIGN), large number of small systems in } \\
\text { subsidiaries (tour planning, etc.); } \\
\text { implementation cost estimates per interface } \\
\text { ranging between } 70 \mathrm{k}-120 \mathrm{k} \text {, depending on } \\
\text { complexity of integration (\#use cases, } \\
\text { information intensity, type) }\end{array}$ \\
\hline $\begin{array}{l}\mathrm{LOX} \\
(26)\end{array}$ & $\begin{array}{l}\text { Sales and } \\
\text { operations / } \\
\text { logistics }\end{array}$ & $\begin{array}{l}\text { See ORDER, estimate for } \\
\text { harmonization of all ERP systems }\end{array}$ & $\begin{array}{l}\text { See ORDER; in addition: board computer } \\
\text { integration in place }\end{array}$ \\
\hline $\begin{array}{l}\text { SIGN } \\
(9)\end{array}$ & $\begin{array}{l}\text { Legal reporting } \\
\text { for hazardous } \\
\text { waste }\end{array}$ & $\begin{array}{l}\text { Overall implementation costs not } \\
\text { available. Transferring the } \\
\text { solution to non-hazardous waste } \\
\text { estimated at } 250 \mathrm{k}\end{array}$ & $\begin{array}{l}\text { Core interfaces: ERP systems (ORDER, } \\
\text { LOX, etc.); external interfaces to using } \\
\text { companies having integrated SIGN in their } \\
\text { own processes }\end{array}$ \\
\hline $\begin{array}{l}\text { LEGA } \\
(3)\end{array}$ & $\begin{array}{l}\text { Distribution and } \\
\text { order mgmt. }\end{array}$ & $\begin{array}{l}\text { Negligible (small license fee and } \\
\text { server costs) }\end{array}$ & $\begin{array}{l}\text { Three interfaces, connecting to local scale } \\
\text { system in subsidiary and SAP/FIN system }\end{array}$ \\
\hline $\begin{array}{l}\text { BOARD } \\
\text { (1) }\end{array}$ & $\begin{array}{l}\text { Telematics } \\
\text { solution for tour } \\
\text { planning }\end{array}$ & $\begin{array}{l}\text { Initial project costs appr. 80k } \\
\text { EUR (considered "very cheap"); } \\
\text { escalation of initial costs }\end{array}$ & $\begin{array}{l}\text { One unidirectional interface, built because } \\
\text { of read only access to ERP }\end{array}$ \\
\hline
\end{tabular}




\title{
A Dynamic Model of Embeddedness in Digital Infrastructures
}

\author{
Daniel Fürstenau ${ }^{1,2}$ \\ ${ }^{1}$ Freie Universität Berlin \\ School of Business \& Economics \\ Department of Information Systems \\ Garystr. 21, 14195 Berlin, Germany \\ daniel.fuerstenau@fu-berlin.de \\ ${ }^{2}$ Einstein Center Digital Future \\ Wilhelmstr. 67, 10117 Berlin, Germany
}

\author{
Abayomi Baiyere ${ }^{3}$ \\ ${ }^{3}$ Copenhagen Business School \\ Department of Digitalization \\ Howitzvej 60, 2000 Frederiksberg, Denmark \\ aba.digi@cbs.dk \\ Natalia Kliewer ${ }^{4}$ \\ ${ }^{4}$ Freie Universität Berlin \\ School of Business \& Economics \\ Department of Information Systems \\ Garystr. 21, 14195 Berlin, Germany \\ natalia.kliewer@fu-berlin.de
}




\title{
A Dynamic Model of Embeddedness in Digital Infrastructures
}

\begin{abstract}
Digital infrastructures are a result of individual yet interdependent systems evolving in relation to each other. In this paper, we identify three processes by which individual systems become embedded into digital infrastructures. First, there are parallel processes, in which systems become embedded independently of each other. Second, there are competitive processes, in which the embeddedness of one system increases at the expense of another. Finally, there are spanning processes, in which bridges are built between different embedded systems. The three processes, synthesized into a dynamic model of digital infrastructure embeddedness, offer much needed conceptual clarity to the area of digital infrastructure evolution. They also provide insight into the emergence of three forms of digital infrastructures: silofied, regenerated, and unified. Reflecting an interconnection view, our research further facilitates an understanding of infrastructure inertia and its associated consequence.
\end{abstract}

\section{Keywords}

Digital Infrastructures, Embeddedness, Inertia, Mixed Methods, Process Models 


\section{A Dynamic Model of Embeddedness in Digital Infrastructures}

\section{Introduction}

The literature on digital infrastructures has long noted a tension between dynamic flexibility and stability underlying the mechanisms that facilitate infrastructure evolution (Hanseth et al. 1996; Hanseth and Lyytinen 2010; Tilson et al. 2010). Companies often struggle to find a balance between allowing new and tailored applications, as well as IT capabilities, to connect to the established infrastructure, and ensuring that those innovative efforts are sufficiently aligned with corporate goals and principles. While the uncontrolled introduction of new systems and connections makes infrastructures overly complex, too strict rules may focus efforts firmly on one rigid, standard approach (Ciborra and Failla 2000; Hanseth and Lyytinen 2010). Therefore, companies need to be mindful of how individual systems are embedded within a digital infrastructure.

Many new systems are initially intended to solve a specific business problem. As they become increasingly popular and entrenched in people's working lives, these systems grow and more systems are connected to them (Henfridsson and Bygstad 2013). In turn, many such systems far exceed their intended life span (Agarwal and Tiwana 2015). In practice, decision-makers often feel powerless when the growth process of a system has progressed for too long (Furneaux and Wade 2011). Such systems, also known as legacy systems, are often highly advanced but also extremely rigid (Bisbal et al. 1999), as illustrated by the $€ 1 \mathrm{bn}$ multi-year project to move away from complex, organically grown mainframe solutions embarked on by Deutsche Bank (Flinders 2015). Before such costly IT transformation, huge resources are needed for operations and maintenance, while some companies fail to take full advantage of the innovative capability offered by new digital services and processes.

In contexts where a system's extensibility is limited, users may seek to satisfy their requirements by introducing new systems or extensions independently of the original system (Gregory et al. 2018). Examples are "workarounds" (Pollock 2010), “end user-developments” (Fischer et al. 2004), "bottomup" (Chua and Storey 2017), or "shadow systems" (Behrens 2009). As a consequence, and as Henfridsson and Bygstad (2013) note, the scope of a single system is no longer sufficient to describe the challenges managers and CIOs face today, whereby systems are interconnected in various and 
complex ways. In light of this, we refer to a set of interconnected information systems as a digital infrastructure. As Tilson et al. (2010) also note, a digital infrastructure may support or enable a global, national, regional, industry, or corporate entity but it has no strict boundaries or distinct set of functions. Boundaries are constructed and constantly renegotiated by users and may be limited by the technologies they draw upon to achieve their goals. According to Henfridsson and Bygstad (2013), the "inner workings" of digital infrastructure evolution deserve special attention. Problems arise when many different systems work together in complex ways but full transparency is lacking. In line with these opening issues, we seek to answer the question: How do information systems become embedded into a digital infrastructure over time?

Drawing on an interconnection view of embeddedness and rich empirical evidence from a longitudinal mixed-methods study in a recycling firm, our paper concludes that there are three embeddedness processes in a digital infrastructure: parallel, competitive, and spanning. The enactment of these processes contributes to the emergence of a digital infrastructure. This integrates into what we call the Dynamic Model of Embeddedness in Digital Infrastructures. The model outlines how the three processes when taken together, provide a theoretical explanation of how different forms of digital infrastructures emerge. With this understanding we propose that the embeddedness process underlying a digital infrastructure can determine if the infrastructure will become silofied, regenerated, or unified.

\section{Views on Embeddedness in Digital Infrastructures}

The information systems literature has developed a broad contextual understanding of what is meant by "embeddedness" and what concepts and processes it describes. It typically draws on sociological and organizational research without making embeddedness the object of a distinct processual theory development. One example is the work of Furneaux and Wade (2011), who understand system embeddedness with reference to organizational routine research as "the extent to which the use of an information system is an integral part of organizational activity" (p. 579). This can be determined as a variable, either by checking the number of other systems a certain system is interlinked with, or how much it is embedded into organizational routines. 
In prior works on digital infrastructures, in which a more dynamic understanding of embeddedness is developed, at least three research streams can be differentiated (see Table 1). A first stream goes under the broad label of institutionalization. Grounded in the literature on the social construction of reality and habitualization (Berger and Luckmann 1966; Schutz and Luckmann 1973), such works typically highlight how systems become, through perpetual use, part of people's routines. They become unquestioned and taken-for-granted. In this view, infrastructures emerge from individual systems and become virtually invisible to users, reducing complexity (Bowker and Star 1999; Karasti and Blomberg 2017; Star and Ruhleder 1996). Infrastructures are therefore embedded in a network of relationships, which only appear when actualized by certain users or user communities (Pipek and Wulf 2009; Vaast and Walsham 2009). Inertia may occur where dysfunctional worldviews or patterns of action become entrenched; often without the users' awareness. Alternatively, normative, cultural, or other habits as well as material and physical constraints may inhibit change. For example, Star and Ruhleder (1996) study a large-scale scientific infrastructure and show how the lack of embeddedness in the users' practices, due to technical problems, contributed to its failure as people preferred the internet to fulfil their information needs.

Second, the embeddedness view of path dependence is premised on the insight that embedding generates increasing returns. After initial uncertainty, a positive spiral in the use of a system, triggered by the path-creating actions of one or more actors (Henfridsson and Yoo 2014), leads to its further improvement. This happens when complementary products are introduced, which in turn creates incentives for the community to adopt it more. Infrastructures, in this view, emerge from a heterogeneous installed base of systems, actors, and their relations (Hanseth and Lyytinen 2004). This view was made popular by the work of Hanseth (2000), based on fundamental insights into the economics of standards and path dependence (Arthur 1989, 1994, 2018; David 1985). It was modified and extended, for example, by highlighting and identifying how systems in early development phases can generate the necessary momentum (Aanestad and Jensen 2011; Hanseth and Aanestad 2003; Hanseth and Lyytinen 2010; Hughes 1987). Moreover, at least implicitly, this thinking is subject to the generative mechanisms of adoption and scaling outlined by Henfridsson and Bygstad (2013), who describe an interplay between individual micro-level decisions and emergent infrastructural outcomes. 
Many of the studies based on this notion of self-reinforcing mechanisms and path dependence recognize the double-edged nature of such processes (Dobusch and Schüßler 2013; Sydow et al. 2009). While selfpropelled growth appears to be desirable at first glance, increasing inertia accumulates over time. The result is irreversibility and lock-in. In classical studies inspired by path dependence, these lock-ins are found in demand-side market situations, e.g., where buyers are tied to the wrong technologies/standards (Arthur 1989) or companies to the wrong vendors (Greenstein 1997; Monteiro 2003). This idea has also been interpreted more broadly and projected onto many organizational coordination problems, which lead over time to a narrowed scope of action due to learning, adaptive expectation, or complementarity (Sydow et al. 2009).

The last research stream views embeddedness from an assemblage perspective. Drawing on actor-network theory (Callon 1991; Latour 1987, 2005), the basic idea is that large-scale systems need to be understood as "heterogeneous assemblages of human and material elements" (Koch 2007, p. 427). According to this view, embeddedness describes "the entanglement of one technology with other apparently unrelated ones" (Monteiro et al. 2013, p. 575). It has been noted in the literature on digital infrastructures that many systems are not equipped per se to meet the user needs within their initial design focus (Monteiro et al. 2014). New systems are constantly being connected to, and stacked under and on top of existing systems, where they are needed to connect people and processes (Hanseth and Braa 2001). Such processes can be triggered by human or material needs and constraints. This is illustrated by the Hydro Bridge project in Norway, where the "Bridge," conceived as a corporate infrastructure for digital cooperation, was constantly expanded by building new systems on top of existing ones, extending them, or connecting them by means of data exchange interfaces. For example, an SAP infrastructure extended the Hydro Bridge infrastructure and was gradually absorbed by it (Hanseth and Braa 2001). It also involved the embedding of the Hydro Bridge infrastructure on top of underlying infrastructure such as operating systems or server hardware, of which only some were standardized. Infrastructures and systems mostly intended to connect split divisions at Hydro. Evolutionary processes contribute to their stabilization and destabilization (Henningsson and Hanseth 2011). The result of these processes of embeddedness is an increasingly complex and entangled digital infrastructure. 
Table 1 Views on embeddedness in digital infrastructures

\begin{tabular}{|l|l|l|l|l|}
\hline $\begin{array}{l}\text { Research } \\
\text { stream }\end{array}$ & Foundational literature & $\begin{array}{l}\text { Definition (of } \\
\text { embeddedness) }\end{array}$ & $\begin{array}{l}\text { Inertial } \\
\text { consequences }\end{array}$ & Example references \\
\hline $\begin{array}{l}\text { Institutio- } \\
\text { nalization }\end{array}$ & $\begin{array}{l}\text { Social construction and } \\
\text { habitualization: } \\
\text { - Berger and Luckmann } \\
\text { (1966) } \\
\text { - Schutz and Luckmann } \\
\text { (1973) }\end{array}$ & $\begin{array}{l}\text { The processes by which users } \\
\text { increasingly take a system } \\
\text { for granted as they make it } \\
\text { part of their routines }\end{array}$ & $\begin{array}{l}\text { Normative or } \\
\text { cultural } \\
\text { persistence }\end{array}$ & $\begin{array}{l}\text { Eriksson and Agerfalk } \\
(2010) ; \text { Pipek and } \\
\text { Wulf (2009); Ribes } \\
\text { and Finholt (2009); } \\
\text { Star and Ruhleder } \\
(1996)\end{array}$ \\
\hline $\begin{array}{l}\text { Path } \\
\text { depen- } \\
\text { dence }\end{array}$ & $\begin{array}{l}\text { Economics of standards } \\
\text { and path dependence } \\
\text { theory: } \\
\text { - Arthur (1989, 1994) } \\
\text { - Hughes (1987) }\end{array}$ & $\begin{array}{l}\text { The process of increasing } \\
\text { returns, by which users are } \\
\text { increasingly drawn to an } \\
\text { installed base of social and } \\
\text { technical components while } \\
\text { the system becomes } \\
\text { increasingly refined }\end{array}$ & $\begin{array}{l}\text { Lock-in, } \\
\text { irreversibility }\end{array}$ & $\begin{array}{l}\text { Hanseth and Aanestad } \\
(2003) ; \text { Hanseth and } \\
\text { Braa (2000); Hanseth } \\
\text { and Lyytinen (2010); } \\
\text { Henfridsson and } \\
\text { Bygstad (2013) }\end{array}$ \\
\hline $\begin{array}{l}\text { Assem- } \\
\text { blage }\end{array}$ & $\begin{array}{l}\text { Actor-network and } \\
\text { assemblage theories: } \\
\text { Callon (1991) } \\
\text { - Latour (1987, 2005) }\end{array}$ & $\begin{array}{l}\text { The processes by which } \\
\text { technologies and their human } \\
\text { and material elements get } \\
\text { entangled with each other }\end{array}$ & $\begin{array}{l}\text { Complexity of } \\
\text { the assem- } \\
\text { blage }\end{array}$ & $\begin{array}{l}\text { Hanseth and Braa } \\
(2001) ; \text { Henningsson } \\
\text { and Hanseth (2011); } \\
\text { Monteiro et al. (2013) }\end{array}$ \\
\hline
\end{tabular}

Together, these three research streams provide rich contextual insights into the processes of embeddededness in digital infrastructures, but they currently lack the granularity and detail necessary to fully unpack the evolution of embeddedness in digital infrastructures. This detail is important to understand the link between embeddedness and continuance inertia and ultimately, to make timely decisions on system replacements, reengineering, and new system investments. Thus, our study aims to develop a process model of embeddedness in digital infrastructures based on a network foundation.

\section{An Interconnection View on Embeddedness in Digital Infrastructures}

The new perspective developed here is premised on the importance of a fine-grained, evolutionary process view (van de Ven and Poole 1995) in embedding systems into digital infrastructures. While earlier research on digital infrastructures challenged the rational actor view of digital infrastructure evolution, the research discussed here calls into question the beliefs that aggregated evolution paths work in the same way on a smaller scale, that generative mechanisms will be universally present (or absent) in all parts of a digital infrastructure, and that the scaling speed of a digital infrastructure is uniform across its constituent parts (Lyytinen et al. 2017). While recognizing that the generative mecahnisms of adoption, innovation, and scaling drive the growth of a digital infrastructure as a whole, we want to explore another set of processes here; ones that change the digital infrastructure from within, 
more endogenously, more subtly, and more granularly, but no less considerably. Such processes are "sequences of "events"” (Langley 1999, p. 692) fueled by the local demands that actors face, the interdependencies between actors and systems, the boundaries set up, and global necessities. Ciborra and Hanseth (2000, p. 2) note:

Infrastructures are puzzles, or better [yet] collages, and so are the design and implementation processes that lead to their construction and operation ... Interdependence, intricacy, and interweaving of people, systems, and processes are the cultural bed of infrastructures.

Dreyfus and Iyer (2008, p. 115), similarly, but more technically, write:

The pattern of interconnections among the deployed software components [-] is frequently the result of multiple, imperfectly coordinated decision makers operating over time. Individual decision-makers frequently make local design decisions regarding infrastructure and application design, deployment, updating, upgrading, and decommissioning that have enterprise-wide ramifications.

From this perspective, embeddedness is not universally present or absent across all the parts that constitute a digital infrastructure. Rather, embedding is seen here as a set of fine-grained processes that happen with different forces and speeds to different elements of a digital infrastructure.

Our view acknowledges and builds on prior network research as proposed by Granovetter (1985) and many others. He and subsequent peers put relation first and stress the importance of "concrete personal relations and structures (or 'networks') of such relations in generating trust and discouraging malfeasance" (1985, p. 490). Relations are not merely transmitters ("pipes") through which resources flow (e.g., data and functions). Instead, they are both "pipes and prisms" (Podolny 2001, p. 33). They create signals and dependencies that the actors involved in a relation act upon (Sundararaja et al. 2014). This thinking is important for understanding why interconnectedness - the way in which elements in a digital infrastructure are related to each other — not only reveals obvious information flows but, more importantly, creates cues for where decision-makers will direct their attention for the future development of a digital infrastructure.

This notion of embeddedness is also key in work that has been done on the evolution of networks (e.g., Barabási 2016, Palla et al. 2007). Structural patterns such as what communities belong together may emerge early on and be reinforced over time through an ongoing sequence of steps creating new interconnections and thus dependencies (Singh et al. 2011). These processes are not deterministic individually, but are driven by mindful actions of particular actors, communities, and projects, although 
with partly unintended outcomes. Eventually, however, this shows that the individual system in a digital infrastructure is not independent; its evolution is interdependent with a host of other systems, which are in turn pushed by the intentions and actions of particular actors. It also suggests that some systems may become important control points that develop a prominent position for the growth and long-term evolution of the digital infrastructure as a whole.

Our view on the emergence of digital infrastructures as a result of fine-grained system-level processes may be best illustrated by a metaphor. Continued proliferation is one of the most important characteristics of digital technologies. Single systems emerge here and there as islands, and nobody can say initially when and where these will grow together or become integrated on a higher level. This understanding owes much to Ortmann's (1984) image of mold on jam, which emerges in spots on the surface and finally grows together into a cotton-wool and felt-like coating that eventually leads to putrefaction. No plan controls the whole thing, and yet there is an underlying process. Each system develops individually but in relation to other systems in a digital infrastructure, and no finite boundaries define the digital infrastructure. Still, we recognize when embedding has happened, and we can determine whether a system has remained in its small isolated silo or has grown together with other systems into an emergent digital infrastructure.

We consider our advanced interconnection view to be pertinent in understanding how the processes of embedding systems shape a digital infrastructure for at least two reasons. Firstly, it is logical to expect that different organizational demands will lead to different embeddedness outcomes, yet we do not understand the primary process through which these unfold. For example, how do local organizational demands versus centralized organizational demands (e.g., mergers and acquisitions) determine the underlying process of embeddedness, and how do such processes influence the trajectory of the digital infrastructure? Secondly, prior research has noted the tension between the flexibility and stability agenda of an organization's digital infrastructure (Hanseth et al. 1996; Hanseth and Lyytinen 2010; Tilson et al. 2010). However, we lack understanding of the processes that underlie the interplay of these tensions at a granular level. Perhaps more importantly, prior research tends to overlook how these minute interactions define the fine-grained embeddedness process that forms the building blocks of a digital infrastructure. 
Informed by ideas of network embeddedness, network evolution, and Ortman's idea of "mold on jam," this paper outlines a perspective of digital infrastructure embeddedness as a result of individual yet interdependent systems evolving in relation to each other. This perspective is central to our analysis of a large distributed company evolving its digital infrastructure. In the study described in this paper, we examine the processes of embeddedness in a digital infrastructure that unfold-over a period of twenty years - and what implications arise from them. These processes differ in the way that the individual systems involved in embedding interrelate, either independently or relationally, and in the nature of the relationship, which can be either synergistic or predatory. Our analysis provides the groundwork for a Dynamic Model of Embeddedness in Digital Infrastructures that offers a conceptual lens through which to focus on types of processes that the views of institutionalization, path dependence, and assemblage cannot discern. In most organizations, embedding will occur through a variety of logics. Indeed, the study reveals elements of institutionalization triggered by routine work in which particular systems are gradually taken for granted. More significantly, however, the study shows the critical role of interconnection processes of embeddedness enacted by system owners locally embedding their systems over time. This interconnection logic has been largely overlooked in digital infrastructures studies and appears to be relevant in the digital age of modular and layered innovation; hence, it is the focus of our attention.

\section{Methodological Framework}

\subsection{The Recycle Inc. Case Context}

We conducted a longitudinal study to explore how and why systems become embedded in a digital infrastructure (Pettigrew 1990; Yin 2013). The case company, which we disguise as Recycle Inc., is a German waste services enterprise. Founded in 1968, it employed nearly 9,000 people when we entered the field. Its business lines are waste management, recyclables trading, corporate services, steel, and metals recycling.

Recycle Inc. was selected for three reasons, guided by theoretical considerations (Eisenhardt 1989; Flyvbjerg 2006; Siggelkow 2007). First, we assumed that a medium to large company with a multi-corporate structure would be subject to inertia. While smaller companies can focus on one or a 
few products and services, larger companies require many different capabilities, systems, and integrative devices to fulfill their tasks (Lawrence and Lorsch 1967). Second, we aimed for a critical example of a digital infrastructure that was described by key informants as rigid. We chose Recycle Inc.'s business area of waste management because it was facing major transformation difficulties at the time of our entry into the field. Third, the case selection was justified because the area chosen was characterized by a high degree of dispersion with respect to the business units' volume and variety. The business area under study (waste management) consisted of approximately 40 legally-independent subsidiaries ranging from tiny recycling sites to large companies with several hundred employees. Selecting a highlydispersed company, we expected to see high levels of consolidation reinforcing tendencies toward the centralization of solutions, in contrast to settings which have less need to integrate specific local demands. Thus, Recycle Inc. represents a company balancing tension between dynamic flexibility and stability in the evolution of its digital infrastructures.

\subsection{Data Sources}

Following the guidelines for conducting case study research (Yin 2013), we relied on multiple sources of data. One data set was the IT architecture data from Recycle Inc. that provided information about the systems used in 26 of the 40 subsidiaries, and their integration. Hereafter, we call this document $\left(a_{1}\right)$ the IT support matrix. The data was collected in a real requirements engineering project conducted over three months in 2011. Access to the data was granted by the headquarter IT architecture group. To create comparability between the units, the project team predefined a standard waste management process and a reporting template, which was completed together with the company delegates in semi-structured interviews. In this template, each subsidiary specified what systems were used along the predefined process. This was made possible because the business models of most subsidiaries hardly differed, while the execution of individual activities differed widely.

A document on integration relationships supplemented the data. It listed source and target systems as well as some qualifying attributes (e.g., online versus offline integration and transferred data). The data stemmed from modeling efforts by technical experts in the subsidiaries, supported by central IT architects, and were from 2011. 
As a second important source of information and an attempt to understand the processes of embedding and its links to inertial dynamics, we conducted 20 semi-structured interviews with 14 key informants (see Table 2). The first round of 15 interviews took place over a period of four months in 2012. Five additional interviews with key informants were conducted in 2015-2016. These interviews generally lasted 60-90 minutes and were tape-recorded and transcribed. To triangulate the data, we also collected a large amount of additional material (see Table 2). This material comprised the 2011 IT project portfolio planning $\left(a_{2}\right)$, which also included financial information along with three important success stories $\left(a_{3}, a_{4}\right.$, and $\left.a_{5}\right)$ capturing periods from 1995 onward. These gave insights into the company's waste management infrastructure and IT strategy at that time and served as valuable sources for limiting retrospective biases in the study (Street and Ward 2011). Our study covered the period from 1995 to 2015 .

\section{Table 2 Data sources}

\begin{tabular}{|c|c|c|c|}
\hline \multicolumn{4}{|c|}{ Semi-structured interviews $(N=20)$} \\
\hline \# & Key informant & Position and engagement with Recycle Inc. & \# Interviews \\
\hline 1 & IT Demand Manager & IT demand manager for waste management (2010-2013) & 4 \\
\hline 2 & Corporate $\mathrm{CIO}$ & Head of group IT (since 2009) & 1 \\
\hline 3 & Developer 1 & Senior system developer ORDER (since 1974) & 2 \\
\hline 4 & Developer 2 & System developer ORDER (since 1995) & 1 \\
\hline 5 & IT Project Mgr. 1 & Responsible for IT projects in Southern Germany (since 2010) & 1 \\
\hline 6 & IT Project Mgr. 2 & Responsible for IT projects in headquarters (2011-2013) & 1 \\
\hline 7 & Business IT Analyst & Business and IT analyst (2011-2013) & 1 \\
\hline 8 & Business Manager 1 & Commercial director in headquarters (since 2005) & 1 \\
\hline 9 & Business Manager 2 & Commercial assistant in headquarters (since 2009) & 1 \\
\hline 10 & Business Manager 3 & Operation manager in headquarters (since 2007) & 1 \\
\hline 11 & Business Manager 4 & Head of one Eastern German subsidiary (since 2007) & 1 \\
\hline 12 & Controller & Corporate controller in headquarters (2011-2014) & 3 \\
\hline 13 & In-house Consultant & In-house consultant involved in ERP selection (2011-2016) & 1 \\
\hline 14 & Vendor Manager & Key account manager ORDER (since 1995) & 1 \\
\hline
\end{tabular}




\begin{tabular}{|c|c|c|c|}
\hline$\#$ & Observation & Detail & $\begin{array}{l}\# \\
\text { Observations }\end{array}$ \\
\hline $\mathrm{o}_{1}$ & User training & $\begin{array}{l}\text { 1-day training for marketing employees on using ORDER and its } \\
\text { reporting component ( } 8 \text { hours) }\end{array}$ & 1 \\
\hline $\mathrm{O}_{2}$ & IT workshop & $\begin{array}{l}\text { Internal workshop in waste management by IT department to } \\
\text { facilitate transformation ( } 2 \text { hours) }\end{array}$ & 1 \\
\hline \multicolumn{4}{|c|}{ Archival documents $(N=27)$} \\
\hline \# & Type & Detail & \# Documents \\
\hline$a_{1}$ & IT support matrix & $\begin{array}{l}\text { Overview of system/applications, integration relations, and usage } \\
\text { relations (timestamp: 2011, cross-sectional) }\end{array}$ & 1 \\
\hline $\mathrm{a}_{2}$ & IT project portfolio & $\begin{array}{l}\text { IT project planning with financial information } \\
\text { (timestamp: 2011, cross-sectional) }\end{array}$ & 1 \\
\hline$a_{3}$ & Journal publication & $\begin{array}{l}\text { Article on selecting/implementing ORDER as a central system } \\
\text { (timestamp: 1999, period captured: } 1995-1999 \text { ) }\end{array}$ & 1 \\
\hline $\mathrm{a}_{4}$ & Public report & $\begin{array}{l}\text { Report on process of outsourcing the IT department } \\
\text { (timestamp: 2003; period captured: 1998-2003) }\end{array}$ & 1 \\
\hline$a_{5}$ & Success story & $\begin{array}{l}\text { Report on changing the system/network outsourcing vendor } \\
\text { (timestamp: 2006; period captured: } 1997-2005 \text { ) }\end{array}$ & 1 \\
\hline $\mathrm{a}_{6}$ & Other documents & $\begin{array}{l}\text { Company brochures (5), annual reports (10), newspaper articles (6), } \\
\text { industry news (1) }\end{array}$ & 22 \\
\hline
\end{tabular}

\subsection{Data Analysis}

Several procedures were carried out to reconstruct the "inner workings" of the digital infrastructure at specific points in time. Our starting point was a quantitative study from an interconnection viewpoint. Firstly, based on the IT support matrix, all potential systems were listed as of 2011. We adopted a definition of systems consistent with Hanseth and Lyytinen's (2010) notion of "applications" as our analytical focus. The raw data set consisted of 231 systems (excluding duplicates), which described relatively self-contained functional modules.

Secondly, following from this analytical focus, we considered two broad directions for identifying linkages between systems: firstly, there is a more technical interaction through concrete information flows. Secondly, there is a more social perspective to be considered (Pipek and Wulf 2009; Vaast and Walsham 2009). Linkages can be constructed if human actors create, use or manage different systems simultaneously. In this paper, we chose to examine the technical interaction between systems. We used the bidirectional information on interfaces between systems to construct a directed network that serves as one important representation of the digital infrastructure. The arrows of the links were 
modelled along the direction of the data flow as specified in the integration relation (from source to target). For example, an incoming link to an ERP from a price calculation spreadsheet could represent prices being uploaded to the ERP. The link does not show how often this happens or the strength of the connection, only that there is a connection. When integration relations existed in both directions (from system $A$ to system $B$ and from system $B$ to system $A$ ), two links were constructed. In this way, we considered data and functional (inter-)dependencies between systems.

Subsequently, this enabled us to create a network visualization of systems and integration relations. A network visualization lends itself well to the network analysis approach then used in the embeddedness evaluation. It is valuable in providing a clearer picture of the structure and connections within a company (Dreyfus and Iyer 2008; Lagerström et al. 2014; Lipnack and Stamps 1997). We iteratively cleansed the data and constructed an adjacency matrix that formed the backdrop to our approach. As only integrated systems were of interest to us, we removed several unconnected systems $(N=19)$. We proceeded with a subset of 212 systems (nodes) that had 264 documented integration relations (directed links).

To evaluate the embeddedness level, we performed a network analysis on the resulting network. This analysis had two parts. The first referred to the level of the whole network and was intended to examine structural features from which conclusions could be drawn about the network's growth. This included a test for preferential attachment (Barabási 2016; Barabási and Albert 1999). The second part was based on the micro-level of individual systems. One premise of this study is that a system's network position can indicate its degree of embeddedness. To this end, we focused on finding metrics for the influence of systems on others. In network analysis, various centrality measures are used to assess a node's influence (Jackson 2008; Wasserman and Faust 1994). We focused on two-degree and betweenness centrality $\left(C_{D}\right.$ and $\left.C_{B}\right)$. We chose these metrics because they are well-used in network research on micro-level centrality and they allow for distinct interpretations. Regarding degree centrality, Dreyfus and Iyer (2008) note that degree allows the positional value of a system to be described. They note that systems "with high positional value may be important because they influence many other [systems]" (p. 124) and give the example of a search engine, which can, due to its positional value, become a gateway or a bottleneck. However, degree centrality shows only part of the picture, 
since only the immediate vicinity of a node is considered, not the paths and connections within the overall network, which is particularly characteristic of the betweenness centrality (Freeman 1977). By means of the betweenness centrality, brokerage and intermediation processes can be determined, which we also assumed to be central, based, e.g., on Hanseth and Braa's (2001) analysis of the Hydro Bridge infrastructure.

Next, we classified the systems for degree and betweenness values by performing an exploratory cluster analysis (Hair et al. 2014). Following Ketchen and Shook's (1996) suggestion, we combined multiple clustering methods to reduce early misclassification. In a first step, we used an agglomerative hierarchical cluster analysis with Ward's Method on the squared Euclidean distance between each system. Based upon the resulting dendrogram and applying the elbow-criterion, we were able to identify the preferable number of three clusters for the dataset. In a second step, we used a non-hierarchical $k$ means clustering method with the fixed number of three clusters, which we called lightly embedded systems, heavily embedded systems, and bridges.

Based on this analysis, we adopted a qualitative approach (involving observation and interview instruments) that also spanned different levels of analysis. At the level of the digital infrastructure as a whole, we reconstructed a case history for the entire study period (1995-2015) (see also Appendix 1). In this step, the qualitative process data helped verify our assumptions, working backward and forward from the 2011 quantitative network data (Newman and Robey 1992). The qualitative process data enabled us to view the architectural excerpts from an event-based perspective, framed by "temporal bracketing" (Langley 1999), and allowed us to accentuate important infrastructural changes and inflection points.

On the micro-level of individual systems, we used qualitative data to investigate how and why embeddedness occurs, along with the implications of inertia associated with heavily embedded systems. We adopted a thematic analysis approach to make sense of the qualitative data in light of the emergent findings from the quantitative data. To do so, our analysis followed the method of Gioia et al. (2012), whereby it is customary in qualitative research to iteratively analyze the data concurrently with data collection. This led to an initial list of first-order concepts from the data. As we proceeded to iterate between the coding and data collection, our theorizing began to form around two emerging ideas: a) the 
process through which the systems attained their respective level of embeddedness and b) the associated consequence. The qualitative approach was structured to help extract a deeper understanding of how a system's degree of embeddedness is associated with the inertia enveloping it, as well as the underlying explanation for the possible digital infrastructure evolution outcomes.

Combining qualitative and quantitative research approaches is valuable in our study as it allows us to highlight the importance of the social and technical elements in the ongoing process of system embedding and its implications. The insights we derived from this study were possible due to the joint interplay of both approaches (Venkatesh et al. 2013). While the quantitative analysis enabled us to see and classify the structure of the digital infrastructure and to discern individual systems' embeddedness levels through network analysis, the qualitative analysis enabled us to draw insights about the underlying processes of embedding. Lastly, the interaction between both research approaches allowed us to triangulate our findings and provided us with a stronger explanatory foundation for our subsequent theoretical and practical implications.

\section{Results}

\subsection{Growth of the Waste Management Infrastructure}

Episode 1 - Implementing standard systems. In the first episode, between 1995 and 1999, the company moved from isolated silo systems to standardized systems. Following an IT strategy discussion, the company concluded that it needed to "reduce the heterogeneity of different software systems in-use for core processes" (as noted in $a_{4}$ ). Triggered by the availability of standard software for cross-industry administrative processes and the need to consolidate different technology platforms, the company implemented SAP R/3. In particular, the finance module (FIN) became a central system. A complementary industry solution for waste management supporting the company's demands was not available at that time; therefore Recycle Inc.'s leadership team triggered the custom development of an order management system, ORDER, which emerged in collaboration with an external vendor. In most subsidiaries, ORDER replaced LEGA, a legacy software with similar capabilities limited in its technology platform, as well as several standalone solutions. By 1999, ORDER had been rolled out in all but two of the company's then 15 subsidaries in Germany and Eastern Europe. 
Figure 1 illustrates the core process of waste management in three essential steps: (1) distribution, (2) operations that include collecting and disposing of waste, and (3) financial accounting. It also displays the main systems in use at that time to support each of those steps. In network terminology, these are the nodes. In this process, FIN mainly supported invoicing and financial steps, while ORDER mainly covered the distribution and operations steps. Systems that were located in the value chain before the financial system (FIN) were referred to as "upstream systems," indicating the leadership team's high prioritization of financial matters. As shown in the figure, LEGA and several standalone solutions still existed. The standalone solutions were supposed to be abandoned soon after this.

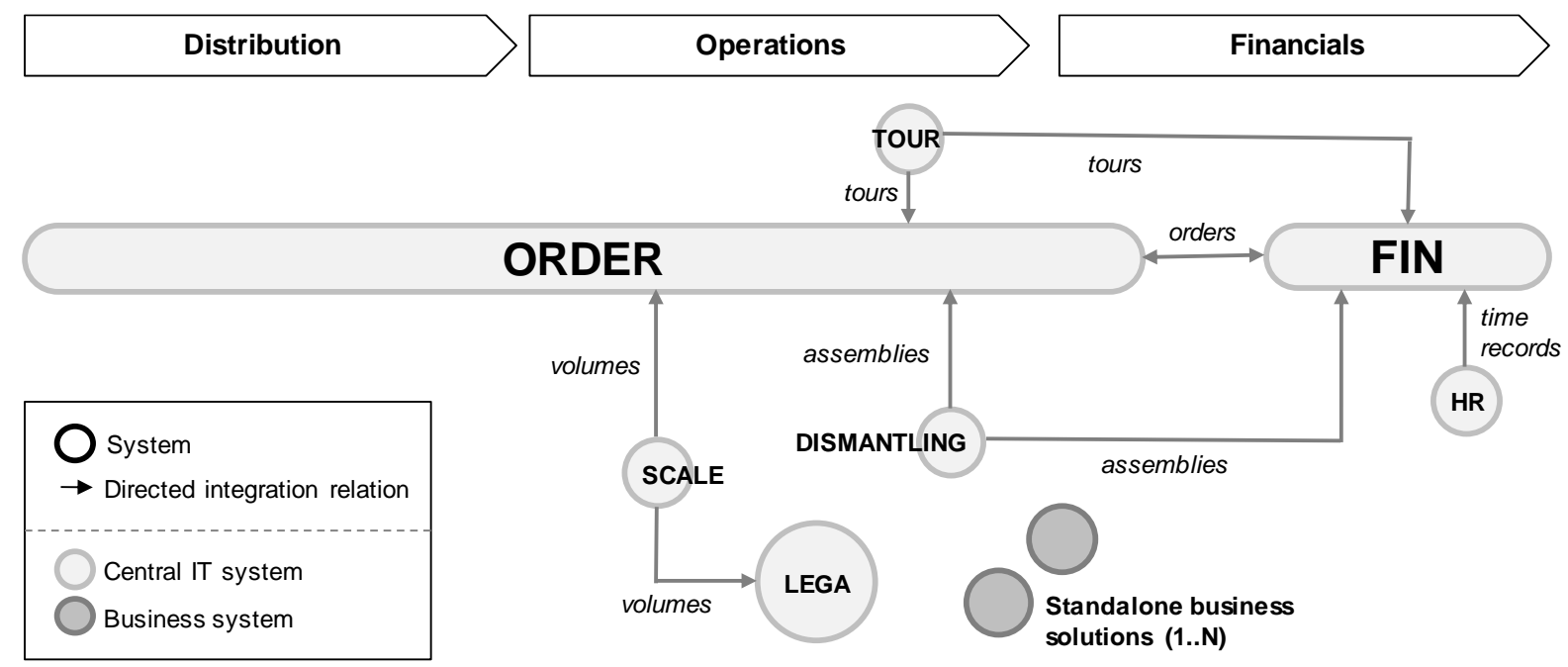

Figure 1 Digital infrastructure for waste management as of 1999

Episode 2: Organic growth. The second period, characterized by poorly controlled growth, took place between 1999 and 2011. At that time, the company outsourced its IT operations and implemented an IT chargeback model, whereby the subsidiaries had to contract the IT unit for their services. Furthermore, central resources and investments were kept to a minimum and IT acted as an autonomous entity that was not subsidized by the group or the subsidiaries. Thus, the IT unit was forced to focus on profitable deals while largely neglecting overarching or innovative projects.

On the system level, the rigid IT investment policy had a profound impact, as it promoted local initiatives and shadow ITs within the subsidiaries. The company's CIO, for instance, mentioned that the subsidiaries compensated and substituted for the centralized systems' lack of innovativeness by investing in their own solutions. One key informant explained: "Often the companies had ideas. Then IT said: the 
price is this-and-that. Then the companies said: that's too much. We will do it on our own" (IT Demand Manager $\left._{1}\right)$.

The data confirms that the trend toward shadow IT was reinforced by three distinct factors. First, as the central systems such as FIN and ORDER aged, their architectural quality suffered and it became harder and more costly to implement new business demands within these systems. Investments for their update or maintenance were only allocated when absolutely necessary. As a consequence, and as suggested by the quote, subsidiaries often turned to local solutions to solve their immediate problems in more cost-effective ways. Second, the company started pursuing a strong external growth path by acquiring several other large waste management companies, creating a need to integrate the system landscape of these companies. For instance, the company bought a competitor in Southern Germany that had installed another standard waste management solution, LOX. The CIO, explaining what he thinks are the reasons for the heterogeneity observed, said:

To summarize - acquisitions, little standardization on the market/IT vendor side, so we turned to proprietary solutions ... we also withheld a lot on another critical issue, the positioning of the IT... which led to a conservative investment policy. But as demands from business units still existed, this produced a situation where a lot of uncontrolled growth occurred. This explains those many small systems, starting with Excel to Access to other special systems, ... which were also necessary to satisfy the[ir] customers. (Corporate $\left.\mathrm{CIO}_{2}\right)$

Episode 3: Attempts to consolidate and stagnation. In 2011, a CIO change triggered a strategic transformation of the IT function. The designated CIO announced measures to renew the fragmented IT infrastructure. To improve the identification and bundling of demands, IT was reorganized from a system-based silo structure to a functional domain structure. Development teams were now grouped according to functional areas (e.g., waste management) instead of systems (e.g., ORDER). The CIO installed new business-IT-linkage roles such as demand managers and business analysts to increase the IT unit's responsiveness to local demands. Furthermore, all IT employees underwent extensive training in business-IT-alignment skills, such as IT project management, and town hall meetings were conducted to increase the subsidiaries' awareness of the new IT capabilities. The IT maxim that emerged was "one unified business solution." To prepare the consolidation mission, a project was begun to identify the requirements in the subsidiaries and to gain transparency about the number and types of systems used in the domain. The architectural data we received originated from this effort. 
Based on this, Figure 2 illustrates the variety of different systems and their integration on the level of the whole network constituting the digital infrastructure (see also Appendix 2). FIN, ORDER, LOX, $L E G A, B O A R D$, a board computer solution, and SIGN, a solution for hazardous waste reporting, which are most important for our theorizing, are highlighted in the figure.

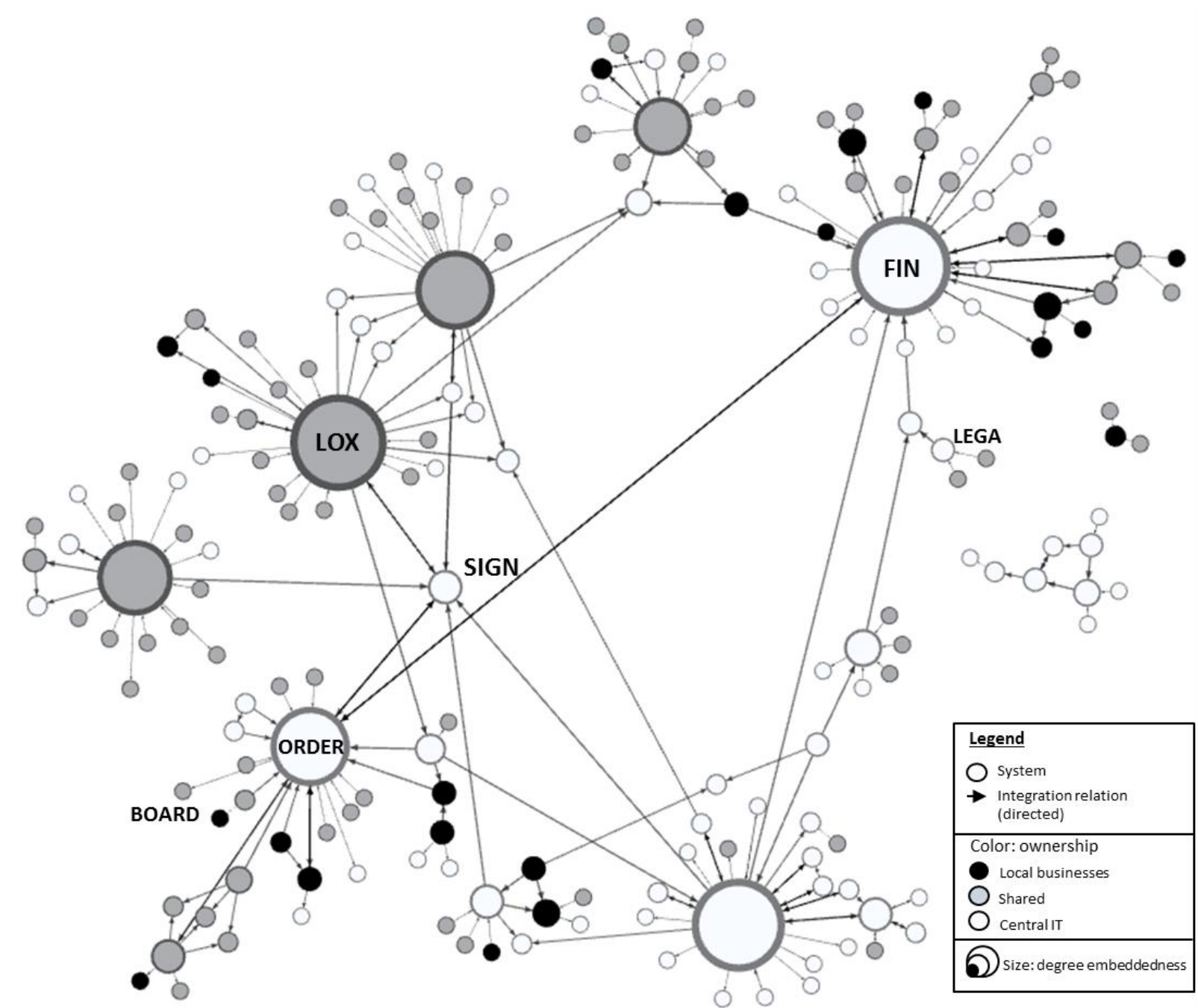

Figure 2

Digital infrastructure for waste management in 2011 after a decade of uncontrolled growth

Consolidation efforts came to a halt in 2013. Once again, the IT was reorganized. Two important decisions were made. First, the consolidation project was halted and resources were withdrawn from the project (at that time, a vendor selection was taking place). Second, the waste management IT was closed down. IT management and operations staff were relocated either to subsidiaries or to headquarters, or they left the company. At the end of our investigation, growth for systems such as ORDER stagnated and the consequences of IT reorganization had not yet become apparent in the digital infrastructure. 


\subsection{Discerning Embeddedness in the Digital Infrastructure}

This section establishes to what extent certain systems are embedded into the digital infrastructure. Table 3 identifies three groups of systems based on exploratory cluster analysis. The first group shows low degree and low betweenness values. We call these lightly embedded systems. The second group comprises systems with high degree and medium or high betweenness values. These are the heavily embedded systems, either hubs or mega-hubs. A third group shows average degree and high betweenness values. We call this last group, consisting of one system, the bridge category. ${ }^{1}$ Table 3 shows examples, which are also highlighted in Figure 2.

Table 3 Quantitative assessment of embeddedness in the digital infrastructure

\begin{tabular}{lllllll}
\hline Category & $\boldsymbol{N}$ & \multicolumn{2}{c}{ Degree $\left(\boldsymbol{C}_{\boldsymbol{D}}\right)$} & \multicolumn{2}{l}{ Betweenness $\left(\boldsymbol{C}_{\boldsymbol{B}}\right)$} & Example $(\boldsymbol{s})$ \\
& & Avg. & Std. dev. & Avg. & Std. dev. & \\
\hline 1: Lightly embedded & 205 & 1.81 & 1.61 & 0.0004 & 0.0022 & LEGA, BOARD \\
2: Heavily embedded & 6 & 24.17 & 4.14 & 0.0337 & 0.0122 & FIN, ORDER, LOX \\
3: Bridge & 1 & 9.00 & 0.00 & 0.0642 & 0.0000 & SIGN \\
\hline Total & 212 & & & & & \\
\hline
\end{tabular}

Lightly embedded systems. Lightly embedded systems are the largest group $(N=205)$. Both $\operatorname{BOARD}\left(C_{D}=1, C_{B}=0.0000\right)$ and LEGA $\left(C_{D}=3, C_{B}=0.0008\right)$ belong to this category and do not figure prominently in degree and betweenness analysis. LEGA was the predecessor to ORDER and can be understood as a peripheral system that has lost importance over time. BOARD receives data for route planning and, like many other lightly embedded systems, it can be understood as a functional complement to a heavily embedded system, in this case ORDER.

Heavily embedded systems. The second group $(N=6)$ consists of heavily embedded systems. FIN $\left(C_{D}=30, C_{B}=0.0326\right)$, a first example, is a long-established SAP system for financials. It is the most heavily embedded system and integrated with LOX and ORDER, as well as many lightly embedded systems. Many of the small nodes in Figure 2 represent extensions to it such as local archives, controlling cockpits, and tour planning solutions, as well as a centralized data warehouse. Numerous transactional systems deliver data to FIN, including ERP/logistics systems such as LOX and ORDER.

LOX $\left(C_{D}=26, C_{B}=0.0470\right)$, a second heavily embedded example, was part of Recycle Inc.'s acquisition strategy in the 2000 s. It connects to many small nodes, mostly lightweight programs in

\footnotetext{
${ }^{1}$ The solution found was robust against a further increase in the number of clusters.
} 
support of activities such as tour planning, weighing, and company and management reporting in the company's southern region. The grey color in Figure 2 indicates responsibility shared between an IT team from the subsidiary and a delegate from the central IT department. As already mentioned, a final example of a heavily embedded system is ORDER, where the "core component of the ORDER" is represented $\left(C_{D}=22, C_{B}=0.0449\right)$. While it has built a significant installed base in many subsidiaries, it has still failed to mobilize new users recently. An IT project manager reflected on LOX compared to ORDER:

LOX has a very high standing in the business units, they value it and are very committed to it so there are lot of "shoots" around it, I would say. Mainly in the area of controlling different sorting and sales processes that are not well covered by the system. For instance, it does not have a customer relationship management module, so a lot of things emerged with Access and Excel. LOX diffused very strongly in the business units and it is rooted in the business units, more than ORDER (IT Project Manager 5). $^{2}$

Bridges: The bridge category is represented by SIGN $\left(C_{D}=9, C_{B}=0.0642\right)$. SIGN scores highest in betweenness, but its degree embeddedness is not very high. The system originally acted as a read-only data aggregator and was procured primarily as a reporting tool without writing or updating functions. Our results, however, suggest that it later began to bridge different systems in different regions. Its central position allows SIGN to become more and more of a gateway. Since it was introduced in 2008, it has grown toward a middleware that exchanges messages between ERPs in different regions. We can derive its significance from its central positioning and speculate about the expected impact of its failure on the entire infrastructure: its position makes it an important boundary spanner, connecting different parts of the network.

\subsection{Growth Patterns of Embeddedness in Digital Infrastructures}

This section presents quantitative evidence for the existence of certain growth patterns within digital infrastructures, which can be described as preferential growth. Our starting point is the work of Barabási and Albert (1999), who conclude that many real-world processes follow a certain logic: new nodes in a growing network are preferentially attached to nodes that are already very important, i.e., they have accumulated many resources and connections in the past. This corresponds to a generative mechanism because it initiates a self-reinforcing dynamic, which further favors people, resources, or components 
that are already preferred. On the other hand, already disadvantaged components receive even less attention, which corresponds to a degenerative mechanism.

This has been expressed formally in the Barabási-Albert model. Consider a network in which new nodes attach themselves to existing ones with a probability proportional to their degree. A new node appears in each period and creates a connection to existing nodes. Over time, the distribution of degrees - a plot of the number of links and their frequency of occurrence-will come to be fat-tailed (Barabási 2016). This means that there are more nodes with a very high degree than is usually expected from a random growth process. The distribution of degrees also shows more nodes with low degree (the spokes), because many nodes will receive little attention (cf. Jackson 2008, p. 131). Substantiating this claim is typically achieved by (a) eyeballing the degree distribution of a network and (b) by performing a regression analysis of the log-logged degree distribution (cf. Jackson 2008).

As Figure 3a shows, in our conceptualization of a digital infrastructure, the horizontal axis of the degree distribution indicates a system's number of connections, while the vertical axis shows the number of systems with this number of connections. Eyeballing the plot is a valuable initial vantage point to argue for the fat-tailed structure typical in preferential attachment (Jackson 2008). Figure 3a indicates an imbalance between the relatively large number of systems with a low and high number of connections and the comparatively small number of systems with medium number of connections.

A further transformation step in the network's degree distribution from a plot of absolute occurrences into a log-logged plot is necessary in order to substantiate the preferential growth proposition. This plot enables the computation of the relative frequencies from the absolute values, which are then brought into a logarithmic form. This is important because previous work indicates that log-logged degree distributions help infer patterns of growth from a network's actual distribution of degree (Jackson 2008). Barabási and Albert's (1999) main observation was that preferential growth would be reflected numerically in a good fit of a straight line in the log-logged degree distribution (Jackson 2008). Thus, we performed an additional regression analysis to establish whether the loglogged degree distribution fits with a linear model. In Figure 3b, the straight line in the log-log plot provides evidence of a preferential attachment process. The regression points to a robust linear 
relationship $\left(R^{2}=0.89, p \leq 0.001\right)$ between the logged degree and the logged relative frequency of occurrences.

Viewed together, figures $3 \mathrm{a}$ and $\mathrm{b}$ suggest that the digital infrastructure can be described as a scale-free network, the growth of which is subject to preferential attachment. This means that a few important (heavily embedded) systems — such as FIN and ORDER — have been surrounded increasingly by (light) spokes such as BOARD, while less important systems such as LEGA have faded into insignificance.
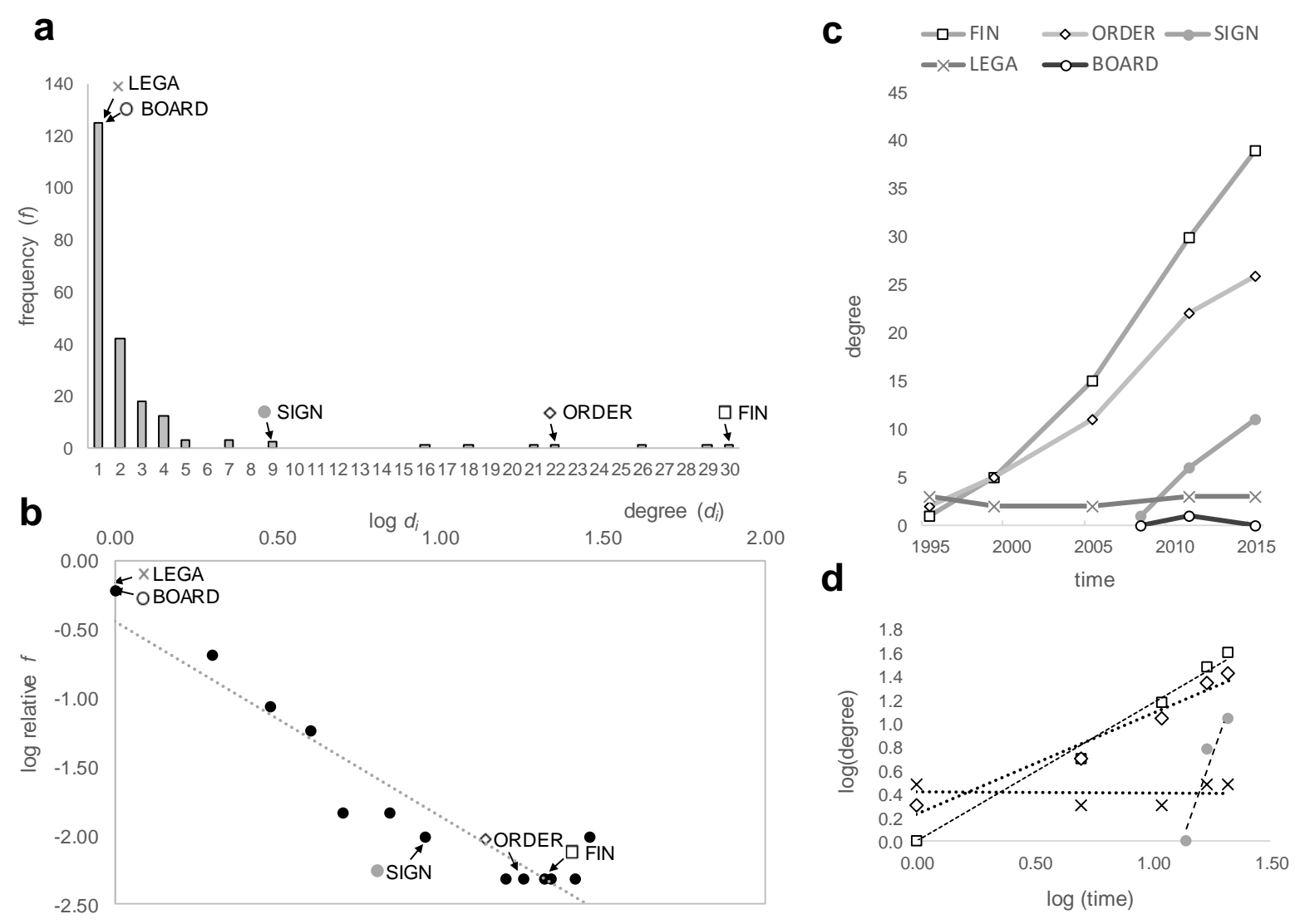

Figure 3 Degree distribution of embeddedness levels: (a) absolute (b) log-logged, (c) sample trajectories, and (d) their log-logged degrees

If the real dynamics of growth are examined (figures $3 \mathrm{c}$ and $\mathrm{d}$ ), it becomes clear that although the Barabási-Albert Model explains the fundamental underlying mechanism, there are noticeable differences between systems. The log-log representation of growth shows that FIN, for example, has grown more strongly than ORDER. In addition, SIGN has grown rapidly in a very short period of time. On the other hand, growth of LEGA stagnated and BOARD disappeared completely after a short time. Thus, our understanding of the process of embedding over time would benefit from richer (qualitative) 
data. By drawing on our qualitative data as well, we were able to go beyond the quantitative observations to uncover some underlying processes of embeddedness in digital infrastructures. Our findings suggest that the growth process requires the differentiation of at least three micro-level processes - parallel, competitive, and spanning (see Table 4). We will now illustrate these with examples from our empirical data.

\subsection{The Processes of Embeddedness in Digital Infrastructures}

\subsubsection{The Parallel Process}

Our data confirm that some systems have increased in size and embeddedness gradually and relatively independently. We refer to this process as a parallel process, which denotes a sequence of events whereby a heavily embedded system emerges and grows independently of others. As Figure 4 shows, systems $\mathrm{S}_{1}$ and $\mathrm{S}_{2}$ grow independently over time. In this situation, each system's loss of connections or gain of extra connections occurs regardless of the presence of the other system.

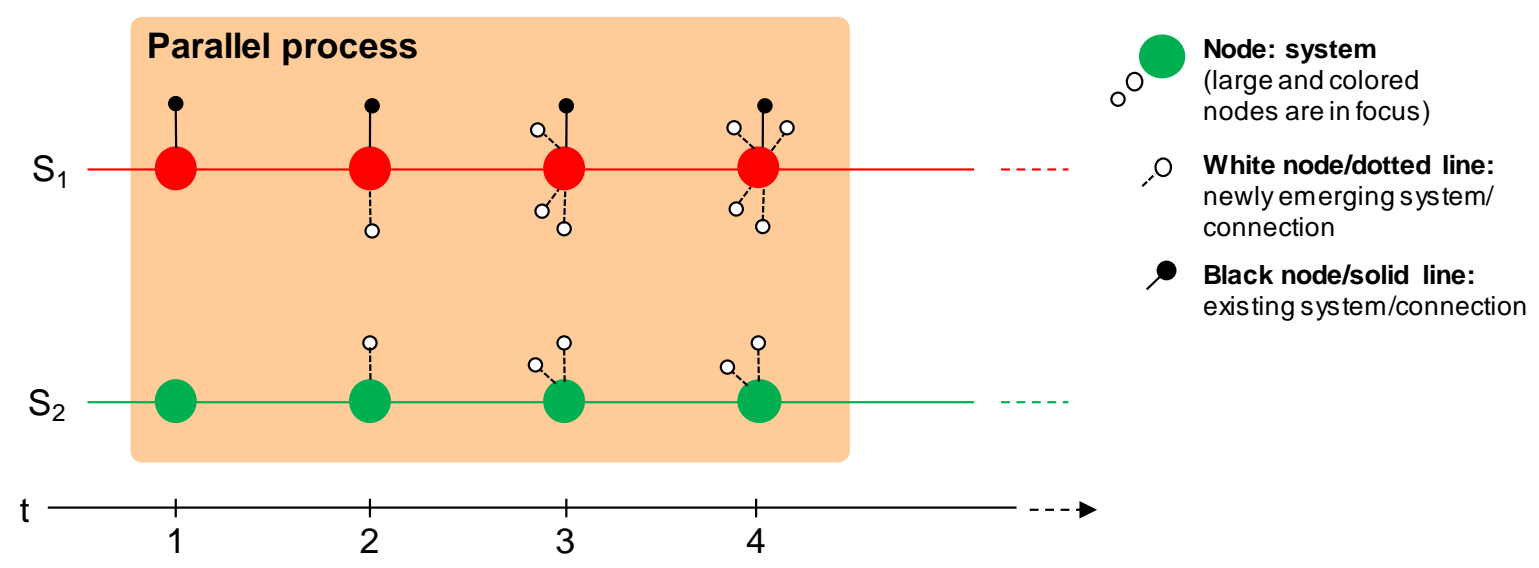

Figure 4 Parallel process of embeddedness

At the field site, parallelity evolved in the context of a growing corporation. New subsidiaries/companies had been added to the group continuously, in southern and eastern Europe, for instance. External acquisitions played a key role in this context, although integration into and with existing systems was not a priority. As the CIO stated, "it is not the case that every waste operations company has different business models and the situation is therefore highly heterogeneous, but...it is based on many acquisitions." 
ORDER and related examples demonstrate this well. Firstly, since scale systems are essential for the workflow and complement the order management, and since individual preferences existed at the individual waste yards, various scale systems were connected to ORDER, some as online (real-time) and others as offline solutions. While most of the companies were working with proprietary scales with their own interfaces, ORDER was connected to an external partner solution, which had to be integrated in turn with the companies' existing infrastructure. This posed major challenges for harmonization and led to many different weighing systems being connected to ORDER.

Another example is tour planning and on-board computer solutions. Because they played an important role in handling the process and because the standard functionality was insufficient, new solutions were repeatedly introduced and linked to ORDER. A particularly illustrative example occurred in a company in which an external partner was assigned to implement a board computer system (BOARD). This system was introduced independently of the central IT, and interfaces to ORDER were created later on. However, the system was not powerful enough, and additional problems with the supplier occurred. Similarly, there were a number of other initiatives, their goal being to complement the much-needed functionality and thus increase the value of ORDER. The corresponding processes can be described as "parallel," since similar solutions have been identified and implemented for other heavy systems, independent of ORDER. For example, companies in the South had decided much earlier to introduce on-board computers on a wide-scale basis.

One boundary condition of the process concerned the orientation of IT. While the management was interested in increasing sales and profits, IT standardization was not in the foreground. As the IT Demand Manager 1 remarked:

"So, a consistent topic for the whole of Recycle Inc. and a crux for Recycle Inc. and its IT is letting a lot of things go. Well, Recycle Inc. IT didn't take care of some things at all. Whether it was from not wanting to or not being able to, I don't know."

This is why new projects often introduced new systems and there was a lack of interest in merging disparate (lightly embedded) systems into the heavy systems. While yearly investments of about one million euros contributed to adapting ORDER to changing business circumstances, embedding the system mostly meant tinkering with and expanding it via add-ons and extensions. Overall, both ORDER 
and the systems connected to it illustrate a parallel dynamic well, when we consider the largely independent growth of embeddedness compared to LOX or other systems.

\subsubsection{The Competitive Process}

Our data analysis reveals a second process that is characterized by alternating dynamics between different systems. In extreme cases, this becomes a "zero-sum" dynamic in the sense that the gain of one system represents the loss of another. We refer to this process as a competitive process, which denotes a process in which one system loses connections to another system. Figure 5 shows how two systems, $\mathrm{S}_{3}$ and $\mathrm{S}_{4}$, are in a competitive flux for connections.

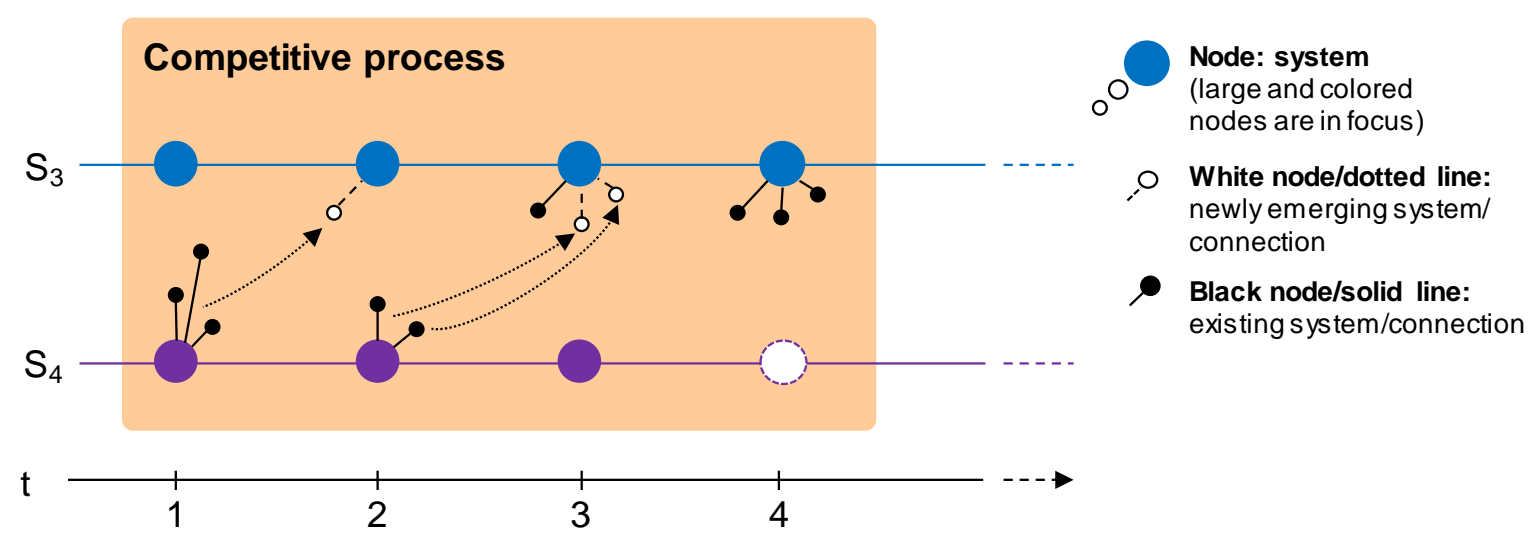

Figure 5 Competitive process of embeddedness

This process is relational and can be observed in contexts in which systems compete for resources. This occurred especially when heavy systems had strong functional overlaps and the user base suggested a decision for a certain system. LEGA and ORDER are examples of this. LEGA was developed by a software supplier working with Recycle Inc., from 1980 onward. In the early 1990s, Recycle Inc., used LEGA in headquarters and in 10 Eastern German subsidiaries. However, the technology platform was limited, and all subsidiaries operated their own servers and client terminals. In 1994, an IT strategy discussion took place and the result was LEGA's discontinuation, so migrating all subsidiaries to ORDER. The resulting ORDER system held the promise of a centralized database system, as it contained standardized master data management and multi-client capability. Moreover, it was aligned to Recycle Inc.'s strategy of migrating to the Windows platform. 
The rollout process of ORDER began in 1996 and was completed in 1999. The benefits of focusing on only one of the two systems were easier administration and operations processes. The growth of ORDER and its increasing embeddedness coincided with the decline in the embeddedness of LEGA. A plausible explanation is given by the evolution of ORDER: it subsumed the functions of LEGA and gradually pulled existing and potential connecting systems away from LEGA. In the initial phase especially, the individual value of a system played an important role, so that even initially lightly embedded systems (ORDER) were able in principle to overtake more heavily embedded systems (LEGA). This illustrates both systems' opposing directions of growth from the inception of ORDER. However, LEGA did not disappear completely but was further maintained and used in a lightweight fashion by one subsidiary. Such step-wise replacement, with leftovers, can often be observed. Another example of this in Table 4 is a system for municipal waste disposal later replaced by ORDER.

The competitive dynamic observed was primarily a result of the pressure to eliminate existing inefficiencies. However, it is clear from the examples that this was only the case when it was absolutely necessary (e.g., because the technology was no longer available or developers had left the company). On the other hand, IT only made a limited contribution to getting this process going.

\subsubsection{The Spanning Process}

Besides these two processes, we observed a third one. We call this a spanning process, which denotes a process by which connections are established between different heavy systems. As Figure 6 shows, systems $S_{1}$ and $S_{2}$ are connected via the addition of a new system- $-S_{5}$, bridging the two parallel branches in the infrastructure. Similarly, two existing systems, $S_{2}$ and $S_{3}$, are connected to each other, thereby increasing both systems' level of embeddedness. This spanning process can be considered a bridging process between systems across the digital infrastructures.

Our empirical material for this process shows that bridge systems such as SIGN in this case played an important role. The process occurred in the context of the IT leadership team's shifting focus on overarching issues and integration, when a greater awareness of the different data and systems led to measures to integrate and standardize information. The best example of this is SIGN, which started as a read-only data aggregator in the context of hazardous waste. Over time, SIGN developed into a form of middleware to organize the exchange of data between the company's various order processing systems, 
thus creating bridges between previously separate system worlds. In one sense, the SAP system (FIN) and the standardization imposed by it also emerged as a bridge technology. In the course of the process, upstream systems were connected to it, which gradually contributed to the consolidation of the digital infrastructure. As one IT project manager stated: "Data need to be transferred to financial accounting according to certain criteria, indeed everything had to fit reciprocally. Really, nothing exists outside of these ranges because you won't get the data into the [FIN] system otherwise" (IT Project Manager ${ }_{6}$ ).

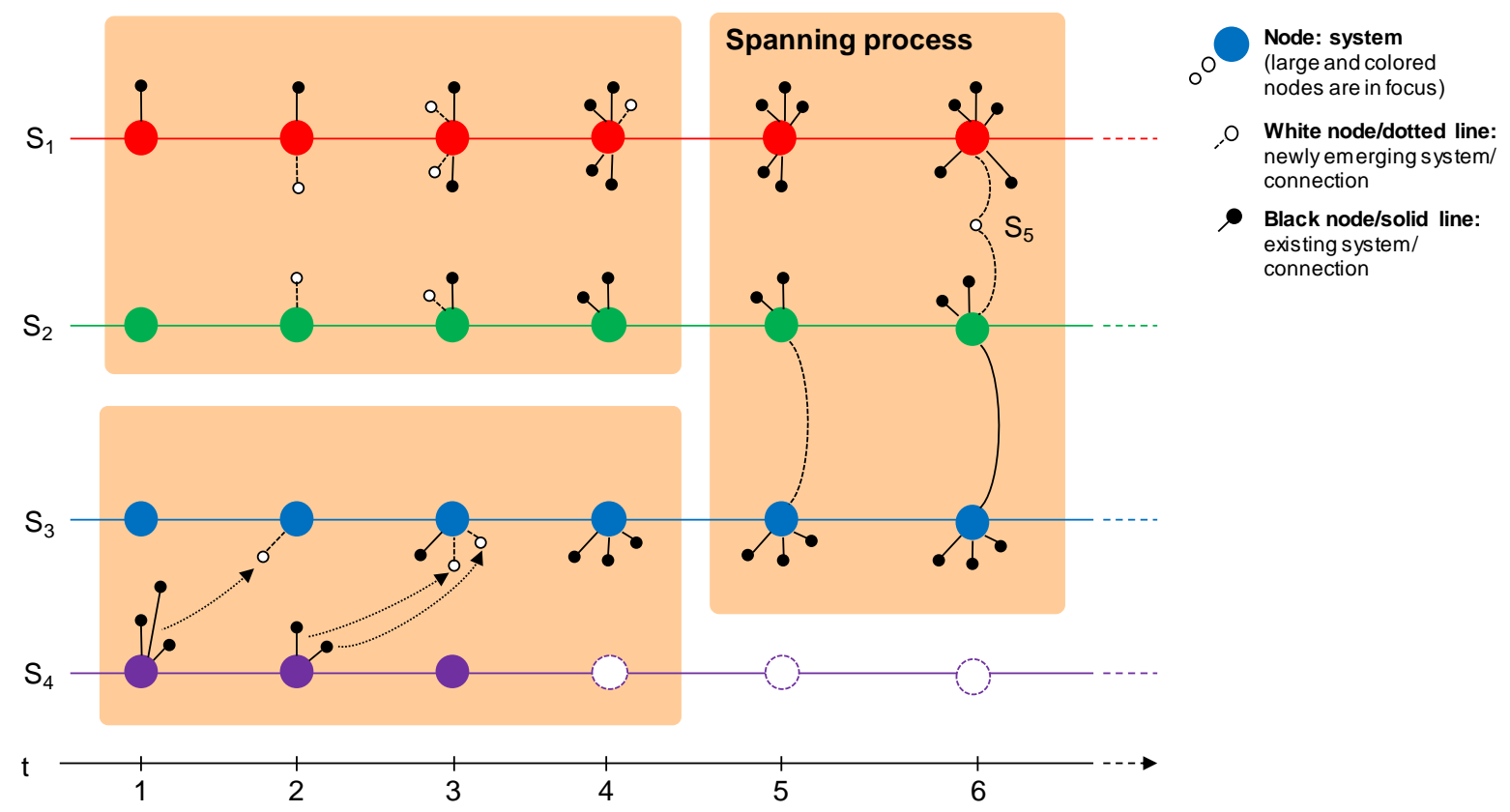

Figure 6 Spanning process of embeddedness

However, the overall extent of integration remained limited. Various data formats and standards, e.g., for the classification and description of materials, customers, and orders in different systems, prevented further integration beyond financial and legal-regulatory purposes. Parallel and competitive processes dominated, while spanning processes developed only to a limited extent.

Table $4 \quad$ Processes of embeddedness in digital infrastructures

\begin{tabular}{|l|l|l|}
\hline \multicolumn{2}{|l|}{ Theme 1: Creating connections to heavy systems independently (parallel processes) } \\
\hline Code & Explanation & Exemplary quote \\
\hline $\begin{array}{l}\text { Independent } \\
\text { weighing }\end{array}$ & $\begin{array}{l}\text { In the case of the weighing system, the starting point is } \\
\text { systems- }\end{array}$ & "The essential interfaces were \\
online and & scale, the weighing software and the commercial & ORDER did not really work \\
offline & systems. Weighing is very complex, and it needs to be & without scales. Because \\
& standardized to avoid disruptions. There were grown & ultimately the whole process \\
& structures on the respective sites, and it was hard for & starts at the scales. How much of \\
& central IT to create aligned structures on the IT side & what quantity at what price do we \\
& (concerning ORDER). With the help of the weighing & actually have? And that price is \\
& system, an automation gap could be closed, and the value & also fluctuating....[The existing \\
\hline
\end{tabular}




\begin{tabular}{|c|c|c|}
\hline & $\begin{array}{l}\text { of ORDER could be increased. ORDER, however, } \\
\text { developed its weighing integration independently from } \\
\text { LOX or other systems. }\end{array}$ & $\begin{array}{l}\text { vendor] had the advantage that } \\
\text { we already had interfaces. And } \\
\text { we understood that." (In-house } \\
\text { Consultant } 13 \text { ). }\end{array}$ \\
\hline $\begin{array}{l}\text { Integrating } \\
\text { tour planning } \\
\text { and board } \\
\text { computers- } \\
\text { mostly } \\
\text { external }\end{array}$ & $\begin{array}{l}\text { There had been a long-term need for board computer } \\
\text { integration, and a system was initially designed and } \\
\text { introduced by one subsidiary, which was independent of } \\
\text { the infrastructure. In the course of time, however, there } \\
\text { was a need to access existing data from ORDER. }\end{array}$ & $\begin{array}{l}\text { "So the need for such a solution } \\
\text { [on-board computers] existed in } \\
\text { the company for a long time ... } \\
\text { and there have been different } \\
\text { ideas and approaches" (IT } \\
\text { Demand Manager }{ }_{1} \text { ). }\end{array}$ \\
\hline \multicolumn{3}{|c|}{ Theme 2: Swapping connections in a zero-sum fashion (competitive processes) } \\
\hline $\begin{array}{l}\text { LEGA loses its } \\
\text { connections to } \\
\text { ORDER }\end{array}$ & $\begin{array}{l}\text { LEGA, which lost importance over time compared to } \\
\text { ORDER, exemplifies a competitive dynamic whereby the } \\
\text { gain of one system represents the loss of another. Early } \\
\text { on, an IT strategy discussion took place, deciding to } \\
\text { discontinue LEGA and to migrate all (but two) } \\
\text { subsidiaries to ORDER. }\end{array}$ & $\begin{array}{l}\text { "For us, of course, it made it } \\
\text { easier to administer the new } \\
\text { system [ORDER]. It also became } \\
\text { easier for the developers to roll } \\
\text { out changes" (Developer } 4 \text { ). }\end{array}$ \\
\hline $\begin{array}{l}\text { Municipality } \\
\text { system loses } \\
\text { its connections } \\
\text { to ORDER }\end{array}$ & $\begin{array}{l}\text { Despite Recycle Inc.'s focus on private waste disposal, in } \\
\text { one case the company cooperated with a municipality. } \\
\text { This created special requirements that could not be met } \\
\text { by standard systems, which is why the subsidiary } \\
\text { developed its own Access-based system. However, the } \\
\text { parallel development of several systems created more and } \\
\text { more problems over time. One of the core developers was } \\
\text { to retire, and a replacement could not be found. } \\
\text { Therefore, the system was replaced, and the functionality } \\
\text { was integrated into ORDER, including connections to the } \\
\text { municipality. }\end{array}$ & $\begin{array}{l}\text { "Two years ago, the entire } \\
\text { ACCESS solution, everything to } \\
\text { do with logistics, was integrated } \\
\text { into ORDER, which was } \\
\text { reprogrammed accordingly. And } \\
\text { adapted. And new functions were } \\
\text { created" (Business Manager }{ }_{4} \text { ). }\end{array}$ \\
\hline \multicolumn{3}{|c|}{ Theme 3: Connecting heavily embedded systems (spanning processes) } \\
\hline $\begin{array}{l}\text { SIGN connects } \\
\text { ORDER to } \\
\text { other heavy } \\
\text { systems and } \\
\text { beyond }\end{array}$ & $\begin{array}{l}\text { In } 2008 \text {, a portal at the federal authority was introduced, } \\
\text { in which all processes involving hazardous substances } \\
\text { had to be stored. This meant that waste producers had to } \\
\text { send data via providers to this portal. This implied great } \\
\text { technical and processual change in the whole waste } \\
\text { industry and required the introduction of electronic } \\
\text { verification procedures. While SIGN was primarily } \\
\text { procured as a reporting tool for hazardous waste without } \\
\text { writing or updating functions, it became a bridge between } \\
\text { different parts of the digital infrastructure and beyond. }\end{array}$ & $\begin{array}{l}\text { "And build interfaces, even in the } \\
\text { direction of this centralized } \\
\text { portal [via SIGN].... This means } \\
\text { that we offer, also for our } \\
\text { subsidiaries, a signature pad and } \\
\text { a portal [SIGN] and stuff like } \\
\text { that" (Business IT Analyst } 7 \text { ). }\end{array}$ \\
\hline $\begin{array}{l}\text { A bridge } \\
\text { between } \\
\text { ORDER and } \\
\text { FIN }\end{array}$ & $\begin{array}{l}\text { Since the SAP [FIN] system was a central tool for group } \\
\text { management, the interfaces were defined by it. This } \\
\text { resulted in an asymmetrical distribution of roles in which } \\
\text { the source systems had to supply data to SAP and comply } \\
\text { with its logic. Subsidiaries had to somehow create the } \\
\text { interfaces, e.g., from ORDER, to get the information in } \\
\text { the SAP system. }\end{array}$ & $\begin{array}{l}\text { "The subsidiaries had to maintain } \\
\text { and supervise our templates } \\
\text { according to the specifications of } \\
\text { the holding... we have uploaded } \\
\text { this information via interfaces to } \\
\text { SAP" (Controller }{ }_{12} \text { ). }\end{array}$ \\
\hline
\end{tabular}

Table 4 illustrates the three processes and gives examples. Firstly, we observed a boost to the heavy systems from having light systems connected to them, independent of other heavy systems (theme 1 : parallel processes). Secondly, we found a relational process of different heavy systems competing for resources and related alternating dynamics (theme 2: competitive processes). Thirdly, the table further demonstrates how heavy systems connect to other heavily embedded systems, e.g., via SIGN, to 
exchange data and ensure an integrated work process across system boundaries (theme 3: spanning processes).

\section{Discussion}

Considerable progress has been made in understanding the nature and evolution of digital infrastructures (Constantinides et al. 2018; Henfridsson and Bygstad 2013; Tilson et al. 2010). Because a digital infrastructure emerges from multiple, heterogeneous systems working and evolving in concert, it is pivotal to understand how systems are embedded in digital infrastructures and by what processes this happens. Our interconnection view on embeddedness in digital infrastructures is sensitive to the "generative mechanisms" (Henfridsson and Bygstad 2013) governing digital infrastructures' evolution. At the same time, it is more specific with respect to the system-level processes driving embeddedness. In particular, our quantitative network analysis offers evidence that a system's position in a system-ofsystems network indicates its future dynamics.

On the other hand, our qualitative study reveals that there are other factors at play, such as the individual value of a system, which explain why some systems grow stronger than others. The combination of the qualitative and quantitative approaches then identifies the three processes that explain how different local and global demands lead to increases, stabilization, or even losses in embeddedness. In this way, evolutionary pathways of systems emerge, which can help us understand how systems grow "in parallel" or "in relation" and so form what becomes a digital infrastructure. In essence, our discussion of the evolution of a digital infrastructure rests on three key findings.

a) There are three underlying sets of processes of system embeddedness in a digital infrastructure-parallel, competitive, and spanning.

b) The processes are triggered by specific local and global demands and are situated in, and bound by the setting in which they arise.

c) The consolidation or fragmentation of these processes shapes the emergence of a digital infrastructure. 


\subsection{Influence of System Embeddedness Processes on a Digital Infrastructure}

Our study has laid out three processes by which systems become embedded in a digital infrastructure. The first is a parallel process, whereby systems become embedded independently of each other. The second is a competitive process, whereby systems compete for resources and attention and one system usually thrives while the other system loses importance. This process is "relational" in the sense that it creates a mutual dependence between systems, which can lead to the eventual replacement or reduced presence of one system by another. The third is a spanning process characterizing a situation of boundary-spanning between distinct parts of a digital infrastructure. This process is also "relational," in that it creates interdependencies among systems. It causes larger structural patterns to emerge, which may be considered a consolidation of mini-digital infrastructures into an holistic view of an organization's digital infrastructure. Figure 7 shows these processes as well as their triggers and the ensuing digital infrastructure outcome, in what we call the Dynamic Model of Embeddedness in Digital Infrastructures.

\section{Example triggers Embeddedness process Emergent digital infrastructure}

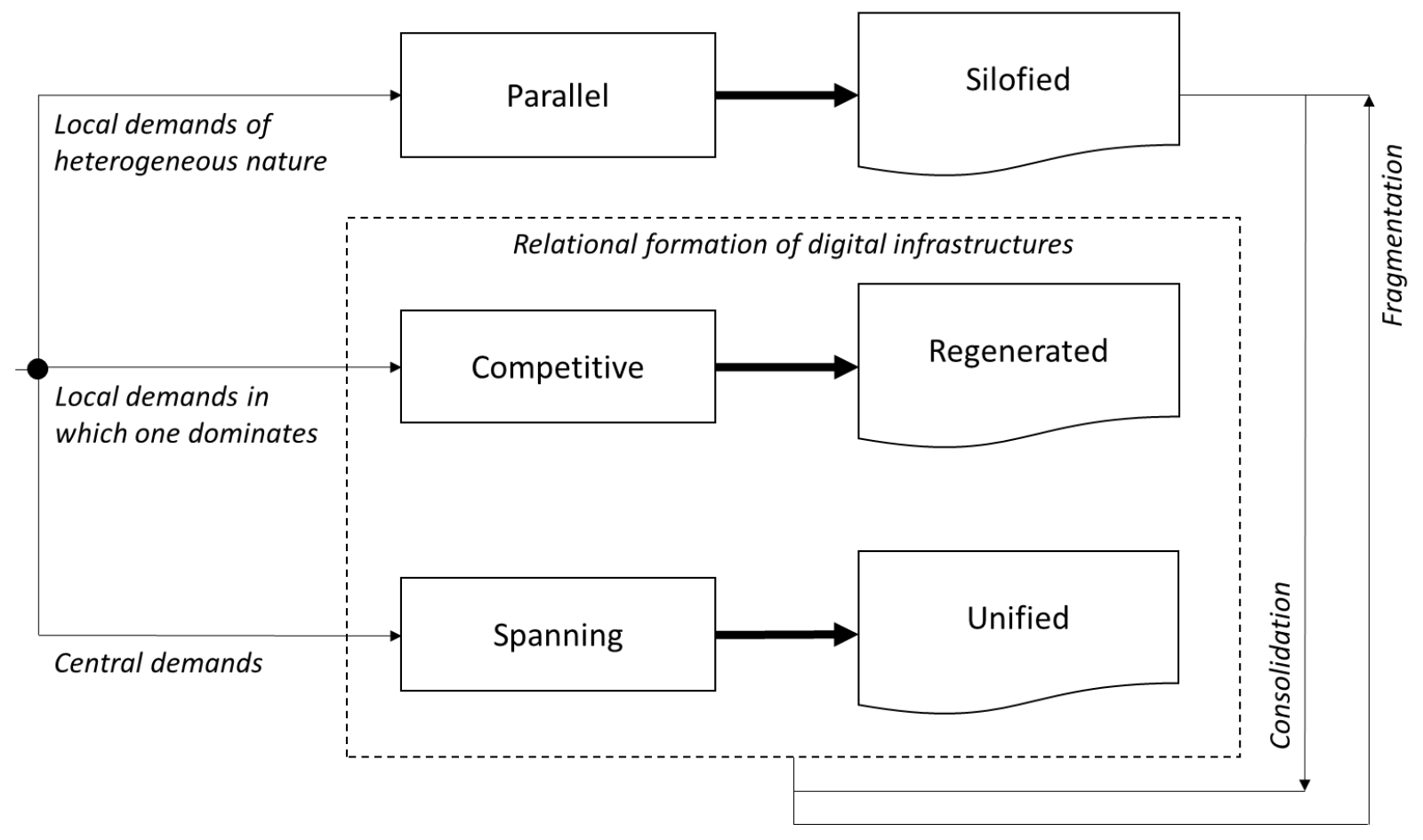

Figure 7 Dynamic Model of Embeddedness in Digital Infrastructures

The model holds that depending on the type of demands and the context in which they arise, distinct processes will occur, which lead to distinct digital infrastructure outcomes. Under a situation of 
heterogeneous local demands and in which there is a need for a specific local solution (Gregory et al. 2018), a parallel process will likely take place. This leads to a local increase in embeddedness for the system subject to such processes. When local demands are competing for attention and resources and one dominates the other, a competitive process will occur and eventually favor one system over another. Lastly, when global or centralized demands occur (Tanriverdi 2006) they can trigger a spanning process that will lead to a dynamic in which multiple areas or clusters of the digital infrastructure become connected. It is worth noting that these processes sometimes also trigger each other and are interdependent. Most importantly, parallel processes will lead over time to a "silofied" or fragmented view (Gal et al. 2008) of the digital infrastructure. That is, a constellation of systems grows out of a particular area or domain. In some cases, these growths may mean strong constellations or stagnated islands of systems. From an organizational perspective, this may be desired if the aim is to develop independent units. However, in a digital era in which value can be amplified by leveraging the combination of data from a variety of sources (Henfridsson and Bygstad 2013; Tilson et al. 2010), this fragmented view may not be desirable. Then, spanning processes will be needed to consolidate the system within the overarching digital infrastructure. This is what we observed in the case of ORDER, when the growth chart indicated stagnation toward the end of our investigation. Only when a larger structure or infrastructure is formed, which is what happened when SIGN was introduced, could there be further opportunities for growth.

Furthermore, the model represents a dynamic rather than a static view of digital infrastructure evolution, incorporating a perspective in which movement between the three infrastructural states is possible. We capture these dynamics as the consolidation and fragmentation of a digital infrastructure. Consolidation implies that different parts of the infrastructure are being brought together. For example, in the case of competitive processes, this may be triggered by the introduction of a new system into the infrastructure, which then gradually replaces a prior system. Or it could also be that two communities of practice have seemingly related processes but different systems for fulfilling those demands (Levina and Vaast 2006). In this case, the process of consolidation implies that one of the two systems used in the separate communities would gradually subsume part or all of the other system's responsibilities. Furthermore, when the spanning process is in place, a new system may integrate disparate systems and 
communities (see Figure 6). Fragmentation, on the other hand, captures the dynamic when a digital infrastructure is split apart, resulting in multiple islands of digital infrastructures. In a fragmented digital infrastructure, the view of the emergent infrastructure depends on the level of abstraction. For example, from the corporate headquarters' view, each digital infrastructure fragment/island forms part of the whole corporate digital infrastructure; at the level of the corporate branch, however, the fragment that defines their community of practice captures their local view of a digital infrastructure. We elaborate further on the dynamic model of embeddedness in digital infrastructures and the underlying processes and premises in subsequent sections.

\subsubsection{Silofied Digital Infrastructure}

This is a digital infrastructure that emerges via the parallel process of embedding, in which the overall digital infrastructure comprises two or more independent "islands." Each island in this view represents a digital infrastructure within the context of a particular community of practice or user base (Levina and Vaast 2006). This silo view of digital infrastructure (Gal et al. 2008) is deepened when a parallel embedding process is in action. Parallel processes leading to a silofied digital infrastructure can be triggered by heterogeneous local demands from users (e.g., van Donselaar et al. 2010; Gregory et al. 2015, 2018). For example, at the recycling company's subsidiaries, some users perceived the need for board computers. Others needed a specific computer-based scale to support their workflows. Given resource shortcomings and the unwillingness of the IT department, they turned to local solutions to satisfy their needs. While these needs may arise equally in different subsidiaries of a large company, the parallel process occurs when demands are not "universalized" (Rolland and Monteiro 2002). They remain specific to the local context. Practices such as IT demand management, project management, and portfolio management represent a management perspective aimed at promoting the use of crossfunctional synergies and avoiding excessively localized requirements that generate high costs for unstandardized and redundant solutions (e.g., Blichfeldt and Eskerod 2008; Tanriverdi 2006).

The logic of the parallel process is that a system develops independently. Those who make changes locally may consider other systems "discontinuous" (Star and Ruhleder 1996), or they may simply not know about them, reinforcing the parallel boundaries within a digital infrastructure. Political and economic factors may also play a role (King 1983). This includes the time and effort for negotiations 
with the IT department over making adjustments. Sometimes the IT department may be dominated by a particular department or manager, leading to the devaluation of other departments' requirements. This happened at the recycling company, where subsidiaries remote from the head office had great difficulties getting their demands realized and were therefore forced to implement their own solutions.

In the recycling company, some systems — such as ORDER and LOX-occupied parallel universes within the digital infrastructure. These systems grew out of their own contexts and communities, remaining largely discontinuous. Support structures differed. In consequence, while these systems overlapped functionally, they grew as independent "islands." As the literature notes, having multiple systems running in parallel opens up challenges of silos within the infrastructure (Gal et al. 2008). This could lead to a lack of integration that would hinder the effective flow of business processes, particularly when the same data have to be entered multiple times into different systems (MacArthur et al. 1994). We argue that an understanding of this embeddedness process can help companies mindfully watch a system's trajectory of embeddedness and a tendency to "silofy" the infrastructure. It can also help prevent shadow IT from growing unintentionally beyond the control of central IT departments (Behrens 2009; Furstenau et al. 2017; Winkler et al. 2014).

\subsubsection{Regenerated Digital Infrastructure}

This is a digital infrastructure that emerges due to the competitive dynamic of systems replacing each other, either fully or partly. The emergent digital infrastructure in this view is analogous to leaves on a plant changing color because of the changing seasons or the shedding of leaves to create room for a budding leaf. In this sense, systems are replaced either partially or totally by either new systems or prior existing systems within the infrastructure. This process sheds redundancies within a digital infrastructure. For example, when ORDER replaced a municipal waste solution in one subsidiary, it also took over the information flows to the municipality. The process does not always have to run simultaneously, but it can also support a portfolio view, with time overlaps in the replacement of individual systems by others (Swanson and Dans 2005). In addition, different approaches may describe the replacement, for example, "big bang” (e.g., Bisbal et al. 1999, Hanseth 2010). It does not always lead to a full replacement of one solution by another; an overtaken system may remain partially operational, as when data are needed from or stored in the system. 
The logic of the competitive process is relational, in that connections held by one system are transferred to another. We observed that the competitive process can be triggered by competing local demands, whereby one dominates the other. As Pollock et al. (2007) note in the context of enterprise software, pressures for consistency will often harmonize local demands and make the organization carve out the commonalities in the local. The condition leading to the competitive process may vary. It may be the liminality of a technical platform, an organizational restructuration, a compliance program, or a large-scale infrastructural transformation (e.g., Gregory et al. 2015). In each case, these situations may condition a need to rethink local solutions, trying to replace one, typically local, with another possibly more global one.

The competitive process implies a choice between two competing options (cf. Farjoun 2010; Wareham et al. 2014) and plays out as redistribution. In this process, a more highly embedded (legacy) system has an advantage, but can be overtaken if the benefits of the other system clearly outweighs it. It also indicates "degenerative mechanisms" (Henfridsson and Bygstad 2013)—not so commonly discussed in the literature on digital infrastructures - in which a system loses importance or value over time due to a lack of relevance for users or connection possibilities. In a way, competitive processes are key to the renewal of digital infrastructure. Old systems are replaced by new ones, resulting in the emergence of a regenerated digital infrastructure. Thus, embeddedness due to the competitive process is not necessarily negative but rather a key mechanism of change in digital infrastructures.

\subsubsection{Unified Digital Infrastructure}

This is a digital infrastructure that emerges from the bridging of different parts of the infrastructure to form a connected and holistic view. In contrast to the silofied digital infrastructure, the unified digital infrastructure brings together independent silos to form a consolidated view. This consolidated view reflects a synergistic status, whereby the connected parts gain more capabilities than they could as separate constellations. Taking our earlier mold analogy, the resulting mold when two spots merge indicates an expansion of their prior status. This view of a digital infrastructure results from an underlying spanning process of system embeddedness.

The logic of the spanning process may include the implementation of middleware, portals, or other integrative technologies (Bidan et al. 2012; Ellingsen and Monteiro 2003; Ellingsen and Røed 
2010). These technologies help to connect formerly "discontinuous" terminologies, processes, and contexts (Star and Ruhleder 1996). The spanning process can be triggered by global or central organizational demands. For example, management wants to get an overview or local stakeholders recognize the need to exchange data. Such situations subsequently lead to the need for these islands to be connected and a willingness for the governing community of the silos to (partially) retract their autonomy.

The outcome of the spanning process is a unified digital infrastructure, whose span is expanded from the perspective of the prior silo infrastructures. The bridge between the infrastructures may be a new system that automatically becomes highly embedded in the digital infrastructure or a connection between existing systems, which increase in value due to their newly acquired boundary-spanning attribute. Drawing from the literature on boundary spanners (Andersson et al. 2008) and the concept of bridging structural holes described by Brass et al. (2004) and Lingo and O'Mahony (2010), this process shifts the focal measure of a system's embeddedness from a solely quantitative assessment exercise to one considering the qualitative value of connections. This is typified by the realization that the value of the connection between systems can be disproportionally high or disproportionally low. For example, the bridge between FIN and LOX is considered highly valuable due to both systems' high embeddedness, while SIGN is valuable because it bridges disparate parts of the network. Value is understood here in terms of socioeconomic implications, for example the efforts/costs caused by removing a connection, or the broader social and organizational consequences brought about by a change in such a connection. The embeddedness of a system cannot simply be evaluated as the sum of its connections. Hence, considering that not all connections are equal reveals the unified digital infrastructure and the underlying spanning process. Therefore, we cannot conclude on embeddedness within a digital infrastructure by assuming that a system with more connections is necessarily more embedded than one with fewer connections. On the contrary, it can be deduced that the value of individual nodes varies with the qualitative importance attached to the system or node they are being connected to.

\subsection{Inertia Entrapment Implications}


As part of alternative views on embeddedness, individual users' habitual behavior and resistance have been discussed as sources of inertia in the event of replacing information systems (Ciborra and Failla 2000; Eriksson and Âgerfalk 2010; Polites and Karahanna 2012). Path dependence, lock-in, and sociotechnical complexity also appear as potential limitations for system replacements (Hanseth 2000; Hughes 1987). Interconnectedness has also been discussed as an obstacle (Monteiro et al. 2013), but its development has not yet been sufficiently studied. Our study contributes here by linking the processes of embedding systems in a digital infrastructure to the inertial consequences.

There comes a time when a company faces the risk of being entrapped by a heavily embedded system, as the system becomes more critical and valuable. This can be traced to the simple fact that as the system's importance and criticality increase, so does the continuance inertia—hence the dilemma. Newton's law of inertia puts this into perspective: In its basic form, inertia indicates that a system will continue in a state of rest or uniform motion unless an external force acts on it (Hanson 1963). Change will not occur unless there is a substantial push or motivation for it.

Investigating how processes of embedding relate to inertia entrapment reveals that each of the processes reflects the inertia tendency on the system differently. Firstly, the parallel process leads to a system that becomes a "honeypot", attracting new systems and potentially shadow IT systems. It is the attractiveness that acts as an allure, leading to increasing embeddedness and inertia entrapment in this process. Secondly, the competitive process unfolds in a duality of criticality and redundancy due to its predatory nature. Hence, this process reflects inertia in a kind of "see-saw" arrangement, whereby the gradual decrease in the embeddedness of one system translates to the increasing embeddedness and subsequent inertia capacity of another. Thirdly, spanning processes may create inertia beyond the pure number of connections when they connect multiple heavy systems. In this sense, the observed development of embeddedness and inertia does not take a linear path whereby the addition of one connection is $=+1$; instead, inertia in this process can grow exponentially with the connection of a single system. The source of inertia in this scenario is not based on direct connections to the system alone, but on sub-systems' or constellations of systems' dependency on this linkage.

These embeddedness processes may mean a system remains critical for the company regardless of capability shortcomings. As discussed in the empirical section, ORDER, one of the case company's 
major ERP systems, stayed important as a system despite several operational shortcomings and innovation bottlenecks. This is because it was already so deeply embedded in the digital infrastructure that replacing it would have been costly and resource intensive (see also Appendix 3, which reflects on the financial costs associated with replacing the sample systems; it illustrates how high levels of integration manifest in high switching costs). The resulting entrapment could lead to an inability to take advantage of recent technological advances and innovations, which could disrupt the company (Baiyere and Salmela 2013) or introduce uncertainty into a rather stable setup.

The ORDER system also illustrates how inertia entrapment may sometimes even stretch a system's continuance beyond its technological and informational capacities. Succumbing to inertia for too long may lead to financial costs, business loss, process breakdown, a new learning curve, and system incompatibility, among others. For instance, internal estimates revealed that it would cost Recycle Inc. up to 20 million euros to transform the infrastructure. Although there may be many rational justifications for not changing a highly embedded system, until change is the only option left. The transition from a state of inertial entrapment to a state of liberation (system replacement) is one that managers dreadbut which offers opportunity for interesting theoretical insights for researchers (Agarwal and Tiwana 2015).

\subsection{Limitations and Future Directions}

Of course, there are some limitations to this research project. We have looked at how systems are embedded in a digital infrastructure based on existing integration relationships between systems and related qualitative assessments. However, our qualitative study also showed similarities to other legacy system studies focusing on cultural and normative, lock-in-related, and complexity challenges in adapting and replacing legacy information systems (Bennett 1995; Bisbal et al. 1999; Kelly et al. 1999; Polites and Karahanna 2012). A more complex characterization of the dependencies between elements in a digital infrastructure is therefore needed in the future. This should include users as well as their perceptions, business units, and infrastructure-external elements in a socio-technical network of human beings and technologies. Cyclical, indirect, and transitive dependencies can also arise in such a network, opening up remarkable opportunities for further research. Finally, considering the contextual nature of 
this study, we believe further studies could provide more insights into the nonlinear growth of embeddedness by incorporating more related contexts. We have, however, benefited from our study's limited context by relying on an extensive longitudinal study that allowed an evolutionary view and helped to strengthen the value of our observations across several data points.

For possible future research, we have advanced the processes of system embeddedness in digital infrastructures and hereby present a call for them to be substantiated, tested, and extended empirically. The need to understand a system's level of embeddedness and its inertial implications is intensified because deciding to discontinue a highly embedded system requires careful—and often costlyconsideration of the dependencies and associated systems that could be affected as well. This remains an open area of inquiry worthy of further scholarship. Another possible future research direction could be exploring how a critical system's value can be accrued without being entrapped by its inertia, particularly in this era of fast-changing business requirements. Future work may also connect our findings to the governance and collective action stream of the digital infrastructure literature (e.g., Constantinides and Barrett 2014; Gregory et al. 2018), as this stream is concerned with mechanisms and processes to codify and institutionalize some of the triggers of the embeddedness processes we have presented.

One other plausible and pertinent research area opened up by this paper is the development of actionable methods or models for assessing the degree of embeddedness and inertia of systems within a digital infrastructure. Information systems paradigms such as design science research and action design research (Hevner et al. 2004; Sein et al. 2011) could find value in such studies. Additionally, from a managerial point of view, a prescriptive study that presents managers with possible solutions after they have identified the level of embeddedness of systems in their infrastructure would provide avenues for engaged scholarship with actionable recommendations. In this context, the initial step of assessing and identifying the areas in which a digital infrastructure might be plagued by inertia becomes highly relevant. Notably for practitioners, it is vital to clarify how to overcome the challenges of embeddedness and the associated consequence of inertia entrapment.

\subsection{Conclusion}


This study holds two implications for the literature on digital infrastructures. Firstly, the paper addresses the implications of yielding to embeddedness in lieu of the propensity of inertial entrapment (Hanseth et al. 1996; Hanseth and Lyytinen 2010; Tilson et al. 2010). It is necessary for both researchers and practitioners to further understand the relationship between "avoiding" inertia and aiming for a balance between stability and flexibility. This is akin to understanding the balance between taking advantage of innovations in IT and having a "good enough" system. Secondly, the digital infrastructure literature has long noted that infrastructures are "patchworks" (Ellingsen and Monteiro 2003), ensembles of multiple heterogeneous systems. Our perspective helps to better understand the emergent interconnection dynamics that glue together such ensembles and shape a digital infrastructure's gestalt. Besides parallel embeddedness processes, we conclude that the emergence of overarching digital infrastructures requires competitive and spanning processes for a powerful digital infrastructure to emerge.

\section{References}

Aanestad, M., and Jensen, T. B. 2011. Building Nation-wide Information Infrastructures in Healthcare through Modular Implementation Strategies. Journal of Strategic Information Systems 20(2) 161176.

Agarwal, R., and Tiwana, A. 2015. Editorial-Evolvable Systems: Through the Looking Glass of IS. Information Systems Research 26(3) 473-479.

Andersson, M., Lindgren, R., and Henfridsson, O. 2008. Architectural knowledge in inter-organizational IT innovation. The Journal of Strategic Information Systems 17(1) 19-38.

Arthur, W. B. 1989. Competing Technologies, Increasing Returns, and Lock-In by Historical Events. The Economic Journal 99(394) 116-131.

Arthur, W. B. 1994. Increasing Returns and Path Dependence in the Economy, Economics, cognition, and societyUniv. of Michigan Press, Ann Arbor.

Arthur, W. B. 2018. Self-Reinforcing Mechanisms in Economics. The Economy as an Evolving Complex System, P. W. Anderson, K. J. Arrow, and D. Pineseds. 9-32.

Baiyere, A., and Salmela, H. 2013. Review: Disruptive Innovation \& Information Technology - Charting a Path. Proceedings of the 24th Australasian Conference on Information Systems 1-11.

Barabási, A.-L. 2016. Network Science, Cambridge University Press, Cambridge, UK.

Barabási, A.-L., and Albert, R. 1999. Emergence of Scaling in Random Networks. Science 286(5439) 509-512.

Behrens, S. 2009. Shadow Systems: The Good, the Bad and the Ugly. Communications of the ACM 52(2) 124-129.

Bennett, K. 1995. Legacy Systems: Coping with Success. IEEE Software 12(1) 19-23.

Berger, P. L., and Luckmann, T. 1966. The Social Construction of Reality, Penguin Group (1st ed) Penguin, London, U.K.

Bidan, M., Rowe, F., and Truex, D. 2012. An Empirical Study of IS Architectures in French SMEs: Integration Approaches. European Journal of Information Systems 21(3) 287-302.

Bisbal, J., Lawless, D., and Grimson, J. 1999. Legacy Information Systems: Issues and Directions. IEEE Software 16(5) 2-10.

Blichfeldt, B. S., and Eskerod, P. 2008. Project Portfolio Management - There's More To It Than What Management Enacts. International Journal of Project Management 26(4) 357-365.

Bowker, G. C., and Star, S. L. 1999. Sorting Things Out: Classification and Its Consequences, MIT 
Press, Cambridge, Mass.

Brass, D. J., Galaskiewicz, J., Greve, H. R., and Tsai, W. 2004. Taking Stock of Networks and Organizations: A Multilevel Perspective. Academy of Management Journal 47(6) 795-817.

Callon, M. 1991. Techno-Economic Networks and Irreversibility. A Sociology of Monsters: Essays on Power, Technology and Domination, J. Lawed. 132-165.

Chua, C. E. H., and Storey, V. C. 2017. Bottom-up Enterprise Information Systems: Rethinking the Roles of Central IT Departments. Communications of the ACM 60(1) 66-72.

Ciborra, C. U. 2000. A Critical Review of the Literature on the Management of Corporate Information Infrastructure. From Control to Drift: The Dynamics of Corporate Information Infrastructures, C. Ciborra, K. Braa, A. Cordella, B. Dahlbom, A. Failla, O. Hanseth, V. Hepso, J. Ljungberg, E. Moneiro, and K. A. Simoneds. (1st ed) 15-40.

Ciborra, C. U., and Failla, A. 2000. Infrastructure as a Process: The Case of CRM at IBM. From Control to Drift: The Dynamics of Corporate Information Infrastructures, C. Ciborra, K. Braa, A. Cordella, B. Dahlbom, A. Failla, O. Hanseth, V. Hepso, J. Ljungberg, E. Moneiro, and K. A. Simoneds. (1st ed) $105-124$.

Ciborra, C. U., and Hanseth, O. 2000. Introduction. From Control to Drift: The Dynamics of Corporate Information Infrastructures, C. Ciborra, K. Braa, A. Cordella, B. Dahlbom, A. Failla, O. Hanseth, V. Hepso, J. Ljungberg, E. Moneiro, and K. A. Simoneds. (1st ed, ) 1-14.

Constantinides, P., and Barrett, M. 2014. Information Infrastructure Development and Governance as Collective Action. Information Systems Research 26(1) 40-56.

Constantinides, P., Henfridsson, O., and Parker, G. 2018. Platforms and Infrastructures in the Digital Age. Information Systems Research 29(2) iii-vi.

David, P. A. 1985. Clio and the Economics of QWERTY. American Economic Review 75(2) 332-337.

Dobusch, L., and Schüßler, E. 2013. Theorizing Path Dependence: A Review of Positive Feedback Mechanisms in Technology Markets, Regional Clusters, and Organizations. Industrial and Corporate Change 22(3) 617-647.

van Donselaar, K. H., Gaur, V., van Woensel, T., Broekmeulen, R. A. C. M., and Fransoo, J. C. 2010. Ordering Behavior in Retail Stores and Implications for Automated Replenishment. Management Science 56(5) 766-784.

Dreyfus, D., and Iyer, B. 2008. Managing Architectural Emergence: A Conceptual Model and Simulation. Decision Support Systems 46(1) 115-127.

Eisenhardt, K. M. 1989. Building Theories from Case Study Research. Academy of Management Review 14(4) $532-550$.

Ellingsen, G., and Monteiro, E. 2003. A Patchwork Planet: Integration and Cooperation in Hospitals. Computer Supported Cooperative Work 12(1) 71-95.

Ellingsen, G., and Røed, K. 2010. The Role of Integration in Health-based Information Infrastructures. Computer Supported Cooperative Work 19(6) 557-584.

Eriksson, O., and Âgerfalk, P. J. 2010. Rethinking the Meaning of Identifiers in Information Infrastructures. Journal of the Association for Information Systems 11(8) 433-454.

Fischer, G., Giaccardi, E., Ye, Y., Sutcliffe, A. G., and Mehandjiev, N. 2004. Meta-Design: A Manifesto for End-User Development. Communications of the ACM 47(9) 33-37.

Flinders, K. 2015. SAP Core Banking Platform Will Ease Deutsche Bank Split Following Strategic Retail Review. Computer Weekly. Retrieved (September 20, 2017), $\mathrm{http} / / / w w w . c o m p u t e r w e e k l y . c o m / n e w s / 4500244734 / S A P-c o r e-b a n k i n g-p l a t f o r m-w i l l-e a s e-$ Deutsche-Bank-split-following-strategic-retail-review.

Flyvbjerg, B. 2006. Five Misunderstandings About Case-Study Research. Qualitative Inquiry 12(2) 219-245.

Freeman, L. C. 1977. A Set of Measures of Centrality Based on Betweenness. Sociometry 40(1) 35-41.

Furneaux, B., and Wade, M. 2011. An Exploration of Organizational Level Information Systems Discontinuance Intentions. MIS Quarterly 35(3) 573-598.

Furstenau, D., Rothe, H., and Sandner, M. 2017. Shadow Systems, Risk, and Shifting Power Relations in Organizations. Communications of the Association for Information Systems 41(1) Article 3.

Gal, U., Lyytinen, K., and Yoo, Y. 2008. The Dynamics of IT Boundary Objects, Information Infrastructures, and Organisational Identities: The Introduction of 3D Modelling Technologies into the Architecture, Engineering, and Construction Industry. European Journal of Information 
Systems 17(3) 290-304.

Gioia, D. A., Corley, K. G., and Hamilton, A. L. 2012. Seeking Qualitative Rigor in Inductive Research: Notes on the Gioia Methodology. Organizational Research Methods 16(1) 15-31.

Granovetter, M. 1985. Economic Action and Social Structure: The Problem of Embeddedness. American Journal of Sociology 91(3) 481-510.

Greenstein, S. M. 1997. Lock-In and the Costs of Switching Mainframe Computer Vendors: What Do Buyers See?. Industrial and Corporate Change 6(2) 247-274.

Gregory, R. W., Kaganer, E., Henfridsson, O., and Ruch, T. J. 2018. IT Consumerization and the Transformation of IT Governance. MIS Quarterly 42(4) 1225-1253.

Gregory, R. W., Keil, M., Muntermann, J., and Mähring, M. 2015. Paradoxes and the Nature of Ambidexterity in IT Transformation Programs. Information Systems Research 26(1) 57-80.

Hair, J. F., Black, W. C., Babin, B. J., and Anderson, R. E. 2014. Multivariate Data Analysis, (7th ed) Pearson Education Limited, Harlow.

Hanseth, O. 2000. The Economics of Standards. From Control to Drift: The Dynamics of Corporate Information Infrastructures, C. Ciborra, K. Braa, A. Cordella, B. Dahlbom, A. Failla, O. Hanseth, V. Hepso, J. Ljungberg, E. Moneiro, and K. A. Simoneds. (1st ed) 56-70.

Hanseth, O. 2010. From Systems and Tools to Networks and Infrastructures-from Design to Cultivation: Towards a Design Theory of Information Infrastructures. Industrial Informatics Design, Use and Innovation: Perspectives and Services 122-156.

Hanseth, O., and Aanestad, M. 2003. Design as Bootstrapping. On the Evolution of ICT Networks in Health Care. Methods of Information in Medicine 42(4) 385-391.

Hanseth, O., and Braa, K. 2000. Globalization and "Risk Society." From Control to Drift: The Dynamics of Corporate Information Infrastructures, C. Ciborra, K. Braa, A. Cordella, B. Dahlbom, A. Failla, O. Hanseth, V. Hepso, J. Ljungberg, E. Moneiro, and K. A. Simoneds. (1st ed) 41-55.

Hanseth, O., and Braa, K. 2001. Hunting for the Treasure at the End of the Rainbow: Standardizing Corporate IT Infrastructure. Computer Supported Cooperative Work 10 261-292.

Hanseth, O., and Lyytinen, K. 2010. Design Theory for Dynamic Complexity in Information Infrastructures: The Case of Building Internet. Journal of Information Technology 25(1) 1-19.

Hanseth, O., Monteiro, E., and Hatling, M. 1996. Developing Information Infrastructure: The Tension Between Standardisation and Flexibility. Science, Technology and Human Values 21(4) 407-426.

Hanson, N. R. 1963. The Law of Inertia: A Philosopher's Touchstone. Philosophy of Science 30(2) $107-$ 121.

Henfridsson, O., and Bygstad, B. 2013. The Generative Mechanisms of Digital Infrastructure Evolution. MIS Quarterly 37(3) 907-931.

Henfridsson, O., and Yoo, Y. 2014. The Liminality of Trajectory Shifts in Institutional Entrepreneurship. Organization Science 25(3) 932-950.

Henningsson, S., and Hanseth, O. 2011. The Essential Dynamics of Information Infrastructures. ICIS 2011 Proceedings

Hevner, A. R., March, S. T., Park, J., and Ram, S. 2004. Design Science in Information Systems Research. MIS Quarterly 28(1) 75-105.

Hughes, T. P. 1987. The Evolution of Large Technological Systems. The Social Construction of Technological Systems 51-82.

Jackson, M. O. 2008. Social and Economic Networks, Princeton Univ. Press, Princeton and NJ.

Karasti, H., and Blomberg, J. 2017. Studying Infrastructuring Ethnographically. Computer Supported Cooperative Work (CSCW)

Kelly, S., Gibson, N., Holland, C., and Light, B. 1999. Focus Issue on Legacy Information Systems and Business Process Change: A Business Perspective of Legacy Information Systems. Communications of the Association for Information Systems 2(7) 1-27.

Ketchen, D. J. J., and Shook, C. L. 1996. The Application of Cluster Analysis in Strategic Management Research: An Analysis and Critique. Strategic Management Journal 17(6) 441-458.

King, J. L. 1983. Centralized versus Decentralized Computing: Organizational Considerations and Management Options. ACM Computing Surveys 15(4) 319-349.

Koch, C. 2007. ERP - A Moving Target. International Journal of Business Information Systems 2(4) 426-443.

Lagerström, R., Baldwin, C. Y., MacCormack, A., and Aier, S. 2014. Visualizing and Measuring 
Enterprise Application Architecture: An Exploratory Telecom Case. HICSS 2014 Proceedings 3847-3856.

Langley, A. 1999. Strategies for Theorizing from Process Data. Academy of Management Review 24(4) 691-710.

Latour, B. 1987. Science in Action: How to Follow Scientists and Engineers Through Society, Harvard University Press, Cambridge, Mass.

Latour, B. 2005. Reassembling the Social - An Introduction to Actor-Network-Theory, Oxford University Press, Oxford, U.K.

Lawrence, P. R., and Lorsch, J. W. 1967. Differentiation and Integration in Complex Organizations. Administrative Science Quarterly 12(1) 1-47.

Levina, N., and Vaast, E. 2006. Turning a Community into a Market: A Practice Perspective on Information Technology Use in Boundary Spanning. Journal of Management Information Systems 22(4) 13-37.

Lingo, E. L., and O'Mahony, S. 2010. Nexus Work: Brokerage on Creative Projects. Administrative Science Quarterly 55(1) 47-81.

Lipnack, J., and Stamps, J. 1997. Virtual Teams: Reaching Across Space, Time, and Organizations with Technology, (1st ed) John Wiley \& Sons, New York.

Lyytinen, K., Sørensen, C., and Tilson, D. 2017. Generativity in Digital Infrastructures. The Routledge Companion to Management Information Systems, R. D. Galliers and M.-K. Steineds.

MacArthur, P. J., Crosslin, R. L., and Warren, J. R. 1994. A Strategy for Evaluating Alternative Information System Designs for Business Process Reengineering. International Journal of Information Management 14(4) 237-251.

Monteiro, E. 2003. Integrating Health Information Systems: A Critical Appraisal. Methods of Information in Medicine 42(4) 428-432.

Monteiro, E., Pollock, N., Hanseth, O., and Williams, R. 2013. From Artefacts to Infrastructures. Computer Supported Cooperative Work (CSCW) 22(4-6) 575-607.

Monteiro, E., Pollock, N., and Williams, R. 2014. Innovation in Information Infrastructures: Introduction to the Special Issue. Journal of the Association for Information Systems 15(AprilMay 2014) i-x.

Newman, M., and Robey, D. 1992. A Social Process Model of User- Analyst Relationships. MIS Quarterly 16(2) 249-266.

Ortmann, G. 1984. Der zwingende Blick: Personalinformationssysteme - Architektur der Disziplin [in German], Campus, Frankfurt, New York.

Palla, G., Barabási, A.-L., and Vicsek, T. 2007. Quantifying Social Group Evolution. Nature 446(7136) 664-7.

Pettigrew, A. M. 1990. Longitudinal Field Research on Change: Theory and Practice. Organization Science 267-292(1) 3.

Pipek, V., and Wulf, V. 2009. Infrastructuring: Toward an Integrated Perspective on the Design and Use of Information Technology. Journal of the Association for Information Systems 10(5) 447-473.

Podolny, J. M. 2001. Networks as the Pipes and Prisms of the Market. American Journal of Sociology 107(1) 33-60.

Polites, G. L., and Karahanna, E. 2012. Shackled to the Status Quo: The Inhibiting Effects of Incumbent System Habit, Switching Costs, and Inertia on New System Acceptance. MIS Quarterly 36(1) 2142.

Pollock, N. 2010. When is a Workaround? Conflict \& Negotiation in Computer Systems Development. Science Technology And Human Values 30(4) 496-514.

Ribes, D., and Finholt, T. A. 2009. The Long Now of Technology Infrastructure: Articulating Tensions in Development. Journal of the Association for Information Systems 10(May 2009) 375-398.

Rolland, K. H., and Monteiro, E. 2002. Balancing the Local and the Global in Infrastructural Information Systems. Information Society 18(2) 87-100.

Schutz, A., and Luckmann, T. 1973. The Structures of the Life-world, Northwestern University Press, Evanston.

Sein, M. K., Henfridsson, O., Purao, S., Rossi, M., and Lindgren, R. 2011. Action Design Research. Management Information Systems Quarterly 35(1) 37-56.

Siggelkow, N. 2007. Persuasion with Case Studies. Academy of Management Journal 50(1) 20-24. 
Singh, P. V., Tan, Y., and Mookerjee, V. 2011. Network Effects: the Influence of Structural Capital on Open Source Project Success. Mis Quarterly 35(4) 813-829.

Star, S. L., and Ruhleder, K. 1996. Steps Toward an Ecology of Infrastructure: Design and Access for Large Information Spaces. Information Systems Research 7(1) 111-134.

Street, C. T., and Ward, K. W. 2011. Improving Validity and Reliability in Longitudinal Case Study Timelines. European Journal of Information Systems 21(2) 160-175.

Sundararaja, A., Provost, F., Oestreicher-Singer, G., and Aral, S. 2014. Research Commentary Information in Digital, Economic, and Social Networks. Information Systems Research 24(4) 883905.

Swanson, E. B., and Dans, E. 2005. System Life Expectancy and the Maintenance Effort: Exploring Their Equilibration. MIS Quarterly 24(2) 277-297.

Sydow, J., Schreyögg, G., and Koch, J. 2009. Organizational Path Dependence: Opening the Black Box. Academy of Management Review 34(4) 689-709.

Tanriverdi, H. 2006. Performance Effects of Information Technology Synergies in Multibusiness Firms. MIS Quarterly 30(1) 57-77.

Tilson, D., Lyytinen, K., and Sørensen, C. 2010. Digital Infrastructures: The Missing IS Research Agenda. Information Systems Research 21(4) 748-759.

Vaast, E., and Walsham, G. 2009. Trans-Situated Learning: Supporting a Network of Practice with an Information Infrastructure. Information Systems Research 20(4) 547-564.

van de Ven, A. H., and Poole, M. S. 1995. Explaining Development and Change in Organizations. Academy of Management Review 20(3) 510-540.

Venkatesh, V., Brown, S. A., and Bala, H. 2013. Bridging the Qualitative-Quantitative Divide: Guidelines for Conducting Mixed Methods Research in Information Systems. Management Information Systems Quarterly 37(1) 21-54.

Wasserman, S., and Faust, K. 1994. Social network analysis: Methods and applications, Structural analysis in the social sciences (19th ed, Vol. 8) Cambridge Univ. Press, Cambridge.

Winkler, T. J., Brown, C. V., and Ozturk, P. 2014. The Interplay of Top-Down and Bottom-Up: Approaches for Achieving Sustainable Health Information Exchange. ECIS 2014 Proceedings 17.

Yin, R. K. 2013. Case Study Research: Design and Methods, Essential guide to qualitative methods in organizational researchApplied Social Research Methods Series (5th ed, Vol. 5) Sage Publications, Thousand Oaks, California. 


\section{Appendices}

Appendix 1: System embeddedness on the level of the whole network

\begin{tabular}{llllll}
\hline System & $\mathbf{1 9 9 5}$ & $\mathbf{2 0 0 0}$ & $\mathbf{2 0 0 5}$ & $\mathbf{2 0 1 0}$ & $\mathbf{2 0 1 5}$ \\
\hline No. nodes/systems & 10 & 22 & 64 & 212 & 215 \\
No. links/integration & 7 & 15 & 66 & 263 & 268 \\
\hline
\end{tabular}

Appendix 2: Number of subsidaries connected to the systems ${ }^{\dagger}$

\begin{tabular}{llllll}
\hline System & $\mathbf{1 9 9 5}$ & $\mathbf{2 0 0 0}$ & $\mathbf{2 0 0 5}$ & $\mathbf{2 0 1 0}$ & $\mathbf{2 0 1 5}$ \\
\hline FIN & 5 & 5 & 8 & 9 & 9 \\
ORDER & 1 & 13 & 13 & 14 & 14 \\
LOX & - & - & - & 7 & 7 \\
SIGN & - & - & - & 16 & 16 \\
LEGA & 11 & 1 & 1 & 1 & 1 \\
BOARD & - & - & - & 1 & - \\
\hline
\end{tabular}

${ }^{\gamma}$ Based on a non-exhaustive sample of 29 subsidiaries. This table represents our own reconstruction of usage in subsidiaries based on sources $\mathrm{a}_{1}-\mathrm{a}_{4}$, as well as interview data. The data was verified by two key informants from the company. For FIN, we report only on the subsidaries that were actively using the system; all others were still oblidged to deliver accounting data in the prescribed format.

\section{Appendix 3: Financial view on interconnectedness}

\begin{tabular}{|c|c|c|c|}
\hline $\begin{array}{l}\text { System } \\
\text { (\#links) }\end{array}$ & Main purposes & Standalone costs & Embeddedness/interconnection costs \\
\hline $\begin{array}{l}\text { FIN } \\
(30)\end{array}$ & $\begin{array}{l}\text { Invoicing, } \\
\text { financial } \\
\text { accounting and - } \\
\text { consolidation }\end{array}$ & $\begin{array}{l}\text { Yearly licenses of } \sim 2 \mathrm{M} \text { EUR from } \\
\text { all subsidiaries, covering costs for } \\
\text { maintenance and further } \\
\text { developments. No information } \\
\text { about replacement costs available }\end{array}$ & $\begin{array}{l}\text { Core interfaces: Upstream systems } \\
\text { (ORDER, LOX, etc.), Controlling / CO, } \\
\text { Business warehouse, human resources (and } \\
\text { other corporate systems), archiving systems }\end{array}$ \\
\hline $\begin{array}{l}\text { ORDER } \\
(22)\end{array}$ & $\begin{array}{l}\text { Distribution and } \\
\text { order mgmt. }\end{array}$ & $\begin{array}{l}\text { Yearly licenses of } \sim 1 \mathrm{M} \text { EUR from } \\
\text { all subsidiaries, covering costs for } \\
\text { maintenance and further } \\
\text { developments. Overall estimate } \\
\text { for replacement: } 15-20 \mathrm{M} \text { EUR } \\
\text { (incl. requirements engineering, } \\
\text { and interface harmonization) }\end{array}$ & $\begin{array}{l}\text { Core interfaces: Scales (online, offline), } \\
\text { corporate systems (FIN), legal reporting } \\
\text { (SIGN), large number of small systems in } \\
\text { subsidiaries (tour planning, etc.); } \\
\text { implementation cost estimates per interface } \\
\text { ranging between } 70 \mathrm{k}-120 \mathrm{k} \text {, depending on } \\
\text { complexity of integration (\#use cases, } \\
\text { information intensity, type) }\end{array}$ \\
\hline $\begin{array}{l}\mathrm{LOX} \\
(26)\end{array}$ & $\begin{array}{l}\text { Sales and } \\
\text { operations / } \\
\text { logistics }\end{array}$ & $\begin{array}{l}\text { See ORDER, estimate for } \\
\text { harmonization of all ERP systems }\end{array}$ & $\begin{array}{l}\text { See ORDER; in addition: board computer } \\
\text { integration in place }\end{array}$ \\
\hline $\begin{array}{l}\text { SIGN } \\
(9)\end{array}$ & $\begin{array}{l}\text { Legal reporting } \\
\text { for hazardous } \\
\text { waste }\end{array}$ & $\begin{array}{l}\text { Overall implementation costs not } \\
\text { available. Transferring the } \\
\text { solution to non-hazardous waste } \\
\text { estimated at } 250 \mathrm{k}\end{array}$ & $\begin{array}{l}\text { Core interfaces: ERP systems (ORDER, } \\
\text { LOX, etc.); external interfaces to using } \\
\text { companies having integrated SIGN in their } \\
\text { own processes }\end{array}$ \\
\hline $\begin{array}{l}\text { LEGA } \\
\text { (3) }\end{array}$ & $\begin{array}{l}\text { Distribution and } \\
\text { order mgmt. }\end{array}$ & $\begin{array}{l}\text { Negligible (small license fee and } \\
\text { server costs) }\end{array}$ & $\begin{array}{l}\text { Three interfaces, connecting to local scale } \\
\text { system in subsidiary and SAP/FIN system }\end{array}$ \\
\hline $\begin{array}{l}\text { BOARD } \\
\text { (1) }\end{array}$ & $\begin{array}{l}\text { Telematics } \\
\text { solution for tour } \\
\text { planning }\end{array}$ & $\begin{array}{l}\text { Initial project costs appr. 80k } \\
\text { EUR (considered "very cheap"); } \\
\text { escalation of initial costs }\end{array}$ & $\begin{array}{l}\text { One unidirectional interface, built because } \\
\text { of read only access to ERP }\end{array}$ \\
\hline
\end{tabular}


no online appendices 


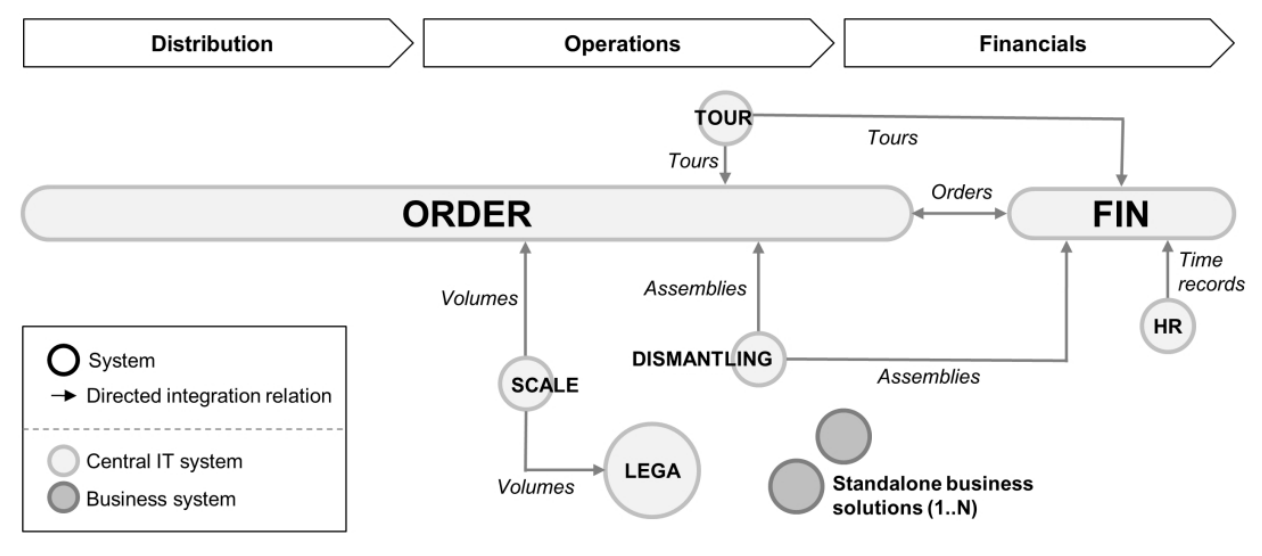

Digital infrastructure for waste management as of 1999

$228 \times 96 \mathrm{~mm}(300 \times 300 \mathrm{DPI})$ 


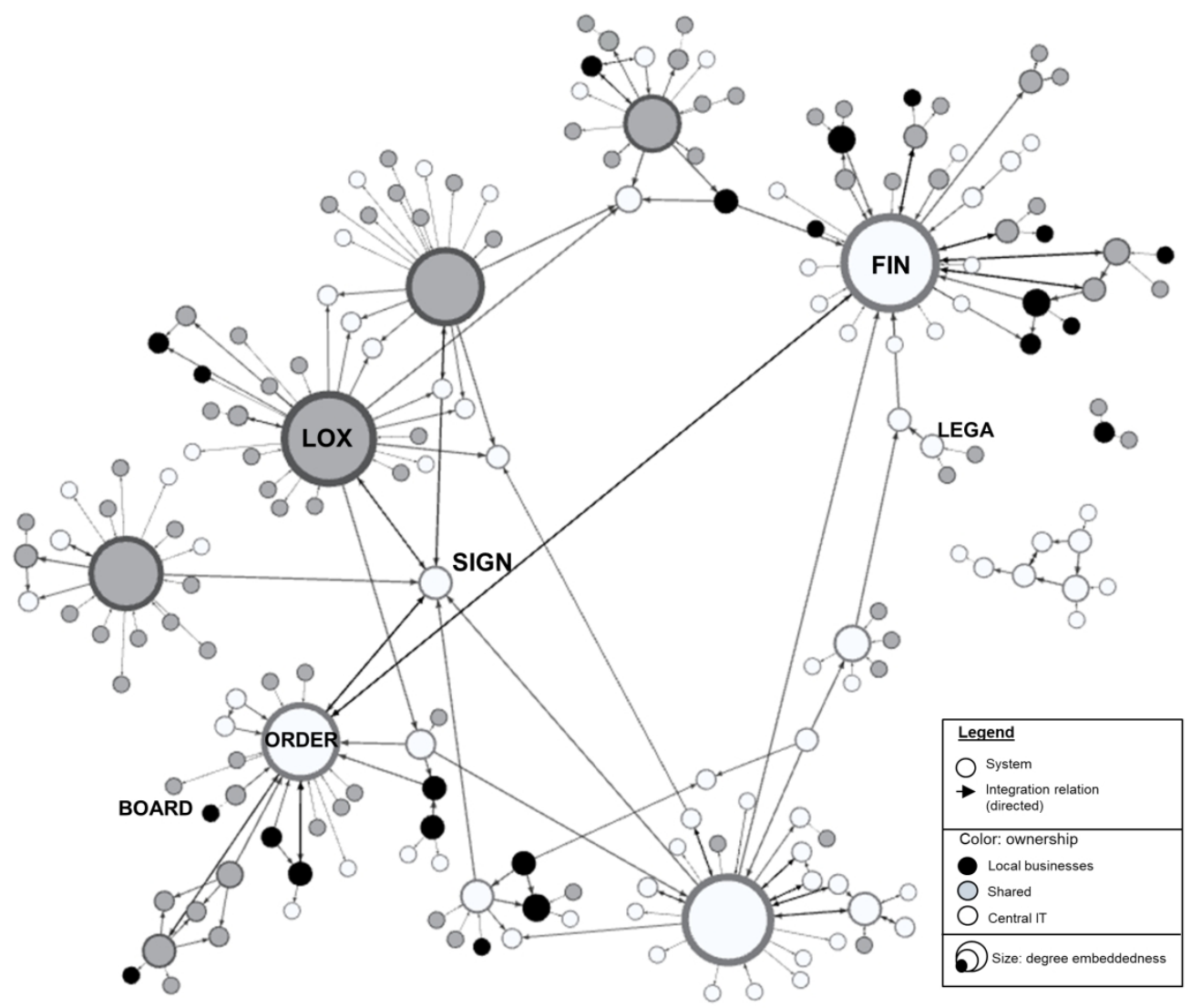

Digital infrastructure for waste management in 2011 after a decade of uncontrolled growth $185 \times 157 \mathrm{~mm}(300 \times 300$ DPI $)$ 
a

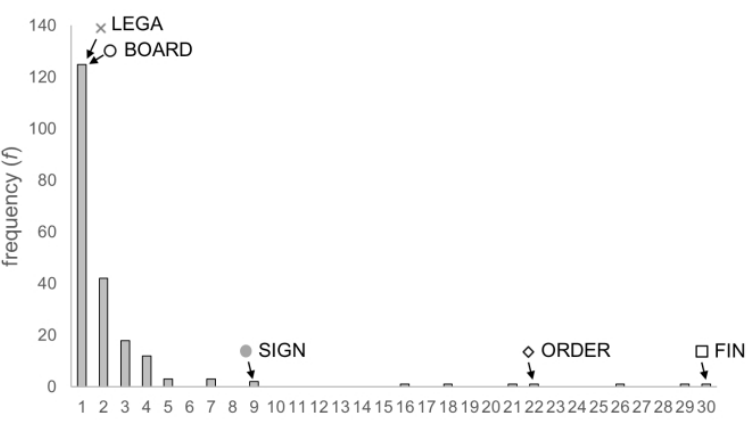

b

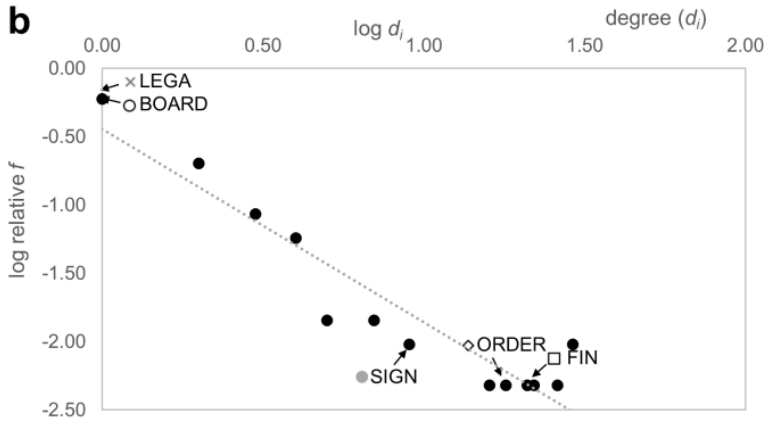

C
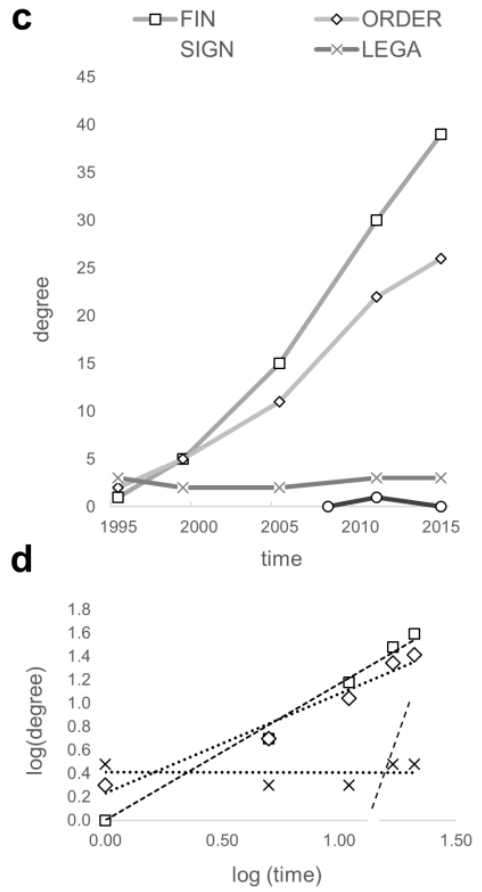

Degree distribution of embeddedness levels: (a) absolute (b) log-logged, (c) sample trajectories, and (d) their log-logged degrees

$215 \times 149 \mathrm{~mm}(300 \times 300 \mathrm{DPI})$ 


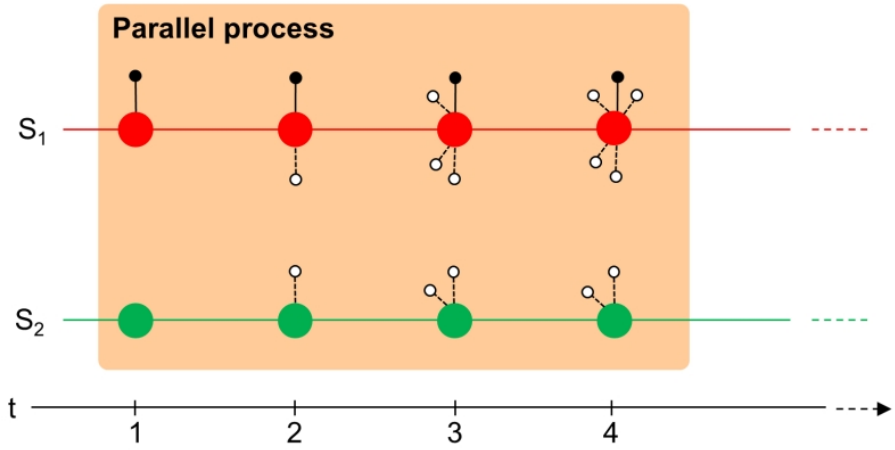

Node: system

(large and colored

nodes are in focus)

O White node/dotted line:

newly emerging system/

connection

- Black node/solid line: existing system/connection

Parallel process of embeddedness

$190 \times 71 \mathrm{~mm}(300 \times 300 \mathrm{DPI})$ 


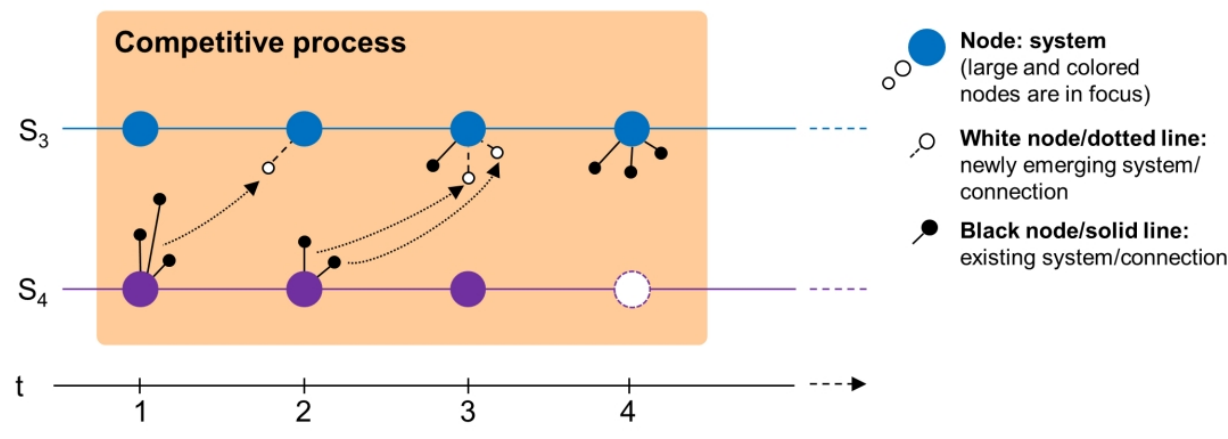

Competitive process of embeddedness

$185 \times 68 \mathrm{~mm}(300 \times 300 \mathrm{DPI})$ 


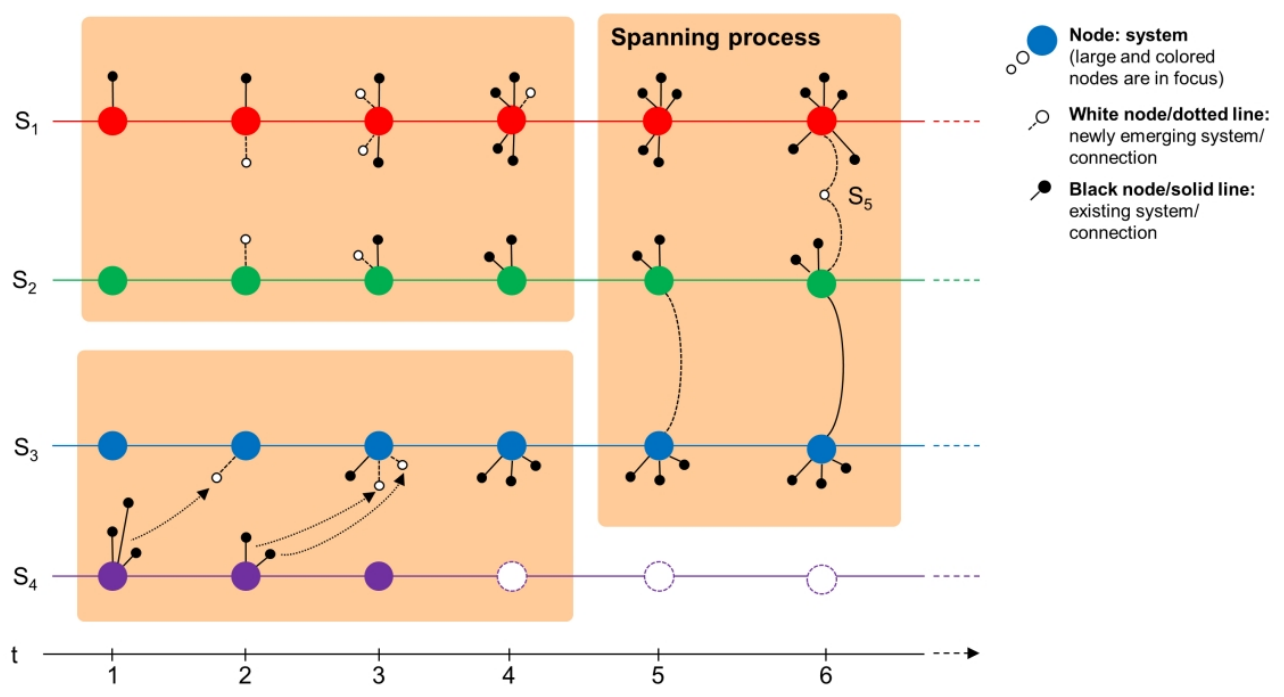

Spanning process of embeddedness

$228 \times 127 \mathrm{~mm}(300 \times 300 \mathrm{DPI})$ 


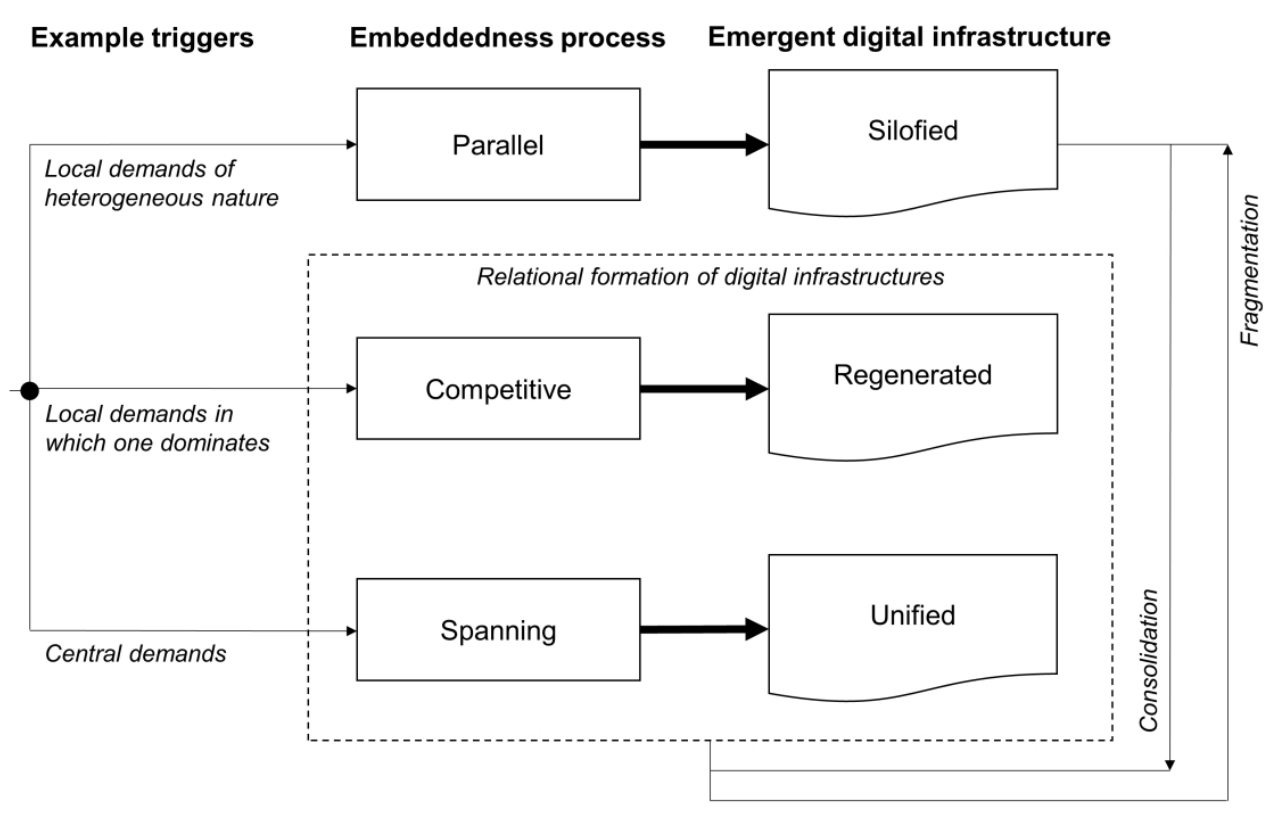

Dynamic Model of Embeddedness in Digital Infrastructures $266 \times 165 \mathrm{~mm}(300 \times 300 \mathrm{DPI})$ 


\section{Figure1. Digital infrastructure for waste management as of 1999}

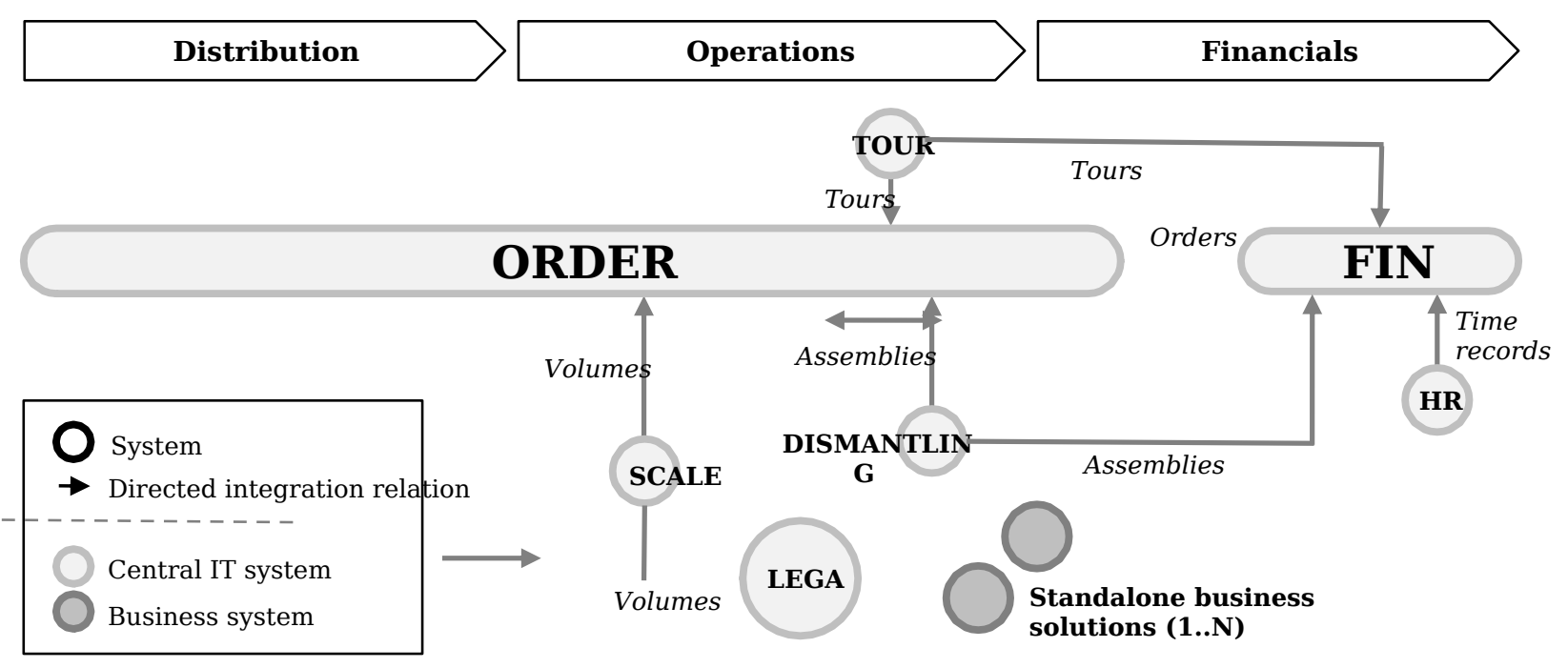


Figure2. Digitalinfrastructure for waste management in 2011 after a decade of uncontrolled growth

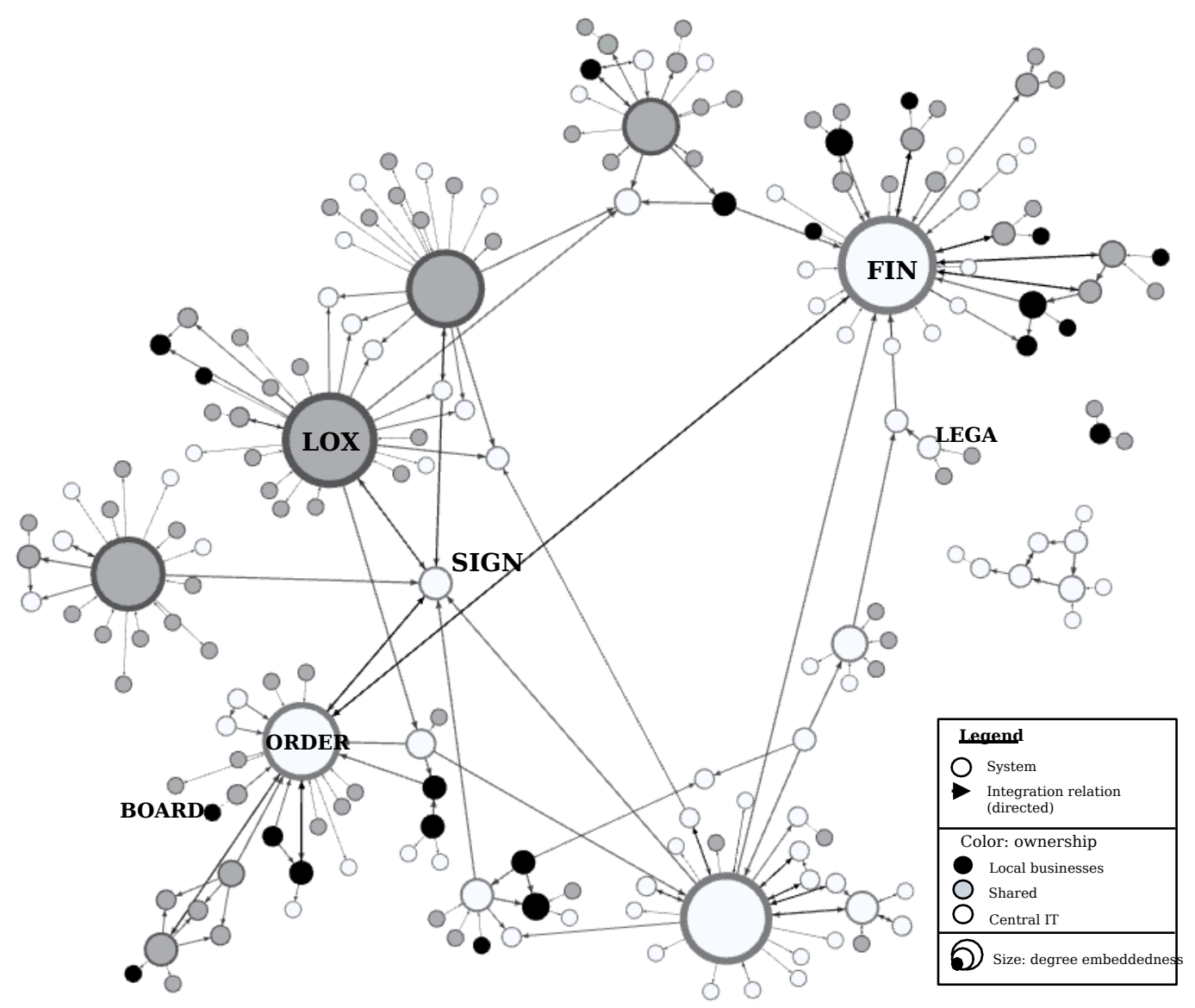


Figure 3Degree distribution of embeddedness levels: (a) absolute (b) log-logged, (c) sample trajectories, and (d) their log-logged degrees

$\mathbf{a}$

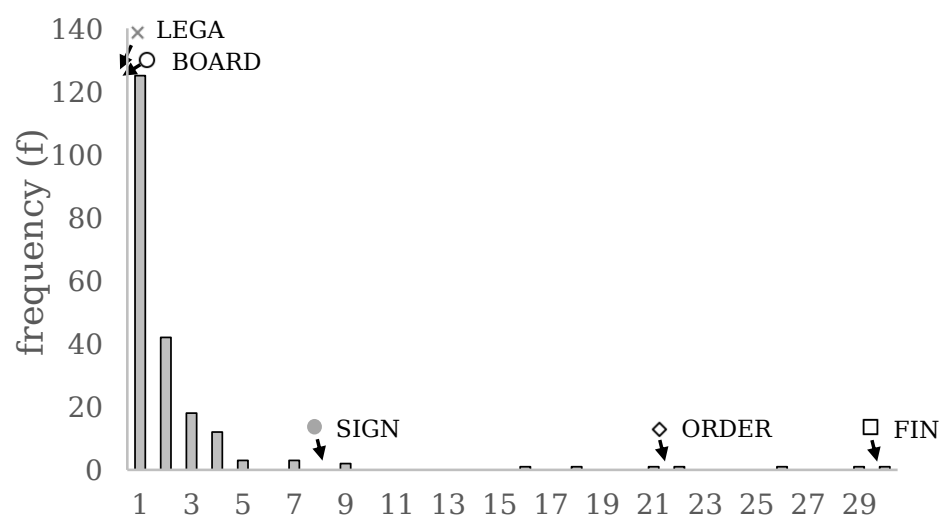

b

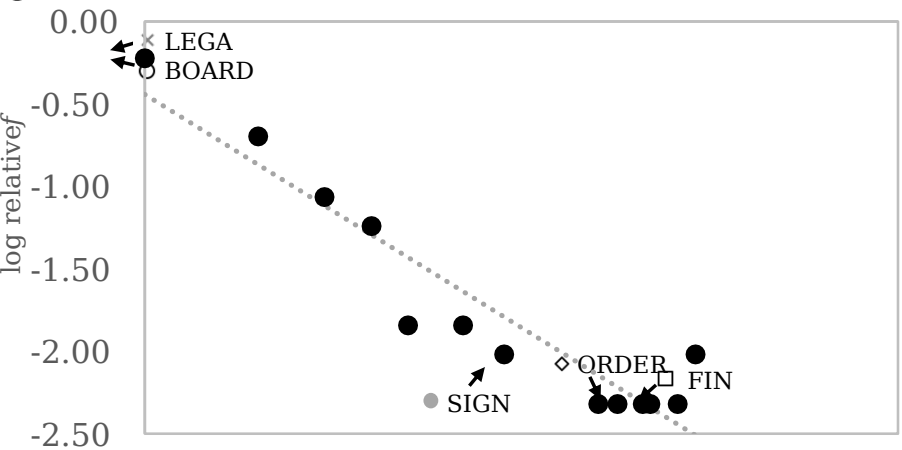

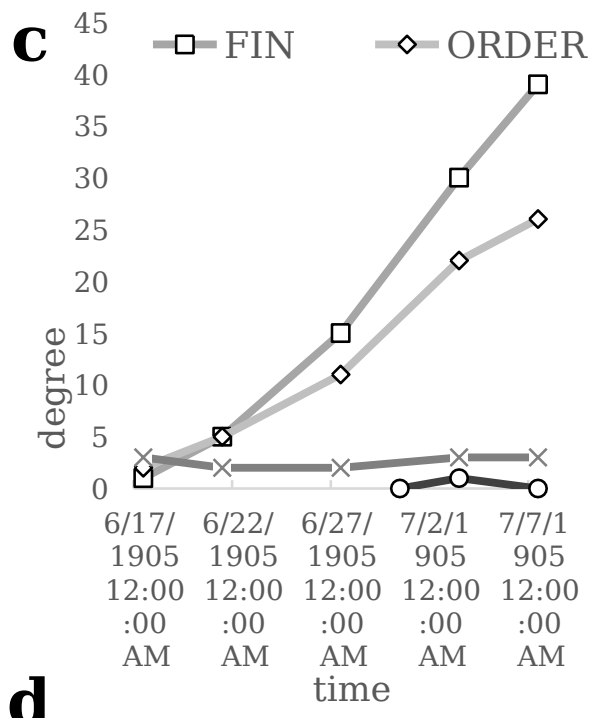

d

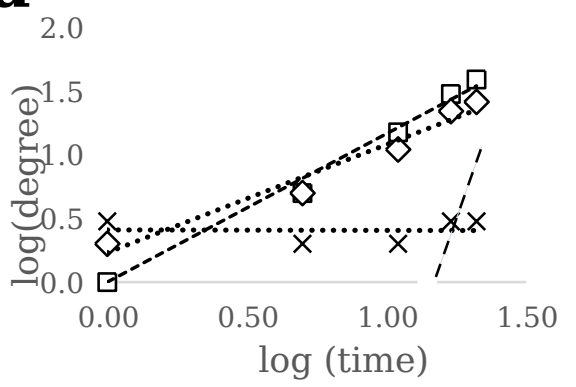




\section{Figure 4. Parallel process of embeddedness}

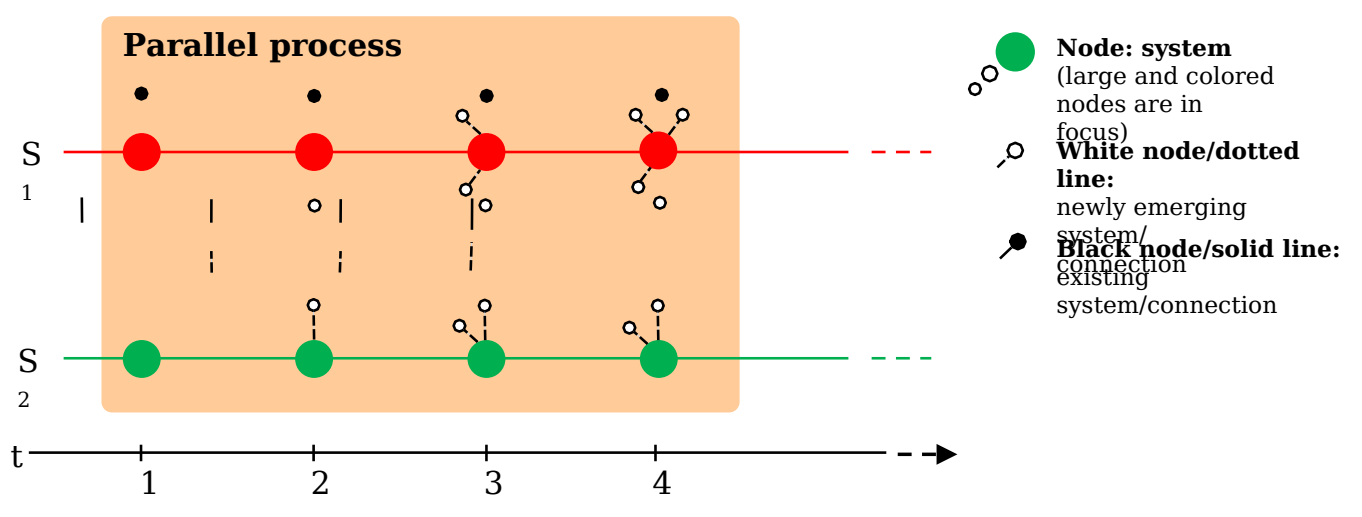




\section{Figure 5. Competitive process of embeddedness}

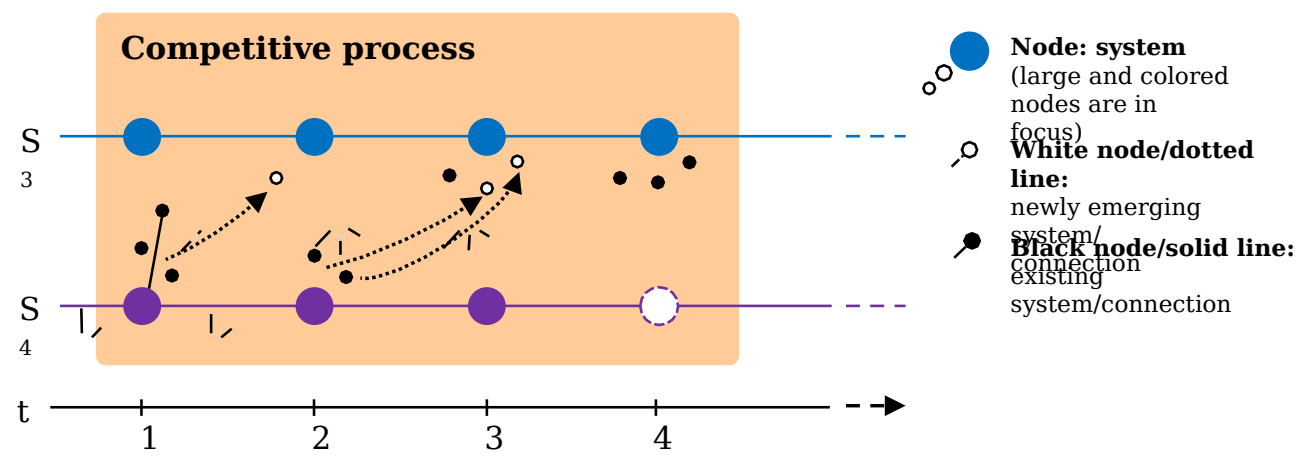




\section{Figure 6. Spanning process of embeddedness}

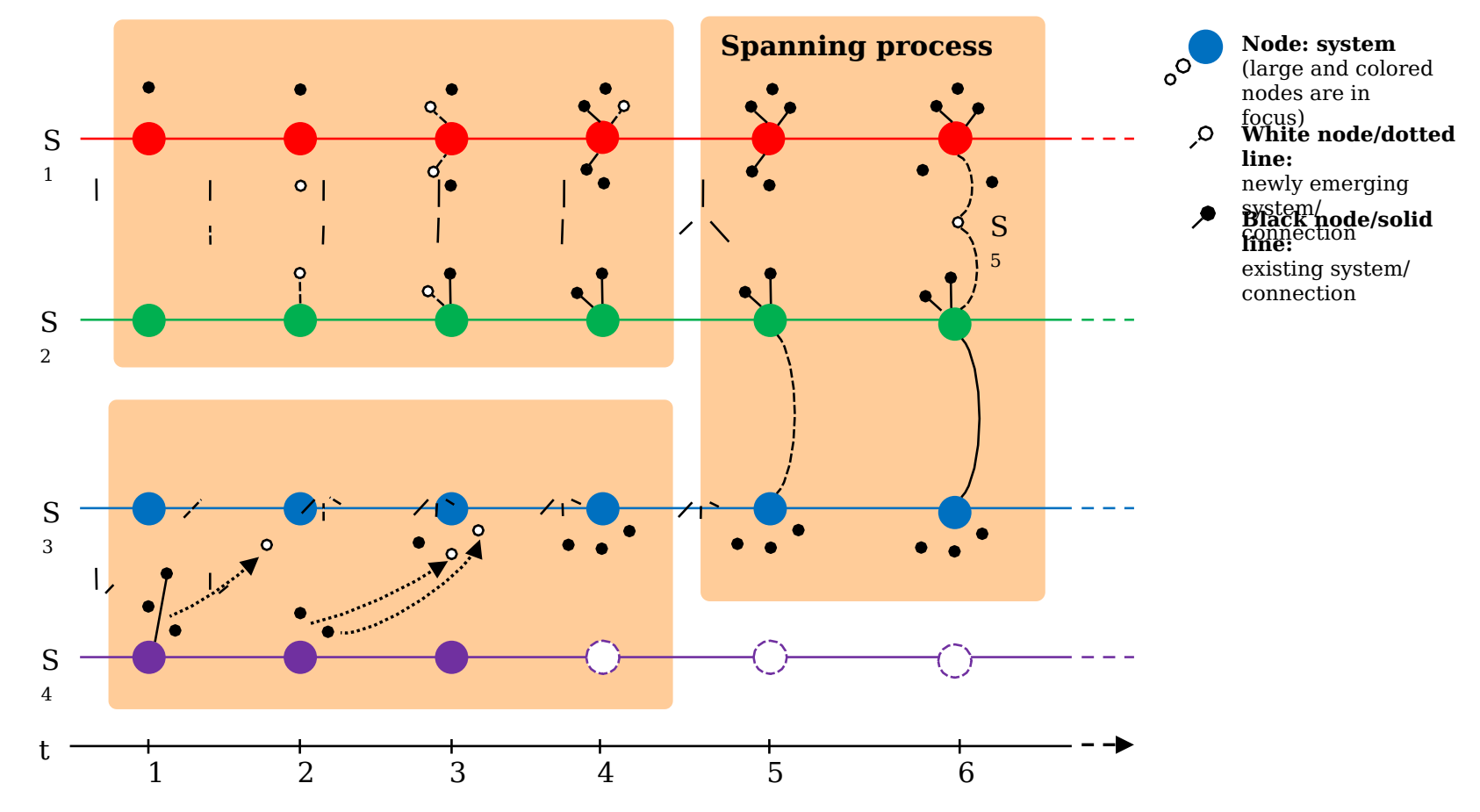




\section{Figure7. Dynamic model of embeddedness in digital infrastuctures}

\section{Example triggers Embeddedness processmergent digital infrastructure}

heterogeneous nature
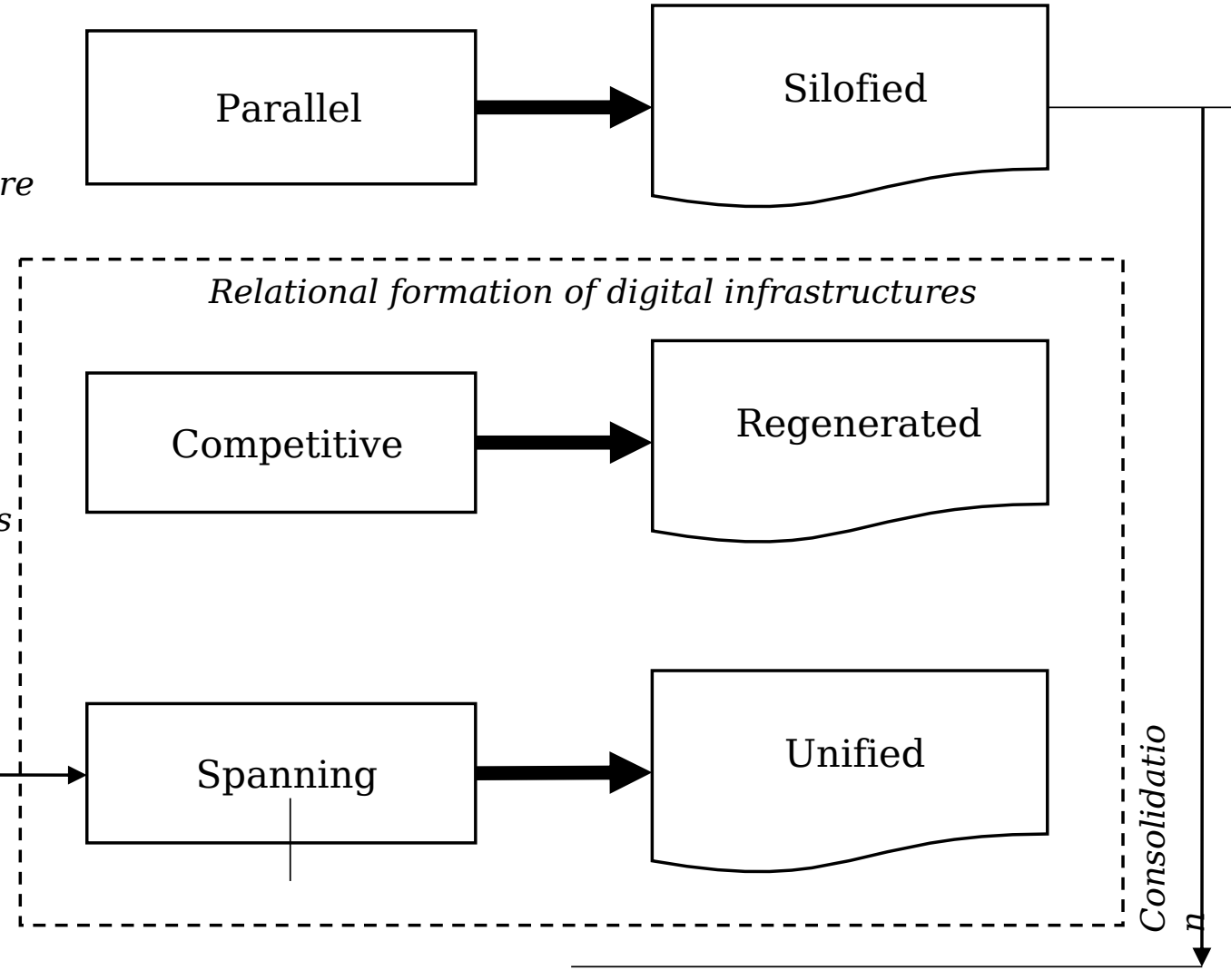

Local demands in which onedominates'

Relational formation of digital infrastructures
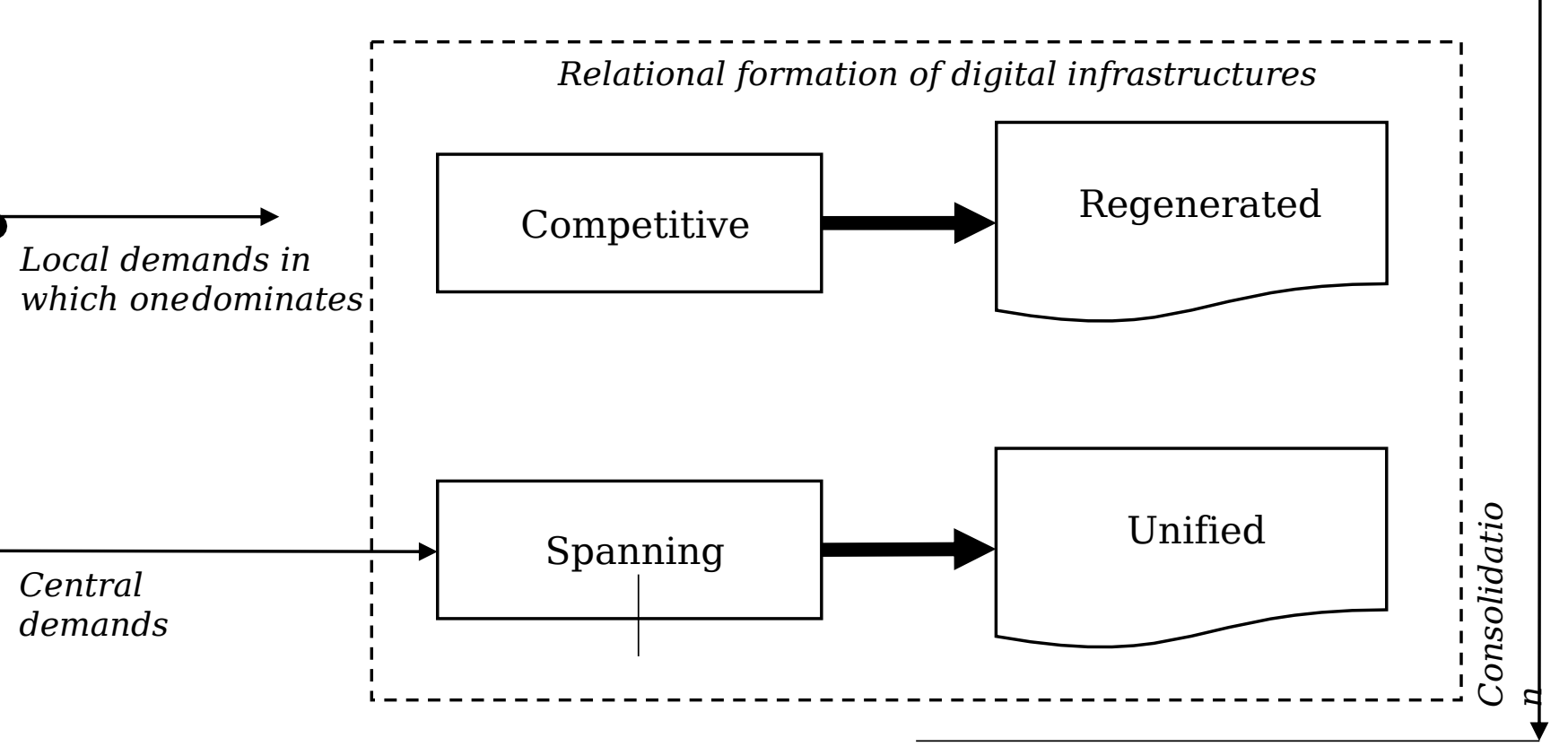

demands 